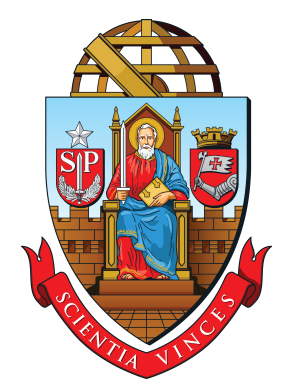

Universidade de São Paulo - USP

Departamento de Engenharia Elétrica

Programa de Pós-Graduação em Engenharia Elétrica

Roteamento de Tráfego e Alocação de Recursos em Redes Ópticas WDM com Base em Economia de Energia

Nereida Celina Llerena Valdivia

São Carlos, 2014 



\title{
Roteamento de Tráfego e Alocação de Recursos em Redes Ópticas WDM com Base em Economia de Energia
}

\author{
Nereida Celina Llerena Valdivia
}

Orientador: Prof. Dr. Amílcar Careli César

\begin{abstract}
Dissertação de Mestrado apresentada à Escola de Engenharia de São Carlos da Universidade de São Paulo, como parte dos requisitos para obtenção do título de Mestre em Ciências, Programa de Engenharia Elétrica.

Área de Concentração: Telecomunicações.
\end{abstract}

USP - São Carlos

Novembro de 2014

Trata-se da versão corrigida da dissertação. A versão original se encontra disponível na EESC/USP que aloja o Programa de Pós-Graduação de Engenharia Elétrica. 
AUTORIZO A REPRODUÇÃO TOTAL OU PARCIAL DESTE TRABALHO, POR QUALQUER MEIO CONVENCIONAL OU ELETRÔNICO, PARA FINS DE ESTUDO E PESQUISA, DESDE QUE CITADA A FONTE.

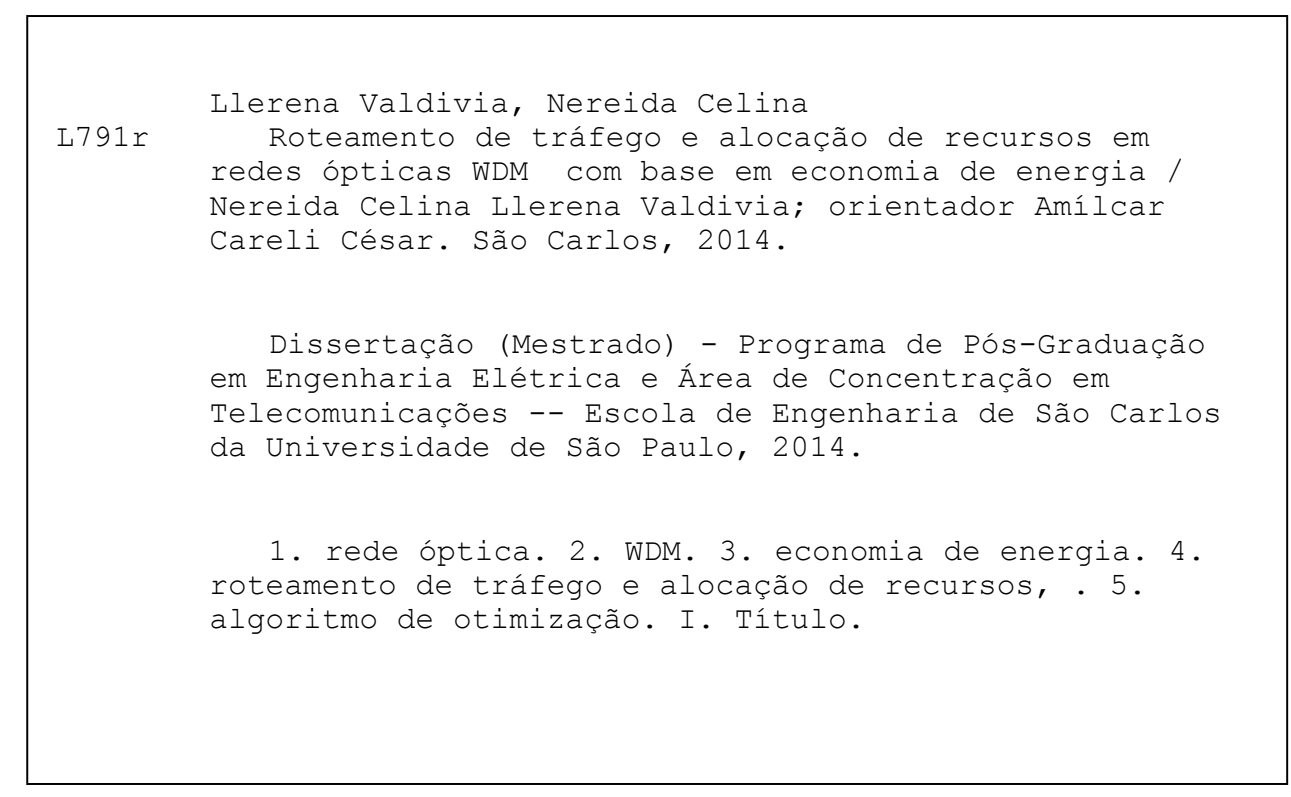




\section{FOLHA DE JULGAMENTO}

Candidata: Bacharel NEREIDA CELINA LLERENA VALDIVIA.

Título da dissertação: "Roteamento de tráfego e alocação de recursos em redes ópticas WDM com base em economia de energia".

Data da defesa: $28 / 11 / 2014$

\section{Comissão Julgadora:}

Prof. Titular Amílcar Careli Cesar (Orientador)

(Escola de Engenharia de São Carlos/EESC)

Profa. Dra. Maria José Pontes

(Universidade Federal do Espírito Santo/UFES)

Profa. Dra. Mônica de Lacerda Rocha

(Escola de Engenharia de São Carlos/EESC)
Resultado:

APROVADA

APROVADA

Coordenador do Programa de Pós-Graduação em Engenharia Elétrica:

Prof. Associado Luis Fernando Costa Alberto

Presidente da Comissão de Pós-Graduação:

Prof. Associado Paulo César Lima Segantine 

Ao meu vovô. 



\section{Agradecimentos}

Gostaria de agradecer inicialmente ao meu orientador Amílcar Careli César, pela oportunidade e apoio para desenvolver este trabalho, e pela sua paciência e compreensão. Aos meninos do laboratório de telecomunicações, em especial ao Arturo, sem ele o tráfego ainda estaria engarrafado. Aos professores e funcionários da USP que contribuíram direita ou indiretamente na conclusão desse trabalho. À CAPES pelo apoio financeiro.

Ao Brasil (quer dizer São Carlos), por me acolher, pelo carinho de sua gente e os churrascos tão gostosos. À minha querida Arequipa, por sempre me receber de braços abertos.

Quero agradecer à minha família, sem seu apoio teria sido uma tarefa impossível. (Agora é a vez do espanhol). Al abuelito querido, aunque ya no estes a una llamada de distancia siempre estarás en mi corazón. Gracias por ser el mejor papá. A la abuelita por todo su cariño, por tantas enseñanzas y tantas jaladas de oreja. A la mamá por siempre estar ahí para mi, por su inmenso cariño, por sus visitas inesperadas y ser ejemplo de esfuerzo y trabajo (aunque no tan duro) para sacar adelante a sus hijitas. A mi Rorris, aunque no me respondas cuando te escribo. A mi Pavito por ser más que una hermana, por su paciencia, aunque no tan infinita como ella cree, por todos esos martes de torturas onduladas, porque sin ti los caminos estarían enredados. A mi papá por el apoyo económico y a mis hermanitos, Chanita, Alejandro y Danae.

Quiero agradecer también a mis queridas sophianitas, en especial a Nitza, Vilma, Nadia y Tania, su amistad es una de las cosas más preciadas que tengo. Gracias por hacer las distancias más pequeñas. A los nuevos y no tan nuevos amigos que hice en São Carlos. Y a mi querido Yoyito, por su paciencia realmente infinita, por su apoyo, cariño y comprensión; por la pipoca en tantas largas noches de trabajo; por ponerle color a mi vida y a mis gráficos.

Com certeza muitas pessoas escaparam da minha mente enquanto escrevia estes agradecimentos, a todos eles minhas sinceras desculpas e muito obrigada. 
«Hakunna Matata. Una forma de ser.»

Timón y Pumba - El rey león 


\section{Resumo}

VALDIVIA, N. L. Roteamento de tráfego e alocação de recursos em redes ópticas WDM com base em economia de energia. 2014. Dissertação (Mestrado) - Escola de Engenharia de São Carlos, Universidade de São Paulo, São Carlos, 2014.

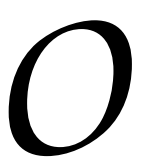

crescimento do tráfego de serviços de telecomunicações tem aumentado o consumo de energia e, em consequência, aumentado as emissões de $\mathrm{CO}_{2}$ que tem efeitos nocivos sobre o meio ambiente. É assim que a economia de energia torna-se um fator chave no planejamento de redes de telecomunicações. Para garantir a disponibilidade e confiabilidade, as redes possuem arquitetura redundante e são projetadas para suportar a demanda de pico de tráfego. Redes com mecanismos de proteção como proteção dedicada de caminhos (DPP), proveem caminhos alternativos para cada demanda de conexão. Os elementos da rede que suportam esses caminhos estão em estado ativo (consumindo energia), apesar de, na maior parte do tempo, não trasportarem tráfego efetivo. Um método para diminuir o gasto de energia é utilizar roteamento adaptado à carga real de tráfego baseado em modo suspenso (estado de baixo consumo de energia que pode passar a estado ativo rapidamente). Assim, o tráfego é roteado com vistas à maximizar a quantidade de componentes que são parte de caminhos de proteção, que podem ser postos em modo suspenso.

Neste trabalho, as redes usadas para os testes são a rede europeia Cost239, a rede estadunidense UsNet e a rede brasileira Ipê. Abordamos o problema de economia de energia em redes WDM com DPP através de quatro estratégias de roteamento. Cada uma tem objetivos diferentes, a Shortest Path-DPP (SP-DPP) faz o roteamento por caminho mais curto, a Energy Aware-DPP (EA-DPP) aloca as demandas por enlaces que estejam ativos, a Energy Aware-DPP with Mixing (EA-DPP-MixS) evita que caminhos principais sejam roteados por enlaces que já são parte de caminhos de proteção e a Energy Aware-DPP with Differentation (EA-DPP-Dif) evita a mistura de caminhos por um mesmo enlace. Em nossas simulações computacionais observamos que a EA-DPP-Dif economiza energia de maneira eficiente, mas a probabilidade de bloqueio aumenta. A EA-DPP-MixS diminui o bloqueio em detrimento da energia economizada. Já a SP-DPP e a EA-DPP são menos eficientes na diminuição da energia consumida. É assim que propomos um roteamento com busca de recursos mais ampla, usando cada uma das estratégias. A proposta será chamada de roteamento intensivo. A EA-DPP-Dif-Intensivo diminui a probabilidade de bloqueio e economiza energia mediante modo suspenso. Neste trabalho, analisamos o desempenho das estratégias para cada uma das redes e avaliamos o impacto da energia economizada sobre a probabilidade de bloqueio. A proposta de roteamento intensivo diminui a energia consumida em até $50 \%$, diminuindo a probabilidade de bloqueio. Porém, os resultados estão diretamente relacionados com a carga de rede e as caraterísticas particulares da topologia de cada rede.

Palavras-chave: rede óptica, WDM, economia de energia, roteamento de tráfego e alocação de recursos, algoritmo de otimização 



\section{Abstract}

VALDIVIA, N. L. Energy-aware traffic routing and resource allocation in WDM optical networks. 2014. Dissertação (Mestrado) - Escola de Engenharia de São Carlos, Universidade de São Paulo, São Carlos, 2014.

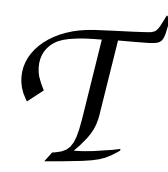

he growth of data traffic in telecommunication networks has increased energy consumption and hence increased $\mathrm{CO}_{2}$ emissions, with harmful effects on the environment. Thus, energy saving becomes a key and a differential factor when planning telecommunication networks. In order to guarantee availability and reliability, core networks have redundant architecture and are designed to support peak-hour traffic demand. Networks with dedicated path protection (DPP) mechanisms provide alternative paths for each connection request. Network elements supporting these paths are in active state (consuming energy), although most of the time they don't carry traffic. One technique to decrease energy waste is by adaptive real traffic routing using sleep mode (a low energy consumption state which is able to rapidly change to an active state). Thus, traffic is routed in order to maximize the amount of network components used by protection paths, which can be set in sleep mode.

In this work, European Cost239, American UsNet and Brazilian Ipê networks were used in computational simulations. We addressed the energy saving problem in WDM networks with DPP through four routing strategies, each with different goals. The Shorthest Path-Dedicated Path Protecction (SP-DPP) technique uses shortest path for routing, Energy Aware-Dedicated Path Protecction (EA-DPP) allocates demands in active links, Energy Aware-Dedicated Path Protecction with Mixing (EA-DPP-MixS) prevents primary paths to be formed by links that are already part of the protection paths and Energy Aware-Dedicated Path Protecction with Differentation (EA-DPP-Dif) prevents mixing primary and protection paths through the same link. We observe that EA-DPP-Dif efficiently saved energy, however blocking probability has increased. EA-DPP-MixS reduced blocking rather than saved energy. At least, SP-DPP and EA-DPP are less efficient in reducing energy consumption. Hence, we propose a wider resource search routing, the in-depth routing, using each of these strategies. Thus, EA-DPP-Dif-In-depth decreased blocking probability while maintaining energy saving through sleep mode. In this work, we analyze the strategies performance for each network and evaluate the impact of energy saved on the blocking probability. Our Indepth routing strategy reduced the energy consumption up to $50 \%$, decreasing blocking probability. However, the results are directly related with the network load and the specific properties of each network topology.

Keywords: optical network, WDM, energy saving, traffic routing and resource allocation, optimization algorithms. 



\section{Sumário}

Resumo........................ xi

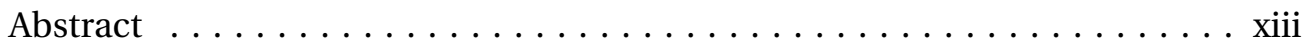

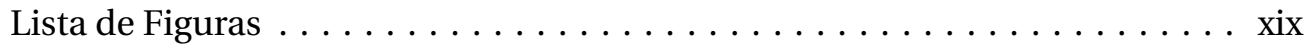

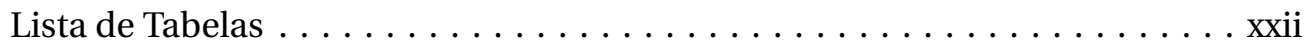

Lista de Algoritmos $\ldots \ldots \ldots \ldots \ldots \ldots \ldots \ldots \ldots \ldots \ldots \ldots \ldots \ldots \ldots \ldots \ldots \ldots$

Lista de Abreviaturas . . . . . . . . . . . . . . . . . . . . xxvi

1 Introdução 1

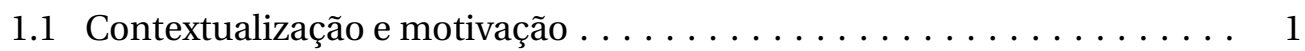

1.2 Objetivo e organização do trabalho $\ldots \ldots \ldots \ldots \ldots \ldots \ldots \ldots$

2 Conceitos prévios 5

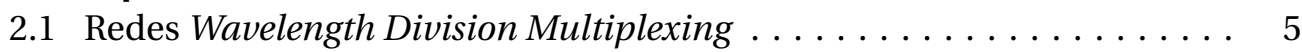

2.2 Teoria de Grafos . . . . . . . . . . . . . . . . . . . . . . . . 8

3 Revisão Bibliográfica $\quad 11$

3.1 Considerações Iniciais $\ldots \ldots \ldots \ldots \ldots \ldots \ldots \ldots \ldots \ldots \ldots$

3.2 Classificação das Abordagens para Redes Energeticamente Eficientes . . 14

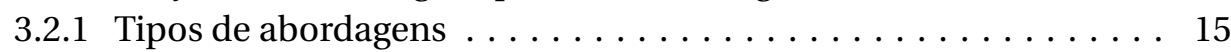

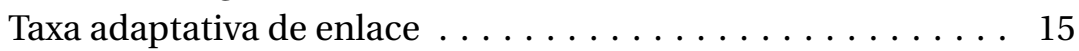

Proxying na interface ................ 15

Infraestruturas de uso eficiente de energia . . . . . . . 16

Software e aplicações de uso de energia eficiente . . . . . . 16

Reengenharia .................... 16

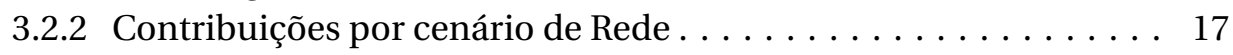

Redes de acesso cabeadas . . . . . . . . . . . . . 17

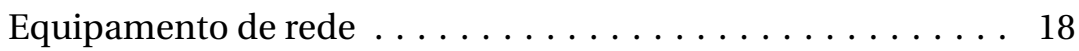

Redes sem fio e redes celulares .............. 18

Redes de acesso mistas: fibra e sem fio . . . . . . . . . 19

Aplicações de redes . . . . . . . . . . . . . . . 20

Redes ópticas de transporte e redes núcleo $\ldots \ldots \ldots \ldots .20$

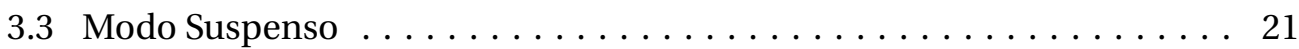

3.3.1 Modo suspenso: soluções orientadas ao tráfego . . . . . . . . 23 
3.3.2 Modo suspenso: soluções orientadas à topologia . . . . . . . . 27

4 Metodologia 2

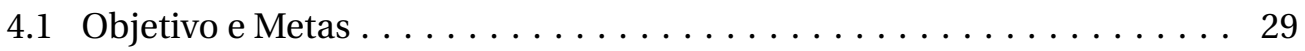

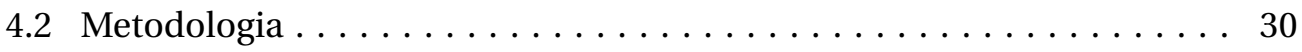

4.2.1 Modelo de consumo de energia em redes wavelength division mul-

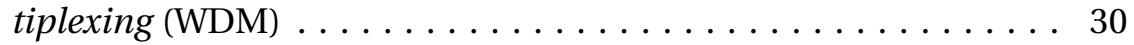

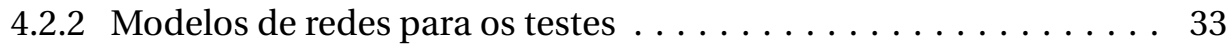

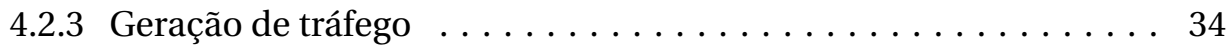

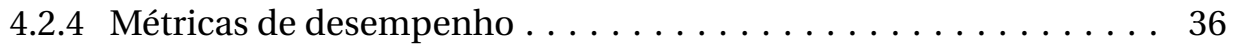

5 Roteamento de tráfego com base em economia de energia usando modo suspenso $\quad 39$

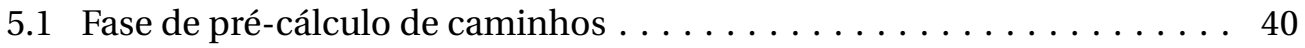

5.2 Roteamento com proteção dedicada de caminhos . . . . . . . . . 41

5.3 Proposta de roteamento intensivo com proteção dedicada de caminhos 42

5.4 Etapa de busca de recursos para o caminho principal . . . . . . . . . 42

5.5 Etapa de busca de recursos para o caminho de proteção . . . . . . . . . 44

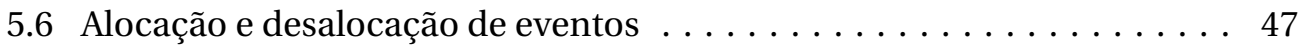

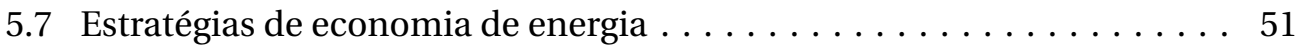

6 Simulações e resultados $\mathbf{5 5}$

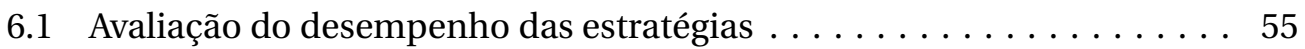

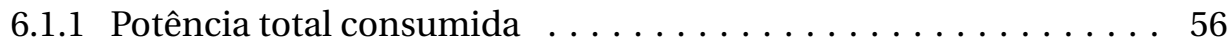

6.1 .2 Probabilidade de bloqueio . . . . . . . . . . . . . . . . . . . 64

6.1 .3 Tipo de utilização do enlace . . . . . . . . . . . . . . 68

6.1.4 Número médio de caminhos de proteção por enlace em modo

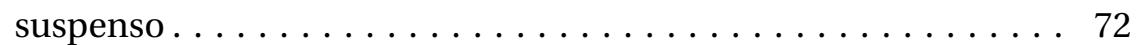

6.1.5 Número de comprimentos de onda por tipo de caminho . . . . . 74

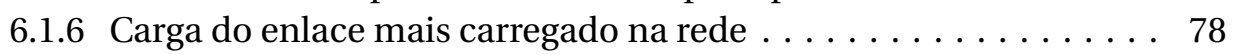

6.1.7 Compromisso entre probabilidade de bloqueio e potência consumida ........................ 81

6.2 Características da topologia das redes $\ldots \ldots \ldots \ldots \ldots \ldots \ldots . \ldots . \ldots 4$

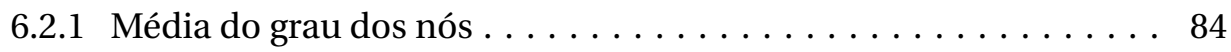

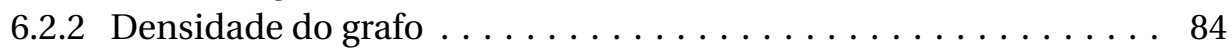

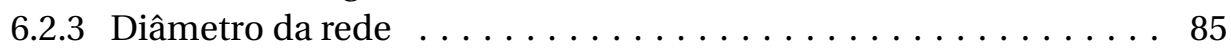

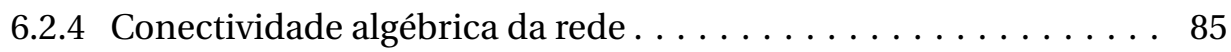


Sumário

7 Conclusões $\quad 87$

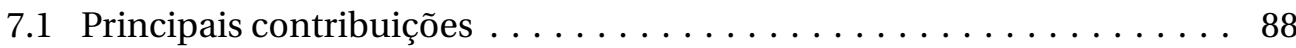

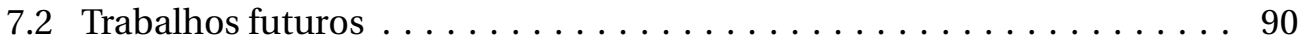

Apêndice A Validação da implementação

Referências Bibliográficas 122 



\section{Lista de Figuras}

2.1 Arquitetura básica de uma rede WDM ponto a ponto . . . . . . . . . 5

2.2 Arquitetura básica de um nó óptico $\ldots \ldots \ldots \ldots \ldots \ldots \ldots \ldots \ldots \ldots \ldots \ldots \ldots$

2.3 Esquema de proteção dedicada $1: 1 \mathrm{DPP} \ldots \ldots \ldots \ldots \ldots \ldots \ldots \ldots$

2.4 Esquema de proteção compartilhada 1:n shared path proteccion (SPP) . . . 8

3.1 Classificação das abordagens para redes energeticamente eficientes. . . . . . 14

3.2 Classificação das soluções baseadas em modo suspenso para rede WDM. . 23

3.3 Comparação entre roteamento sem economia de energia e roteamento com

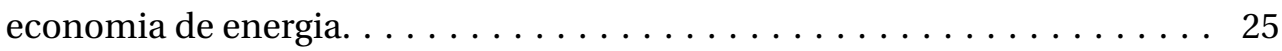

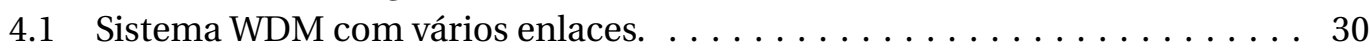

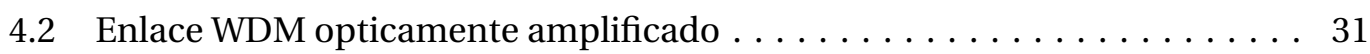

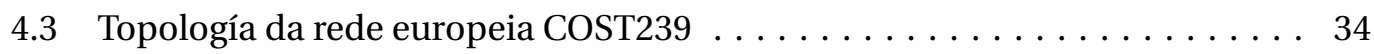

4.4 Topología da rede estadunidense USNet $\ldots \ldots \ldots \ldots \ldots \ldots \ldots \ldots \ldots$

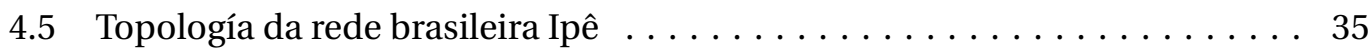

5.1 Fluxograma do roteamento de tráfego com base em economia de energia. . 50

6.1 Potência total consumida pela rede Cost239 versus carga de rede para às

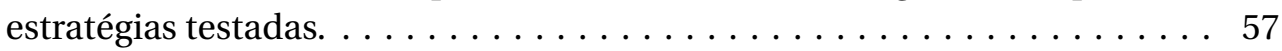

6.2 Potência total consumida pela rede Cost239 usando modo suspenso versus

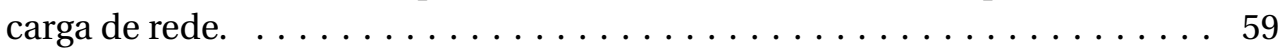

6.3 Potência total consumida pela rede USNet versus carga de rede para às es-

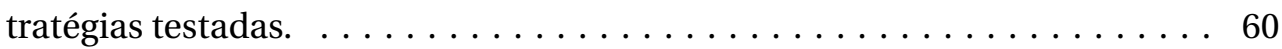

6.4 Potência total consumida pela rede USNet usando modo suspenso versus

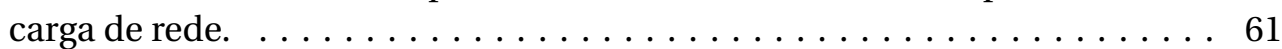

6.5 Potência total consumida pela rede brasileira Ipê versus carga de rede para às estratégias testadas. . . . . . . . . . . . . . . . 62

6.6 Potência total consumida pela rede brasileira Ipê usando modo suspenso

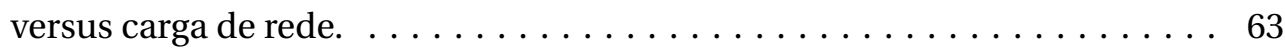

6.7 Probabilidade de bloqueio vs. carga da rede para Cost239. . . . . . . . . 65

6.8 Probabilidade de bloqueio (saturação) vs. carga da rede para Cost239. . . . . 65

6.9 Probabilidade de bloqueio vs. carga da rede para USNet. . . . . . . . . . 66

6.10 Probabilidade de bloqueio (saturação) vs. carga da rede para USNet. . . . . 66

6.11 Probabilidade de bloqueio vs. carga da rede para a rede brasileira Ipê. . . . . 67 
6.12 Probabilidade de bloqueio (saturação) vs. carga da rede para a rede brasi-

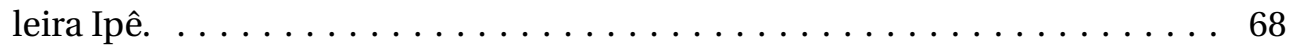

6.13 Número de enlaces usados por $W_{\text {paths }}$ ou $W \& B$ e enlaces somente por $B_{\text {paths }}$ para a rede Cost $239 . \ldots \ldots \ldots \ldots \ldots \ldots \ldots \ldots$

6.14 Número de enlaces usados por $W_{\text {paths }}$ ou $W \& B$ e enlaces somente por $B_{\text {paths }}$ para a rede USNet. $\ldots \ldots \ldots \ldots \ldots \ldots \ldots \ldots \ldots \ldots \ldots \ldots$

6.15 Número de enlaces usados por $W_{\text {paths }}$ ou $W \& B$ e enlaces somente por

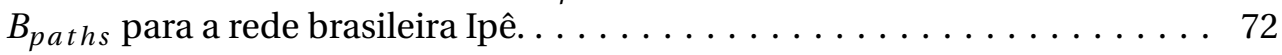

6.16 Média de caminhos de proteção por enlace em modo suspenso, rede Cost23973

6.17 Média de caminhos de proteção por enlace em modo suspenso na rede UsNet. . . . . . . . . . . . . . . . . . . . . . . . . . 74

6.18 Média de caminhos de proteção por enlace em modo suspenso na rede

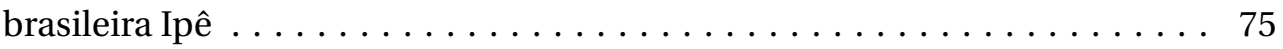

6.19 Comprimentos de onda por caminhos principais para a rede Cost239 . . . 76

6.20 Comprimentos de onda por caminhos de proteção para a rede Cost239 . . . 76

6.21 Comprimentos de onda por caminhos principais para a rede UsNet . . . . . 77

6.22 Comprimentos de onda por caminhos de proteção para a rede UsNet . . . 77

6.23 Comprimentos de onda por caminhos principais para a rede brasileira Ipê. 78

6.24 Comprimentos de onda por caminhos de proteção para a rede brasileira Ipê 79

6.25 Carga do enlace mais carregado para a rede Cost 239 . . . . . . . . . . . . 80

6.26 Carga do enlace mais carregado para a rede UsNet . . . . . . . . . . . . 80

6.27 Carga do enlace mais carregado para a rede brasileira Ipê . . . . . . . . 81

6.28 Compromisso entre probabilidade de bloqueio e potência consumida para

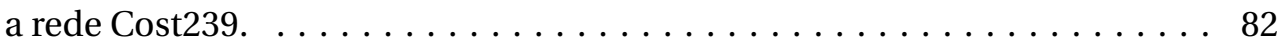

6.29 Compromisso entre probabilidade de bloqueio e potência consumida para a rede UsNet. . . . . . . . . . . . . . . . . . . . . . . . . . . . . 82

6.30 Compromisso entre probabilidade de bloqueio e potência consumida para a rede brasileira Ipê. . . . . . . . . . . . . . . . . . . 83

A.1 Rede de teste. . . . . . . . . . . . . . . . . . . . . . . . 94

A.2 Primeiro caminho mais curto entre os nós 2 e $5 \ldots \ldots \ldots \ldots \ldots \ldots$. . . . . . 94

A.3 Primeiro caminho de proteção para a rota $2-1-5 \ldots \ldots \ldots \ldots \ldots 9$

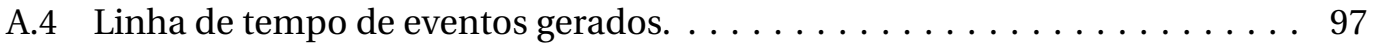




\section{Lista de Tabelas}

4.1 Potência consumida por dispositivos de rede $\mathrm{WDM}(\mathrm{em}$ watts $) \ldots \ldots \ldots 33$

5.1 Custos por enlace segundo a estratégia. $\ldots \ldots \ldots \ldots \ldots \ldots \ldots \ldots$

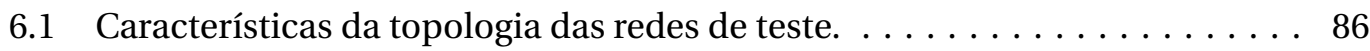

A.1 Lista de caminhos principais entre os nós 2 e $5 \ldots \ldots \ldots \ldots \ldots$

A.2 Lista de caminhos de proteção entre os nós 2 e $5 . \ldots \ldots \ldots \ldots \ldots \ldots 9$

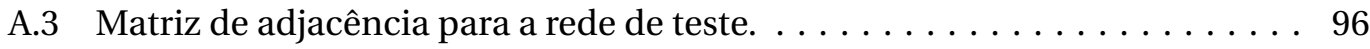

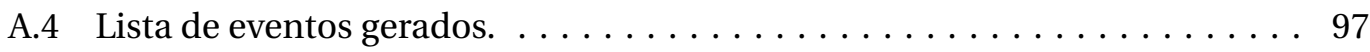

A.5 Lista de candidatos a caminho principal entre os nós 1 e $4 \ldots \ldots \ldots \ldots 9$

A.6 Lista de rotas disponíveis para o caminho principal entre os nós 1 e 4 . . . . 98

A.7 Matriz de quantidade de amplificadores por enlace para a rede de teste. . . 99

A.8 Matriz inicial de tipo de utilização do enlace. . . . . . . . . . . . . 100

A.9 Matriz inicial de custos por enlace. . . . . . . . . . . . . . . 100

A.10 Lista de custos para os caminhos principais disponíveis entre os nós 1 e 4. . 101

A.11 Lista de candidatos a caminho de proteção entre os nós 1 e 4 . . . . . . . 101

A.12 Lista de caminhos de proteção disponíveis entre os nós 1 e $4 \ldots \ldots \ldots \ldots 101$

A.13 Matriz de custos por enlace atualizada. . . . . . . . . . . . . . 102

A.14 Lista de custos para os caminhos de proteção disponíveis entre os nós 1 e 4.102

A.15 Matriz de tráfego para $\lambda 1 \mathrm{com}$ o caminho principal do primeiro evento alo-

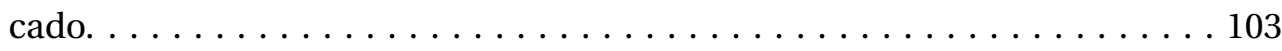

A.16 Atualização da matriz de tráfego para $\lambda 1$ com o caminho de proteção do primeiro evento alocado. . . . . . . . . . . . . . . . . . 104

A.17 Atualização da matriz de utilização de enlaces para o primeiro evento. . . . . 104

A.18 Atualização da matriz quantidade de caminhos principais por enlace para o primeiro evento. . . . . . . . . . . . . . . . . . . . . 104

A.19 Atualização da matriz quantidade de caminhos de proteção por enlace para

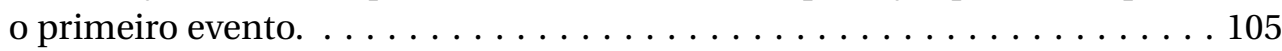

A.20 Lista de candidatos a caminho principal entre os nós 2 e 4 . . . . . . 105

A.21 Lista de rotas disponíveis para o caminho principal entre os nós 2 e 4 . . . . 105

A.22 Matriz de custos por enlace atualizada. . . . . . . . . . . . . . 106

A.23 Lista de custos para os caminhos principais disponíveis entre os nós 2 e 4. . 106 
A.24 Lista de candidatos a caminho de proteção entre os nós 2 e 4 . . . . . . . 106

A.25 Lista de rotas disponíveis para o caminho de proteção entre os nós 2 e 4 . . 107

A.26 Matriz de custos por enlace atualizada. . . . . . . . . . . . . . 107

A.27 Lista de custos para os caminhos de proteção disponíveis entre os nós 2 e 4.107

A.28 Atualização da matriz de tráfego para $\lambda 1$ no evento 2 . . . . . . . . . 108

A.29 Atualização da matriz de tráfego para $\lambda 2$ no evento 2 . . . . . . . . . 108

A.30 Matriz de tipo de utilização do enlace para o evento $2 . \ldots \ldots \ldots$. . . . . . 108

A.31 Atualização da matriz de quantidade de caminhos principais por enlace para o evento $2 . . \ldots \ldots \ldots \ldots \ldots$. . . . . . . . . . . . . . . 109

A.32 Atualização da matriz de quantidade de caminhos de proteção por enlace para o evento $2 . . \ldots \ldots \ldots \ldots$. . . . . . . . . . . . . . . . . 109

A.33 Atualização da matriz de tráfego para $\lambda 1$ no evento $5 . \ldots \ldots \ldots$. . . . . . 109

A.34 Atualização da matriz de tráfego para $\lambda 2$ no evento $5 . \ldots \ldots \ldots \ldots \ldots 110$

A.35 Atualização da matriz de tráfego para $\lambda 3$ no evento $5 . \ldots \ldots \ldots \ldots \ldots 110$

A.36 Atualização da matriz de utilização de enlaces para o evento $5 . \ldots \ldots \ldots 110$

A.37 Atualização da matriz de quantidade de caminhos principais por enlace

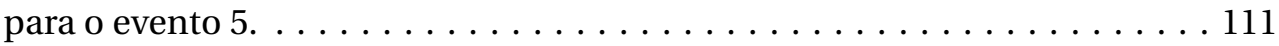

A.38 Atualização da matriz de quantidade de caminhos de proteção por enlace

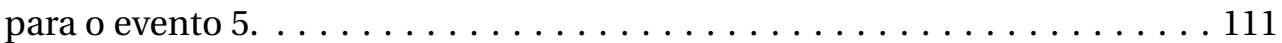

A.39 Atualização da matriz de tráfego para $\lambda 1$ no evento $6 . \ldots \ldots \ldots \ldots \ldots 112$

A.40 Atualização da matriz de tráfego para $\lambda 2$ no evento $6 . \ldots \ldots \ldots \ldots \ldots 112$

A.41 Atualização da matriz de tráfego para $\lambda 3$ no evento $6 . \ldots \ldots \ldots \ldots \ldots 112$

A.42 Atualização da matriz de utilização de enlaces para o evento $6 . \ldots \ldots \ldots 113$

A.43 Atualização da matriz de quantidade de caminhos principais por enlace para o evento $6 . . \ldots \ldots \ldots \ldots \ldots \ldots \ldots \ldots \ldots \ldots \ldots \ldots \ldots$

A.44 Atualização da matriz de quantidade de caminhos de proteção por enlace para o evento 6. . . . . . . . . . . . . . . . . . . . . . . . . . . . . . . 114 


\section{Lista de Algoritmos}

1 Pré-cálculo de caminhos principais e de proteção $\ldots \ldots \ldots \ldots \ldots \ldots 40$

2 Roteamento com proteção dedicada de caminhos . . . . . . . . . . . . . 41

3 Nossa proposta de roteamento intensivo com proteção dedicada de caminhos 43

4 Procurar comprimentos de onda para o caminho principal . . . . . . . . 45

5 Procurar comprimentos de onda para o caminho de proteção . . . . . . . . 46

6 Alocação do caminho principal e de proteção . . . . . . . . . . . . 48

7 Desalocação dos caminhos principal e secundário . . . . . . . . . . . . 49 



\section{Lista de Abreviaturas}

WDM wavelength division multiplexing

DPP dedicated path protection

SPP shared path proteccion

TICs Tecnologias de Informação e Comunicação

QoS Quality of Service

OXC Optical Cross-Connector

ECS Electronic Control System

WC Wavelength Converter

MEMS Micro Electromechanical System

ILP Integer Linear Programing

EA-DPP Energy Aware-Dedicated Path Protecction

SP-DPP Shorthest Path-Dedicated Path Protecction

EA-DPP-Dif Energy Aware-Dedicated Path Protection with Differentation

EA-DPP-MixS Energy Aware-Dedicated Path Protecction with Mixing

PASPP Power Aware Shared Path Protecction

ESTOP Energy Saving based on TOPology 



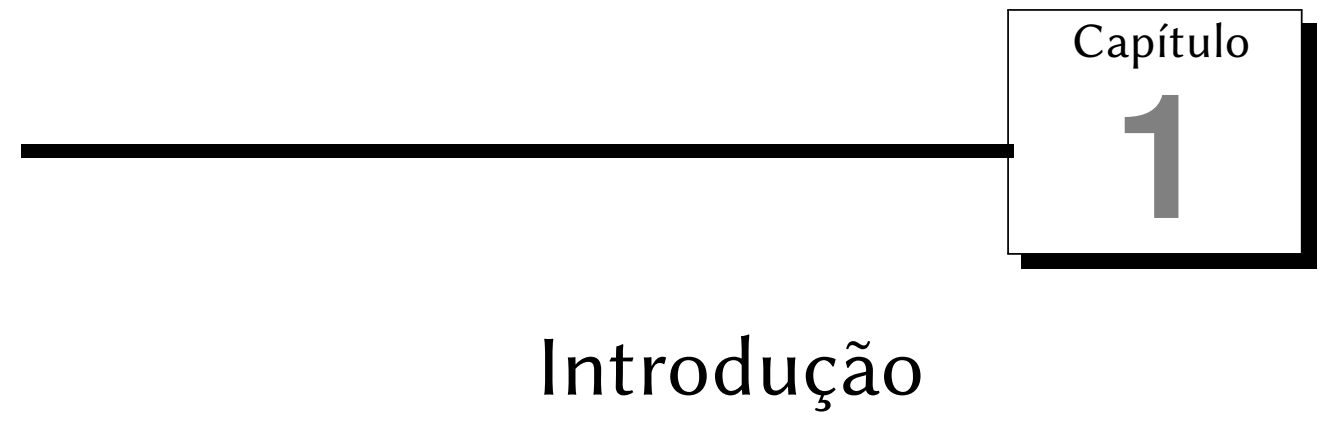

\subsection{Contextualização e motivação}

A crise energética e o aquecimento global têm gerado a necessidade de investigação das causas do problema e as possiveis soluções em diferentes campos da ciência. O setor das telecomunicações não é alheio a esse problema. Os autores de [1-4] coletaram alguns dados a respeito do consumo de energia em telecomunicações.

As Tecnologias de Informação e Comunicação (TICs), em 2009, fizeram uso de $8 \%$ da energia no mundo [5], e as projeções de incremento da energia consumida na área são altas. Tem-se previsto que a energia consumida no ano de 2017 será $120 \%$ maior com relação a 2009 [6]. Em 2020 o incremento do consumo de energia pelas TICs poderá alcançar $15 \%$ da energia mundial [7].

As fontes tradicionais de energia, como os hidrocarbonetos, são fontes não renováveis que liberam grandes quantidades de gases de efeito estufa (compostos principalmente por $\mathrm{CO}_{2}$ ). Esses gases têm efeitos devastadores no meio ambiente e são, em parte, responsáveis pela mudança climática [8]. As emissões do $\mathrm{CO}_{2}$ produzidas pelas TICs foram estimadas em 2\% em 2007 (860 milhões de toneladas), e a porcentagem dessas emissões pode atingir $4 \%$ em 2020 [9].

As TICs permitem o desenvolvimento de diversas atividades a distância como: trabalho remoto, comércio eletrônico, videoconferências, etc. Essas atividades são vistas como amigáveis ao meio ambiente porque diminuem o impacto causado pelo ser humano na natureza. A diminuição da exclusão digital, a facilidade de acesso e a necessidade de 
informação e comunicação têm feito das TICs parte da vida cotidiana. Isso traz como consequência o incremento tanto de dispositivos de acesso (computadores, smartphones, etc.) como de equipamentos de redes de comunicação e de tráfego. Tudo isso é refletido no incremento do consumo de energia [1].

O consumo de energia das redes de comunicações vem sendo estudado. Em 2002 foram analisadas algumas das contribuições em redes Wide Area Network (WAN) e Local Area Network (LAN) [10]. Como resultado do estudo obteve-se que os switches de área local foram responsáveis por $53,7 \%$ do consumo e os hubs por $26 \%$, o que dá um total de quase $80 \%$ para as LAN. Os resusltados para as redes WAN foram que os roteadores das redes consumiram 17,9\% e os switches 2,4\%. Em 2005 foi estimado o consumo das Network Interface Cards (NICs) ou placas de rede, concluindo que gastam quase $50 \%$ da energia consumida pela rede [11].

As redes de telecomunicações podem ser divididas em redes núcleo ou backbone, metropolitana e de acesso. Uma estimativa do consumo da rede núcleo feita em 2009 para o ano de 2017, estimou que a energia consumida pelo núcleo será igual à consumida pela rede de acesso [12]. Em [13] foi estimada a porcentagem de energia efetivamente utilizada nas três divisões de rede, concluindo que nas redes núcleo não se utiliza $50 \%$ da energia, nas redes metropolitanas $70 \%$ e nas redes de acesso $85 \%$. Isto revela altas porcentagens de energia desperdiçada.

As estruturas de rede e armazenamento de informação das TICs têm envolvidos dispositivos de alto desempenho e disponibilidade. Essas estruturas são baseadas em dispositivos de alto consumo de energia, adicionalmente precisam de uma arquitetura redundante, para garantir a disponibilidade, o que aumenta a quantidade de equipamentos. A faixa de temperatura de trabalho destes equipamentos não deve superar certo limite (ao redor de $23^{\circ} \mathrm{C}$ [14]). Para dissipar o calor produzido pelos equipamentos em funcionamento é necessária a utilização de ar condicionado, o que incrementa o consumo de energia [3]. Elevando adequadamente o limite de temperatura pode-se reduzir a quantidade de energia utilizada pelo ar condicionado [14].

Por outro lado as arquiteturas de rede estão projetadas para suportar a demanda de pico de tráfego de dados. Esse pico de demanda é requerido só durante certas horas do dia, o que se traduz na subutilização da rede. Do mesmo modo, quando uma rede é planejada, é considerada a degradação dos dispositivos que a compõem. Por isso a rede é projetada para trabalhar com maior energia do que a necessária, para garantir o desempenho quando os equipamentos e dispositivos se degradarem [3].

Devido à importância da economia de energia organizações internacionais como International Telecommunication Union (ITU), Institute of Electrical and Electronics Engineers (IEEE), European Telecommunication Standard Institute (ETSI), Telecommunication Industry Association (TIA), Alliance for Telecommunications Industry Solutions (ATIS), 
Energy Consumption Rating Initiative (ECR) e Energy Efficiency Requirements for Telecommunications Equipment (TEEER), estão trabalhando em padrões novos para garantir a eficiência de energia nas redes [15]. Em abril de 2009 a Comissão Europeia anunciou os objetivos 20-20-20, a fim de diminuir o $\mathrm{CO}_{2}$ em $20 \%$, reduzir o consumo de energia em $20 \%$ e incrementar o uso de energia renovável em $20 \%$ para o ano de 2020 [16].

\subsection{Objetivo e organização do trabalho}

$\mathrm{Na}$ literatura foram encontrados trabalhos onde são classificadas as abordagens para economia de energia em redes de comunicação, mas essas classificações não são homogêneas. A primeira etapa deste trabalho foi relacionar e integrar as classificações encontradas. As soluções foram classificadas segundo seu tipo de abordagem e cenário de rede. Baseado nessa informação foi determinado o foco do estudo: economia de energia em redes WDM com modo suspenso.

A segunda etapa foi realizar um estudo das soluções baseadas em modo suspenso, do qual foi escolhido o roteamento baseado na diferenciação de tipo de caminhos. Foram testadas quatro estratégias em três redes: europeia, estadunidense e brasileira.

Observando os resultados em relação a economia de energia e probabilidade de bloqueio a terceira etapa foi propor um algoritmo de roteamento de busca mais ampla em recursos. Finalmente, o algoritmo foi testado e avaliado usando as estratégias previamente estudadas.

Assim, o objetivo deste projeto de mestrado foi desenvolver um algoritmo de roteamento baseado em economia de energia para redes WDM com proteção dedicada de caminhos, mediante a utilização de modo suspenso. O algoritmo proposto tem o intuito de diminuir a probabilidade de bloqueio, mantendo e, em alguns casos, melhorando a quantidade de energia economizada. Esse balanço entre demandas atendidas e potência economizada garante a qualidade de serviço das redes.

Organizamos este texto nos seguintes capítulos:

Capítulo 2: são apresentados alguns conceitos básicos que serão utilizados ao longo do trabalho.

Capítulo 3: é apresentado um resumo dos trabalhos relacionados, incluindo as primeiras iniciativas e uma classificação das estratégias em economia de energia contempladas pelos trabalhos revisados. Também será apresentada a definição e classificação das soluções baseadas em modo suspenso.

Capítulo 4: são apresentados os principais objetivos e descrita a metodologia seguida para os testes. 
Capítulo 5: são apresentados os algoritmos implementados, assim como o algoritmo de roteamento intensivo proposto.

Capítulo 6: são apresentados os resultados para as métricas avaliadas nas três redes.

Capítulo 7: são apresentadas as conclusões e principais contribuições do trabalho. 


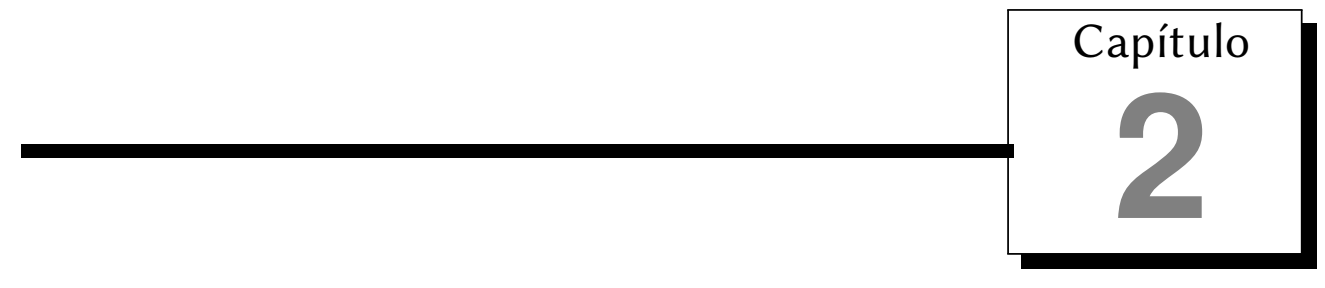

\section{Conceitos prévios}

Nesta seção serão apresentados alguns conceitos básicos sobre redes ópticas WDM e sobre a representação de redes mediante grafos, conceitos esses que serão utilizados ao longo do trabalho.

\subsection{Redes Wavelength Division Multiplexing}

As redes ópticas WDM utilizam uma técnica de multiplexação que consiste na combinação de vários comprimentos de onda $(\lambda)$ sobre uma mesma fibra. O objetivo é incrementar a capacidade de transmissão num mesmo enlace de fibra óptica.

A arquitetura básica de uma rede WDM ponto a ponto é representada na Figura 2.1. Onde os transmissores $T_{x}$ são fontes de luz com diferentes comprimentos de onda, esses

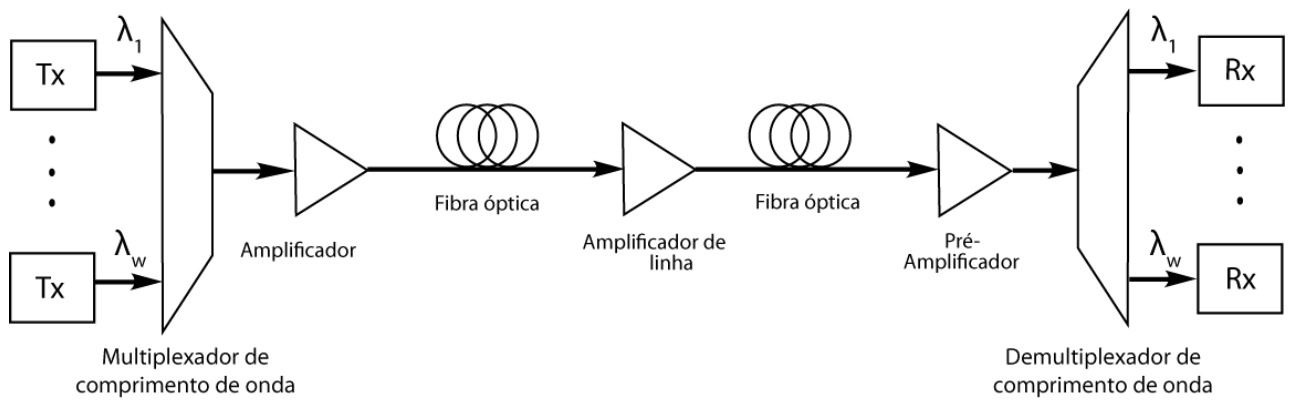

Figura 2.1.: Arquitetura básica de uma rede WDM ponto a ponto [17]. 


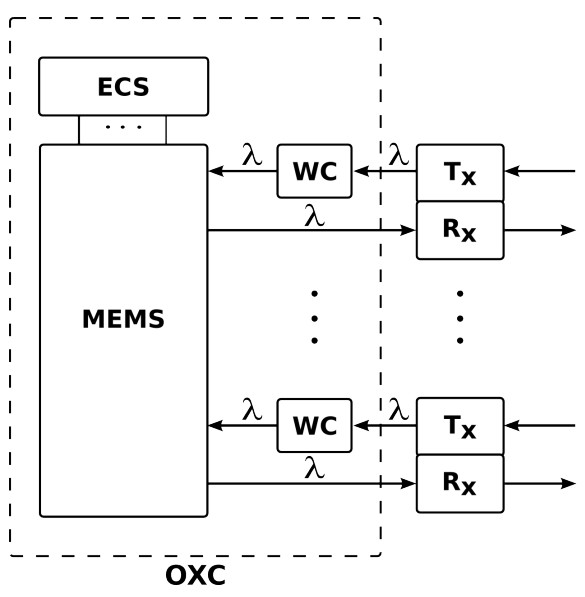

Figura 2.2.: Arquitetura básica de um nó óptico [18].

comprimentos são combinados pelo multiplexador. O sinal já combinado é transmitido pela fibra óptica é demultiplexado (separado novamente nos comprimentos de onda iniciais) quando chegar a seu destino $R_{x}$. Devido à grande distância (vários $\mathrm{km}$ ) percorrida pelos sinais ópticos, são necessários amplificadores ópticos. Esses amplificadores podem ser separados em três categorias, amplificadores de potência, amplificadores de linha e pré-amplificadores. Os mais utilizados são os baseados em fibra dopada com érbio, Erbium Doped Fiber Amplifier (EDFA) [17].

Outro elemento das redes WDM são os comutadores ópticos, Optical Cross-Connector (OXC). Os OXC encaminham um determinado comprimento de onda proveniente de uma porta de entrada para uma outra porta de saída. A arquitetura básica de um OXC inclui uma estrutura de chaves e um sistema de controle, Electronic Control System (ECS). Além disso, um OXC pode incluir amplificadores, multiplexadores de inserção e remoção de canais ópticos, Optical Add/Drop Multiplexer (OADM), e conversores de comprimento de onda, Wavelength Converter (WC). Tem-se uma variedade de tecnologias para a construção da estrutura de chaves, dentro deles estão os Micro Electromechanical System (MEMS). Os MEMS são estruturas eletromecânicas complexas, que permitem o encaminhamento de comprimentos de onda. Existem estruturas MEMS 1D, 2D e 3D [17]. Na Figura 2.2 mostramos uma arquitetura básica de nó óptico com capacidade de conversão de comprimento de onda. Note-se que na estrutura de chaves MEMS, os conversores de comprimento de onda WC e os $T_{x} / R_{x}$ trabalham a nível de comprimento de onda; e o sistema de controle ECS a nível de nó.

Para transmitir informação pelas redes ópticas é indispensável a designação de um caminho de conexão. Esse caminho é chamado lightpath ou caminho óptico. São caminhos unidirecionais que podem utilizar um mesmo comprimento de onda ao longo da rota estabelecida ou comprimentos diferentes em cada salto (percurso entre dois nós consecuti- 
vos). Neste último caso é necessário que os equipamentos da rede possuam conversores de comprimento de onda. O uso de conversores de comprimento de onda reduz a probabilidade de bloqueio ao estabelecer os caminhos ópticos.

O estabelecimento de caminhos ópticos pode ser feito de forma estática ou dinâmica. Estática quando as demandas de tráfego são dadas a priori e os caminhos ópticos são précalculados antes de começar a transmissão, e dinâmica quando os caminhos ópticos são calculados em tempo real (enquanto novas demandas surgem) [17].

As redes núcleo de telecomunicações devem garantir disponibilidade de 99,99\% até 99,999\% do tempo, ou seja devem ter um alto grau de confiabilidade e fornecer uma ótima qualidade de serviço. Portanto, devem possuir esquemas de proteção contra falhas, as quais podem ter relação aos enlaces ou aos caminhos ópticos [19]. Esses esquemas podem ser dedicados ou compartilhados.

Os esquemas de proteção dedicada de caminho calculam dois caminhos ópticos para cada demanda: um caminho principal e um caminho de proteção. Existem dois tipos de esquemas dedicados: os esquemas de proteção $1+1$ e 1:1. No primeiro esquema os dados são transmitidos simultaneamente pelos dois caminhos, principal e de proteção. No caso dos esquemas 1:1 os dados são transmitidos pelo caminho principal, enquanto a rede opera normalmente, e no caso de falha os dados serão transmitidos pelo caminho de proteção. Esses caminhos calculados são disjuntos, ou seja, passam por rotas físicas diferentes [17]. Para a demanda $s_{1}-d_{1}$ é mostrado na Figura 2.3 o caminho óptico principal e seu respectivo caminho de proteção dedicado.

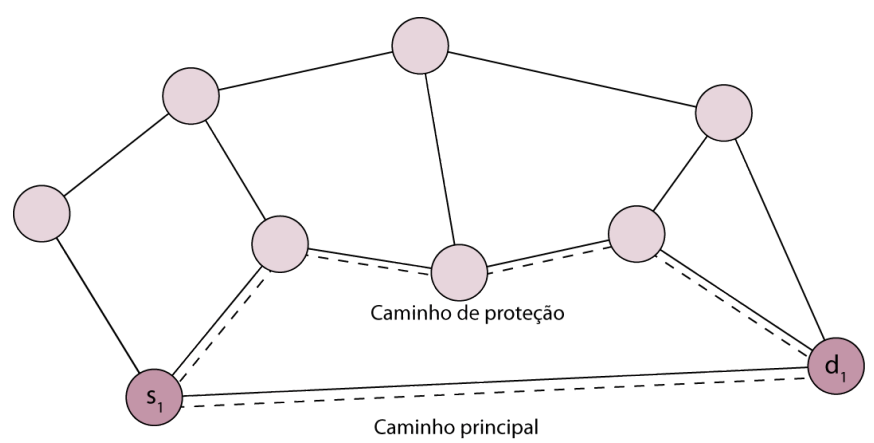

Figura 2.3.: Esquema de proteção dedicada 1:1 DPP [20].

No entanto os esquemas de proteção compartilhada 1:n calculam só um caminho de proteção para um grupo de caminhos principais. Isso faz com que sejam economizados mais recursos, porém, no caso de ocorrer uma falha, somente um dos caminhos principais poderá ter acesso ao caminho de proteção. Na Figura 2.4 são mostrados os caminhos ópticos principais para as demandas $s_{1}-d_{1}$ e $s_{2}-d_{2}$, e seu respectivo caminho de proteção compartilhado. 


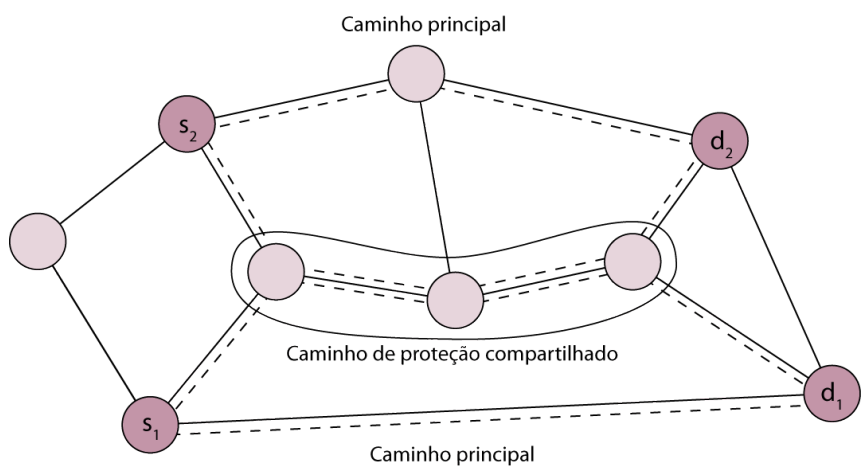

Figura 2.4.: Esquema de proteção compartilhada 1:n SPP [20].

\subsection{Teoria de Grafos}

Varias soluções descritas ao longo do trabalho fazem uso da teoria de grafos para descrever a rede. Os grafos são úteis na modelagem de problemas que representam sistemas reais. Por exemplo, a representação da topologia de uma rede óptica considera cada nó como um vértice e os cabos de fibra óptica como arestas. Resumidamente, o grafo é um modelo matemático usado para representar o mundo real. Matematicamente, "um grafo $G$ propriamente dito é uma representação gráfica das relações existentes entre elementos de dados. Ele pode ser descrito num espaço euclidiano de $n$ dimensões como sendo um conjunto $V$ de vértices e um conjunto E de curvas contínuas (arestas)". Em outras palavras, os grafos representam conjuntos de itens conectados por alguma relação. Uma contribuição teórica relevante sobre o tema pode ser encontrada em [21].

\section{Notações , Conceitos e Propriedades Básicas}

Existem dois tipos de grafos, os não-direcionados (simples) e os direcionados (ou dirigidos), indicando, respectivamente, se existe ou não direção na relação entre dois vértices. Em grafos direcionados, também chamados dígrafos, a relação é expressa por uma seta ligando o nó fonte $s$ ao nó terminal $d$.

Um grafo simples possui um conjunto finito de vértices, representados por $V$, e um conjunto finito de arestas representados por $E$. Assim a notação de grafo é dada por $G=$ $(V, E)$. A notação que usaremos para as redes ópticas será $G=(N, E)$, onde os vértices serão representados por $N$ para facilitar sua relação simbólica com os nós da rede.

Computacionalmente, um grafo representa uma estrutura de dados que declara um conjunto de objetos (vértices) e suas relações (arestas). Os dados de um grafo podem ser expressos através de uma matriz de adjacência $A=\left(a_{i, j}\right)$, onde: 


$$
a_{i, j}= \begin{cases}1 & \text { se existe uma aresta entre os vértices } i, j \\ 0 & \text { caso contrário }\end{cases}
$$

Em alguns casos, quando se utiliza modelagem baseada em grafos, é relevante considerar algumas propriedades [22]. Uma propriedade relacionada a cada vértice é o grau, que é o número de arcos (enlaces) que incidem sobre esse vértice. Assim, o grau do vértice $i$ é dado por

$$
\operatorname{deg}\left(v_{i}\right)=\sum_{j=1}^{|V|} a_{i, j},
$$

onde $|V|$ é o número de vértices no grafo.

Cada aresta $a_{i, j}$ pode ter um peso $w_{i, j}$ associado que representa a relação entre dois nós. Nesse caso, pode-se utilizar a matriz de pesos $W=\left(w_{i, j}\right)$ para representar o grafo.

Informações particulares sobre as relações entre os vértices está presente na modelagem de problemas que envolvem rotas. No nosso problema é importante armazenar dados referentes à distância entre os nós. Essa distância será o comprimento físico do enlace.

Outras propriedades do grafo, relevantes para este trabalho, são densidade e diâmetro do grafo. A densidade é a taxa do número de arestas do grafo versus o número de arestas se o grafo for completo. Um grafo é completo se cada par de vértices está conetado por uma aresta. Em grafos direcionados, a densidade é definida

$$
D=\frac{|E|}{|V|(|V|-1)}
$$

onde $|E|$ é o número de arestas. Note-se que, $|V|(|V|-1)$ é o número de arestas de um grafo direcionado completo.

O diâmetro do grafo é a longitude do caminho mais curto entre o par de vértices mais distanciados. Formalmente, se $d(u, v)$ é a distância mais curta entre os vértices $u$ e $v, o$ diâmetro do grafo é

$$
\operatorname{diam}(G)=\max _{u, v} d(u, v)
$$

\section{Matriz Laplaciana}

Algumas propriedades de grafos podem ser representadas mediante métodos de álgebra linear [23]. Um grafo pode ser associado com diferentes matrizes, cujos autovalores podem mostrar algumas propriedades da estrutura do grafo. Algumas matrizes que são utilizadas para realizar esses estudos são a Matriz de Adjacência $(A)$ e a Matriz Laplaciana $(L=D-A)$, onde $D$ é a matriz diagonal dos graus dos vértices.

As redes ópticas podem ser representadas por grafos simples não direcionados sem la- 
ços. A matriz de adjacência desse grafo é simétrica com espectro real de $n$ autovalores $\lambda_{i}$. A matriz laplaciana $L=\left(l_{i, j}\right)$, também chamada matriz de admitância, é dada por:

$$
l_{i, j}= \begin{cases}k_{i} & \text { se } i=j \\ -1 & \text { se } i \neq j \text { e existe uma aresta entre os vértices } i, j \\ 0 & \text { caso contrário }\end{cases}
$$

onde $k_{i}$ é o grau do vértice $i$.

Algumas propriedades de $L$ são:

- se o grafo é não-direcionado, $L$ é simétrica;

- $L$ é positiva definida: todos os autovalores $\lambda_{i} \geq 0$.

- se o grafo é conexo, o primeiro autovalor $\lambda_{1}$ é 0;

- o segundo autovalor $\lambda_{2}$ é chamado autovalor fielder;

- $\lambda_{2}$ representa a conectividade algébrica, refletindo a robustez da rede. 


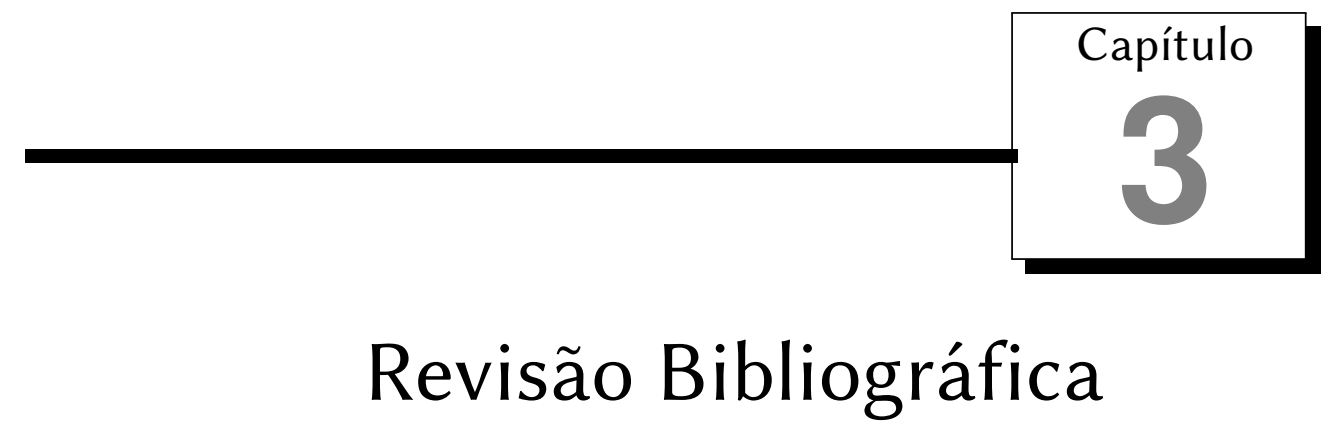

\subsection{Considerações Iniciais}

Devido à importância para o meio ambiente e para a economia estão sendo desenvolvidas pesquisas importantes visando a diminuição do consumo de energia em redes. Frente aos problemas de conservação da energia e do meio ambiente tem-se duas direções de pesquisa: o desenvolvimento de fontes de energia renovável não contaminante e o desenvolvimento de estratégias que permitam a conservação da energia.

As fontes de energias renováveis podem ser divididas em fontes controláveis e fontes não controláveis. As primeiras são fontes de energia primária que permitem controlar a produção de energia elétrica [24]. Fuel cell energy server é um exemplo de uma fonte controlável, é uma classe de geradores que converte óleo em eletricidade por meio de um processo eletroquímico limpo. As fontes incontroláveis, como o sol e o vento, são independentes do homem. Nas redes celulares a maior parte da energia é consumida pelas estações bases. Para cobrir a demanda de energia requerida pelas estações base estão sendo utilizados painéis solares, turbinas baseadas no vento e servidores de energia baseados em celas de óleo [24].

Primeiras iniciativas em economia de energia

As estratégias de conservação da energia em redes são muito variadas. Uma das primeiras contribuições que buscam a otimização do consumo de energia em redes foi pu- 
blicado em 1988. O objetivo era diminuir o consumo de energia dos computadores mediante uma nova opção de conexão em modo sleep, ou suspenso, do protocolo TCP/IP [25]. Em 2003 Gupta e Singh [26] e em 2004 Christensen et al. [27] publicaram pesquisas sobre o consumo de energia nas rede de internet. O tema já estava sendo estudado no início deste século, enfatizando a importância da melhora no consumo de energia.

Em 2007, a Nippon Telegraph and Telephone Corporation (NTT), devido à alta porcentagem de energia consumida pelas redes de telecomunicações no Japão, desenvolveu uma estratégia chamada Green integration [28]. Essa estratégia não estava limitada às telecomunicações, mas também envolviam o planejamento de sistemas de energia, desenho do edifício, ar condicionado, etc. Foi a partir do 2008 que pesquisadores e empresas de telecomunicações e de equipamento para telecomunicações começaram a trabalhar fortemente nessa área. No editorial de notícias e tendências da revista da IEEE Computer Society já começava a falar sobre as redes tornando-se verdes [29]. Em 2008 pesquisadores [30] da empresa Juniper desenvolveram algumas estratégias e tecnologias para economizar energia em equipamentos de rede, como roteadores. Por outro lado Jimeno et al. [31] apresentaram uma estratégia de proxying ao nivel de aplicação que permitia que terminais fossem postos em modo suspenso. Também em 2008 foram desenvolvidas estratégias de diminuição de consumo através máquinas virtuais [32].

Eficiência de energia em redes de comunicações

Em primeiro lugar é importante notar que no planejamento de sistemas de comunicação a economia de energia não é um tema que não era analisado. Mas, a importância da economia de energia estava focada na ampliação da capacidade do sistema. Esse incremento de capacidade não seria possível sem tecnologias de transmissão energeticamente eficientes. Agora, porém, a faceta da economia de energia em redes ou redes verdes está ligada à compreensão de que o mundo em que vivemos é um mundo com energia limitada [33].

As redes verdes podem ser entendidas como um novo esquema de roteamento onde o objetivo de otimização é o consumo de energia nas redes de comunicação [34]. Muitas das soluções em economia de energia conseguem diminuir significativas porcentagens de energia, mas o desafio está em conseguir minimizar a energia consumida mantendo a qualidade de serviço, evitando o congestionamento, inacessibilidade ou retardo e garantindo a segurança.

Nos últimos anos foram desenvolvidos três importantes trabalhos [1-3] que recompilam as diferentes técnicas e abordagens em torno de redes verdes de comunicação. Zhang et al. [1] apresentaram uma visão global acerca das pesquisas em economia de energia em redes ópticas, dividindo as abordagens segundo a parte da rede a que correspondem, 
como em redes núcleo, de transporte e de acesso. Além disso, há ênfase na aplicação de tecnologias ópticas para o uso eficiente de energia em data centers e na camada de aplicação.

Os autores de [1] também dividem as estratégias de minimização de consumo de energia para redes ópticas em níveis: o nível de componente, onde estão considerados equipamentos como buffers, switches e conversores de comprimento de onda que sejam mais eficientes; o nível de transmissão com fibras, com menor dispersão e atenuação; o nível de rede que inclui distribuição de recursos nas redes ópticas de acesso de largo alcance; e o nível de aplicação que aborda computação em nuvem e proxying.

Bianzino et al. [3] propuseram quatro tipos de soluções para a economia de energia: consolidação de recursos, conectividade seletiva, virtualização e computação proporcional. A consolidação de recursos busca diminuir o consumo de energia dos dispositivos da rede subutilizados. Por exemplo, desligando roteadores pouco usados, encaminhando o tráfego que passe por eles a outros roteadores, para diminuir o número de equipamentos ativos na rede. A conectividade seletiva, consiste em pôr em estado de espera recursos não utilizados na borda da rede ( proxying). Assim evita-se tráfego produzido por tarefas de conectividade da rede que são feitas periodicamente como heartbeats e broadcast. A virtualização permite operar vários serviços na mesma peça de hardware. E a computação proporcional consiste em colocar o consumo de energia em concordância com o nível de utilização.

Bianzino et al. [3] propõem também um modelo taxonômico para classificar os trabalhos de pesquisa em redes com fio baseando-se no tipo de abordagem. O modelo de classificação proposto tem em consideração outros critérios, detalhados a seguir. Consideram se as soluções são aplicadas em tempo real (online) ou se as soluções são aplicadas a priori, por exemplo, roteamento estático. Se a solução é local (um nó só) ou global (precisa da informação de vários nós). Também têm em conta o nível em que atua a solução de acordo com o modelo de camadas TCP/IP. Consideram adicionalmente, como é a entrada do processo, isto é, se a solução é instantânea ou baseada em dados históricos. Por último fazem uma avaliação das abordagens em termos de metodologia, vantagens e limitações [3].

Bolla et al. [2] apresentam uma revisão que inclui as tecnologias emergentes, projetos e padrões em desenvolvimento para redes que têm como objetivo reduzir a pegada de carbono e a energia consumida pelas infraestruturas de redes fixas. O estudo inclui redes de acesso cabeadas, redes celulares, comutadores e roteadores em redes de trasporte e redes ethernet. No entanto não são inclusos nem data centers nem redes de área local sem fio, como redes de sensores e redes ad hoc. A taxonomia de classificação que os autores utilizaram é derivada dos critérios de gestão disponíveis em sistemas de computação. As abordagens podem ser classificadas em reengenharia, adaptação dinâmica e 


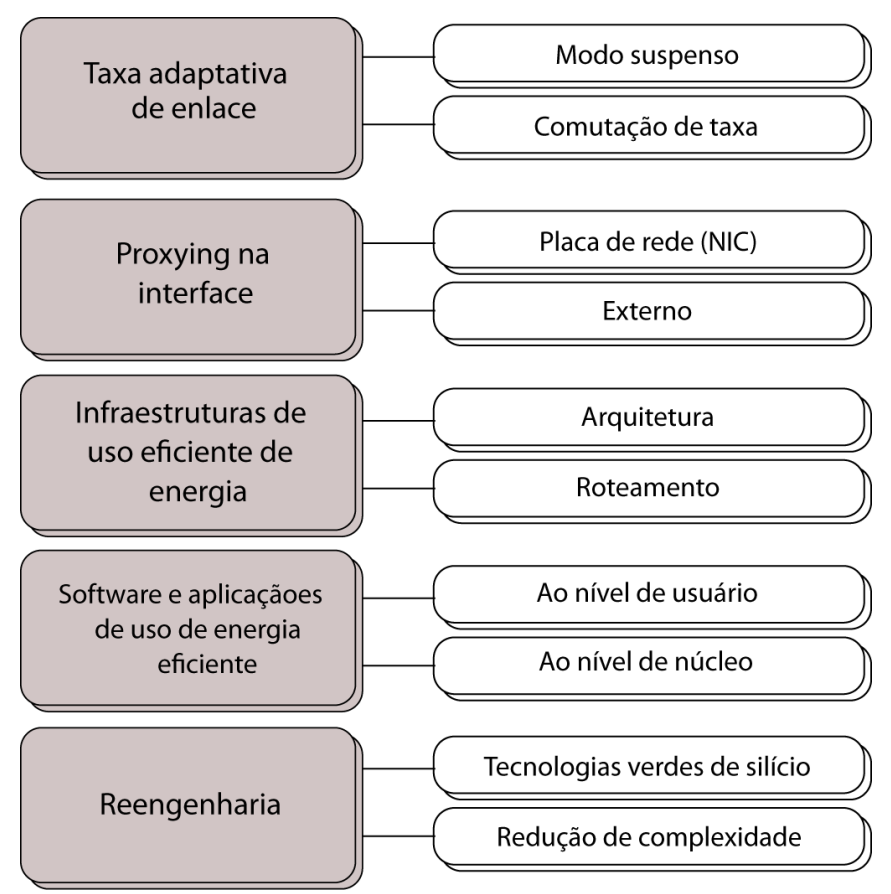

Figura 3.1.: Classificação das abordagens para redes energeticamente eficientes.

modo suspenso ou de espera. A reengenharia trata do desenho de elementos eficientes para a arquitetura da rede do ponto de vista de consumo de energia, e procura otimizar a estrutura interna e diminuir a complexidade do equipamento. A adaptação dinâmica modula a capacidade de processamento com relação à carga de tráfego da rede em termos de energia consumida. E o modo suspenso ou de espera coloca elementos da rede ou setores não utilizados em um estado quase desligado.

\subsection{Classificação das Abordagens para Redes Energeticamente Efici- entes}

A classificação das abordagens revisadas na literatura foi realizada integrando as classificações feitas por [1-3] como é detalhado a seguir. Achamos a taxonomia de classificação dos tipos de abordagens feitos por Bianzino et al. [3] mais representativa, mas a separação por cenários ou tipos de rede de Bolla et al. [2] mais adequada. Isto devido à heterogeneidade das abordagens e sua dependência com o tipo ou parte especifica da rede. Por essa razão adotaremos uma mistura das classificações e introduziremos alguns critérios considerados por Zhang et al. [1]. Na Figura 3.1 mostramos a classificação das abordagens a ser considerada neste trabalho. 


\subsubsection{Tipos de abordagens}

Taxa adaptativa de enlace

Nas redes convencionais, quando nenhum dado está sendo transmitido , os enlaces são utilizados para o envio de tráfego de sincronização ou de broadcast, que na prática é tráfego sem significado, que não carrega informação. A taxa adaptativa de enlace utiliza esse fato e toma vantagem dele para reduzir assim o consumo de energia de acordo com o nível de utilização do enlace. As propostas baseadas nesta estratégia podem ser divididas em: modo suspenso, desligar os enlaces durante os períodos de não utilização, $\mathrm{e}$ comutação de taxa durante os períodos de transmissão de baixo tráfego [3].

Tem-se várias maneiras de abordar o modo suspenso: o modo inativo profundo, onde os pacotes são descartados durante o período de suspensão; o modo alerta no qual o enlace é acordado com a recepção de algum pacote; o modo de armazenamento, que utiliza um buffer para armazenar os pacotes que são recebidos durante o período de suspensão; e o modo que usa uma shadow port que maneja os pacotes de um conjunto de portas suspensas [3].

A classificação, taxa adaptativa de enlace, pode ser comparada com o critério de classificação de Bolla et al. [2], adaptação dinâmica; e com a classificação de Zhang et al. [1], desligamento seletivo de elementos da rede.

Proxying na interface

No caso de taxa adaptativa de enlace, os enlaces inativos ou suas funcionalidades podem ser desligados para conseguir economizar energia. No caso de dispositivos terminais não é possível desligar completamente estes da rede sem afetar sua funcionalidade. Esses tipos de dispositivos, como computadores, precisam manter certo tipo de sinalizações para permanecer conectados à rede. Para colocar os dispositivos terminais em modo suspenso, esse tráfego de rotina deve ser processado por equipamentos que sejam energeticamente mais eficiente. Mas nem todo esse tráfego de rotina precisa de processamento ou de resposta. Esse é o caso das tramas de broadcast ou de busca de porta, que podem ser ignoradas depois de serem filtradas.

No caso de troca de Address Resolution Protocol (ARP), Dynamic Host Configuration Protocol (DHCP) ou Internet Control Message Protocol (ICMP) são necessárias respostas simples que podem ser processadas na interface de rede, ou também por entidades externas que processam esse tipo de tráfego para vários dispositivos terminais. Portanto o proxying pode ser feito tanto internamente nas NICs do dispositivo, quanto de maneira externa [3]. Proxying na interface pode ser comparado com suspensão inteligente da classificação de [2]. 
Infraestruturas de uso eficiente de energia

Contrariamente às abordagens anteriores, onde a economia de energia é baseada em um só dispositivo nas infraestruturas com uso eficiente de energia, a otimização nessas infraestruturas é feita de maneira coletiva. Os diferentes elementos da rede colaboram entre si para conseguir o uso eficiente da energia. Essa abordagem contempla arquiteturas e roteamento energeticamente eficientes. Dentro das arquiteturas eficientes temse dois tipos de soluções, uma abordagem incremental sobre a rede existente, e um replanejamento completo da rede, o que significa uma nova arquitetura [3]. Essa subclassificação é considerada por Zhang et al. [1] como planejamento de rede energeticamente eficiente.

Por outro lado o roteamento energeticamente eficiente consiste em redistribuir o tráfego de um subconjunto de enlaces e equipamentos com tráfego leve, para um outro subconjunto de enlaces, a fim de colocar em modo suspenso o primeiro subconjunto. Porém o desafio dessas soluções é garantir a qualidade de serviço e a conectividade [3]. Essa subclassificação é considerada por [1] como roteamento verde.

Software e aplicações de uso de energia eficiente

Os sistemas operacionais, protocolos e diferentes aplicações estão diretamente relacionados com o consumo de energia nas redes. Desse modo, algumas modificações nesses elementos podem ser feitas para conseguir o objetivo das redes verdes, a minimização do uso da energia. Essas modificações são divididas em: modificações em aplicações ao nível de usuário e modificações ao nível de núcleo, na camada de transporte da rede, para assim conseguir uma maior economia de energia [3]. Dentro dessa categoria pode ser incluída a classificação de [1], envio energeticamente eficiente de pacotes IP.

\section{Reengenharia}

A abordagem da reengenharia consiste na pesquisa de tecnologias energeticamente eficientes aplicadas na estrutura interna do equipamento de rede, ou a substituição de elementos da rede por elementos mais eficientes. São consideradas duas categorias de reengenharia: novas tecnologias verdes de silício e reengenharia de redução de complexidade. A primeira consiste em novas tecnologias de silício energeticamente eficientes, como tecnologias de processamento, de armazenamento e de enlaces. E a reengenharia de redução de complexidade é focada na arquitetura de dispositivos de rede, contemplando soluções como novos desenhos de equipamentos de rede e redução de funcionalidades dos equipamentos atuais [2]. 
É importante ter em consideração que as abordagens anteriormente descritas não são excludentes, e que muitas das contribuições propostas envolvem mais de um tipo de solução. A seguir as contribuições serão divididas de acordo com o cenário de rede a que pertencem, em concordância com a classificação de abordagem anteriormente descrita.

\subsubsection{Contribuições por cenário de Rede}

Na seção anterior foi realizada uma correspondência e compilação entre as classificações das abordagens consideradas por Zhang et al. [1], Bolla et al. [2] e Bianzino et al. [3]. Os autores apresentaram ótimos resumos das contribuições mais notáveis em economia de energia em redes feitas até 2010. A seguir serão descritas algumas dessas contribuições e algumas pesquisas recentemente publicadas.

Redes de acesso cabeadas

A maioria das contribuições foi feita neste cenário, já que o setor de redes de acesso com fio é um dos que atualmente apresenta o maior gasto de energia [9].

\section{Taxa adaptativa de enlace}

Modo suspenso: dada a pouca eficiência em economia de energia encontrada por [35] nas unidades de rede ópticas Optical Network Unit (ONU) em modelos de tráfego real em Passive Optical Network (PON) (redes ópticas passivas), os autores propuseram dois modelos de arquiteturas ONU com eficiente recuperação de relógio quando acordam do modo suspenso. Em [36] foi proposto um componente físico que controla o estado suspenso ou ligado, baseando-se na detecção de tráfego ao nível de usuário em pontes de enlace residenciais.

Comutação de taxa: foi proposto um esquema de roteamento e alocação de taxa de serviço baseada em Q-learning (técnica de reforço de aprendizagem) para redes tolerantes ao atraso, conseguindo melhorar a eficiência de energia [37].

\section{Proxying na interface}

Khan et al. [38] propuseram uma técnica de proxying para redes LAN com o objetivo de reduzir o consumo de energia na rede. Foram considerados três tipos de proxying: auto-proxying através das NICs, proxying pelo roteador, ou switch e proxying híbrido, onde o proxy está localizado num outro host da rede.

\section{Software e aplicações de uso de energia eficiente}

Ao nível de usuário: dado o consumo de energia de modems em redes de acesso de banda larga Digital Susbcriber Line (DSL), os autores de [39] propõem um fra- 
mework com políticas para o modo suspenso considerando um compromisso entre a energia consumida e o desempenho da rede.

\section{Reengenharia}

Em [40] são feitas comparações entre tecnologia e arquiteturas DSL, Very-high-bitrate Digital Susbcriber Line (VDSL) e Fiber To The Home (FTTH) baseando em um modelo real, concluindo que FTTH tem vantagem sobre DSL. Essa vantagem consiste em que os enlaces de fibra oferecem maior economia de energia que as linhas de cobre. Outra das soluções sugeridas é o planejamento da trajetória em FTTH, para determinar que trechos das conexões das redes de acesso devem conectar de maneira direta os nós de acesso com os usuários. A proposta consiste em usar o Cable Trench Problem (CTP), quer dizer a combinação do caminho mais curto com a árvore de expansão mínima em redes FTTH. Economia de $7 \%$ a $20 \%$ da energia foi alcançada [41].

Equipamento de rede

Os equipamentos considerados dentro dessa categoria são elementos físicos necessários para o tráfego de dados em diversos tipos de redes. As contribuições encontradas contemplam equipamentos como roteadores, switches e amplificadores. Tuker, [33, 42], com o objetivo de encontrar a minima energia requerida pelas redes ópticas, fez uma análise para encontrar o limite inferior no consumo de energia em amplificadores e switches nesas redes.

\section{Reengenharia}

Para contribuir com a conservação de energia em equipamentos de rede como roteadores e switches foi proposto um esquema de escalamento de múltipla frequência, assim os componentes dos dispositivos de rede são escalados de maneira dinâmica de acordo ao tráfego que suportam [43]. Foi proposto também um esquema para a tomada de decisão de estado (suspenso ou ligado) em roteadores Optical Burst Switching (OBS) (comutação de rajadas ópticas) de redes núcleo em [44].

Redes sem fio e redes celulares

Diversas contribuições foram desenvolvidas nesse cenário. Recentemente Hasan et al. [45] proporcionaram uma revisão dos principais métodos para melhorar a eficiência de energia em redes de celulares, e Fehske et al. [46] apresentaram uma análise do consumo total de energia em redes móveis de acesso. 


\section{Taxa adaptativa de enlace}

Modo suspenso: atualmente a maior parte do consumo de energia nas redes celulares se encontra nas Base Transceiver Station (BTS). O modo suspenso é uma das estratégias para economizar energia nas BTS, e em [47] propõe-se o uso desse modo em redes celulares Long Term Evolution (LTE).

Comutação de taxa: Ismail et al. [48] propuseram suspender ou ligar os recursos das redes sem fio de acordo com as flutuações de carga de tráfego. No caso de redes celulares um esquema parecido foi proposto em [49], onde a potência dos transceptores das BTS é ajustada dinamicamente de acordo com o tráfego respeitando taxas mínimas para todos os usuários.

\section{Infraestruturas de uso eficiente de energia}

Arquitetura: Guo et al. [50] propõem um processo de melhoria espectral que combina arquitetura, técnicas de transmissão, manejo de recursos e hardware para a redução de consumo de energia em redes celulares.

\section{Reengenharia}

Para alcançar objetivos verdes foram propostos amplificadores de múltiplo estágio reconfiguráveis com modulação de carga para redes WiMAX [51], além de políticas de compartilhamento espaço-temporal de celas em redes celulares [52].

Redes de acesso mistas: fibra e sem fio

As redes de acesso mistas são redes híbridas que combinam duas classes de infraestruturas, fibra e sem fio. Parker et al. [53] analisaram as possibilidades de otimização subjacentes à associação de diversos tipos de redes sem fio e infraestruturas de redes de acesso ópticas.

\section{Taxa adaptativa de enlace}

Modo suspenso: Ali et al. [54] propõem uma heurística de suspensão de elementos da rede e conseguem além da economia de energia uma melhoria no desempenho em redes Fiber-Wireless (FiWi)

Comutação de taxa: o objetivo da proposta em [55] é garantir o compromisso entre economia de energia e qualidade de serviço, especificamente para o transporte de vídeo sobre redes FiWi. A ideia básica é o re-roteamento de pacotes que passem por enlaces com tráfego leve, para colocar eles em modo de suspenso. Esse roteamento leva em conta o número de saltos do novo caminho. 


\section{Infraestruturas de uso eficiente de energia}

Roteamento: Reaz et al.[56] propõem roteamento por balanceamento de carga de tráfego através da suspensão de dispositivos ativos da rede como ONUs. A proposta está focada em serviços na nuvem sobre redes de acesso de banda larga mistas (ópticas e sem fio), conseguindo economizar quase $50 \%$ da energia.

Aplicações de redes

As contribuições em economia de energia em aplicações de redes, como data centers, são as mais estudadas, mas sempre surgem novas oportunidades e desafios. Em [57] é apresentado um resumo de técnicas chaves para fazer frente a esses novos desafios como redes cognitivas, codificação de redes e redes elétricas inteligentes. Também foram feitas avaliações sobre economia de energia em máquinas virtuais e computação em nuvem em [58] e medições do consumo de energia por serviços web em [59].

\section{Taxa adaptativa de enlace}

Comutação de taxa: em [60] é realizada uma análise do consumo de energia em aplicações Peer to Peer (P2P), concluindo que se alguns dos pares gasta um pouco mais de energia (warm-hearted ou smart peers), a potência consumida pelo outro par diminuirá num certo tempo. Deste modo, o sistema completo e beneficiado em termos de economia total de energia.

\section{Infraestruturas de uso eficiente de energia}

Arquitetura: algumas das pesquisas nessa área incluem alocação dinâmica de recursos fazendo uso de máquinas virtuais para computação em nuvem [61]. Também incluem o impacto sobre servidores físicos, em termos de energia, quando se tem virtualização de servidores em data centers [62].

Redes ópticas de transporte e redes núcleo

As redes de transporte e redes núcleo (backbone) consomem em torno de $30 \%$ da energia gasta pelas TICs[9]. Isso junto a alta porcentagem de energia desperdiçada, 50\% [13], são umas das motivações dos pesquisadores para o estudo dessa área. Há diversas contribuições em redes de transporte e núcleo ao longo dos últimos anos, abordaremos os trabalhos mais relevantes.

Tzanakaki et al. [63] fizeram uma análise da energia consumida pela rede óptica PanEuropeia considerando dados reais e projeções de crescimento de tráfego. O cálculo foi feito para três períodos: atual, e para daqui a cinco e dez anos, ressaltando que é necessária a aplicação de políticas de economia de energia. O estudo ressalta as porcentagens 
de economia de energia quando são usadas tecnologias ópticas transparentes. Farias [4] estuda o consumo de energia em redes de transporte baseando-se no crescimento do tráfego IP, e faz uma análise dos serviços que constituem esse tráfego.

\section{Taxa adaptativa de enlace}

Modo suspenso: algumas das contribuições nessa classe de abordagens são o agendamento dinâmico do modo suspenso em roteadores [64] e a otimização do tempo de reconfiguração na suspensão de enlaces baseado numa heurística gulosa [65-67]. Em [68] é proposto minimizar o consumo de energia pondo nós e placa de rede em modo suspenso de acordo as variações do tráfego ao longo do tempo. [69] propõe pôr enlaces de rede backbone em modo suspenso de acordo à variação do tráfego, mas limitando o número de variações de estado dos elementos da rede (ativo ou suspenso).

Comutação de taxa: Tan et al. [70], baseando-se na carga de tráfego no enlace, muda alguns recursos para o modo suspenso quando não se tem alto tráfego. É considerada também a proteção dedicada de caminho para garantir a disponibilidade da rede.

\section{Infraestruturas de uso eficiente de energia}

Diversas contribuições foram feitas baseadas em alocação estática ou dinâmica de comprimentos de onda, determinação e agendamento das demandas de tráfego por enlace, e suspensão dos enlaces com programação linear inteira ou algoritmos heurísticos. Para garantir a disponibilidade da rede, Jirattigalachote et al. [71] analisaram o compromisso entre a economia de energia e a probabilidade de bloqueio, e propuseram algoritmos baseados no modo de suspensão como provisão dinâmica de caminhos de proteção dedicados. [72] propõem uma solução de uso eficiente de energia em redes com proteção compartilhada de caminhos usando modo suspenso. Foram propostas também soluções orientadas à topologia da rede como em [73], onde a solução, baseada em teoria de grafos, poda os enlaces menos usados. Essas soluções serão explicadas mais detalhadamente na seção seguinte.

\subsection{Modo Suspenso}

Não só a quantidade de usuários e dispositivos conectados à rede de dados são maiores a cada dia, mas também vem aumentando a quantidade de dados consumida por cada um desses usuários. Um exemplo é o fluxo de vídeos em alta resolução. Em consequência, a demanda por largura de banda aumenta a cada dia. O acelerado crescimento do fluxo de dados e a exigência pelos usuários por melhor qualidade de serviço implicam um desafio. 
Mas, há também um novo desafio pela redução do consumo de energia [71].

Como foi mencionado, as redes de transporte são projetadas para satisfazer a demanda de pico de tráfego para manter a qualidade e confiabilidade de serviço. Como resultado a rede é subutilizada quando o tráfego de dados é baixo. Do mesmo modo, como parte da Quality of Service (QoS), as redes devem garantir sua disponibilidade e adiantar eventos que poderiam descontinuar o serviço, como possíveis quedas de enlaces. É por isso que são necessários enlaces de redundância, que são utilizados só se ocorre algum evento não desejado na rede principal [3]. Essas características de planejamento são chamadas de sobredimensionamento da rede [73].

Quando o tráfego de dados é baixo, enlaces e componentes da rede que não estão sendo usados estão consumindo energia de maneira desnecessária. Uma maneira de diminuir o gasto de energia na rede é tomar vantagem dessa subutilização mediante a adaptação da rede à carga real de tráfego [67]. Na Seção \$3.2.1 essas adaptações foram classificadas como infraestruturas de uso eficiente de energia. No cenário de redes ópticas essa abordagem faz uso do roteamento de tráfego conjuntamente com o modo suspenso (sleep mode) para economizar energia.

Os dispositivos ópticos para redes pequenas podem trabalhar em três modos: ativo, desligado e suspenso. Transladando essa particularidade a dispositivos ópticos em redes núcleo, é possível abordar o problema de economia de energia em redes WDM mediante a aplicação do modo suspenso. Este modo é um estado perto do modo desligado em termos de consumo de energia, mas a diferença está em que o dispositivo pode passar para o modo ativo de maneira rápida (microssegundos) no momento que seja preciso [67]. Essa transição rápida é importante para garantir a disponibilidade dos dispositivos da rede em caso de precisar de sua utilização. Se um enlace redundante é posto em modo suspenso e a transmissão no enlace principal sofre alguma interrupção, o enlace redundante deve passar ao modo ativo quase imediatamente para não sofrer perdas de dados e garantir a comunicação.

Uma das maneiras mais efetivas de adaptação dos enlaces é por meio do cálculo de rotas e análise de tráfego na rede para encontrar as rotas menos utilizadas. Isto com o intuito de colocar os enlaces menos usados em modo suspenso. As soluções comprendidas nesta abordagem podem ser classificadas em soluções orientadas ao tráfego ou à topologia [73].

As soluções orientadas ao tráfego estão baseadas num controle conjunto da topologia da rede e do roteamento de tráfego. Geralmente essas soluções são resolvidas com programação linear inteira ou mediante heurísticas, que formulam problemas de engenharia de tráfego.

As soluções orientadas à topologia da rede não têm conhecimento do tráfego, e não consideram a distribuição do tráfego através dos caminhos ópticos. Também não garan- 


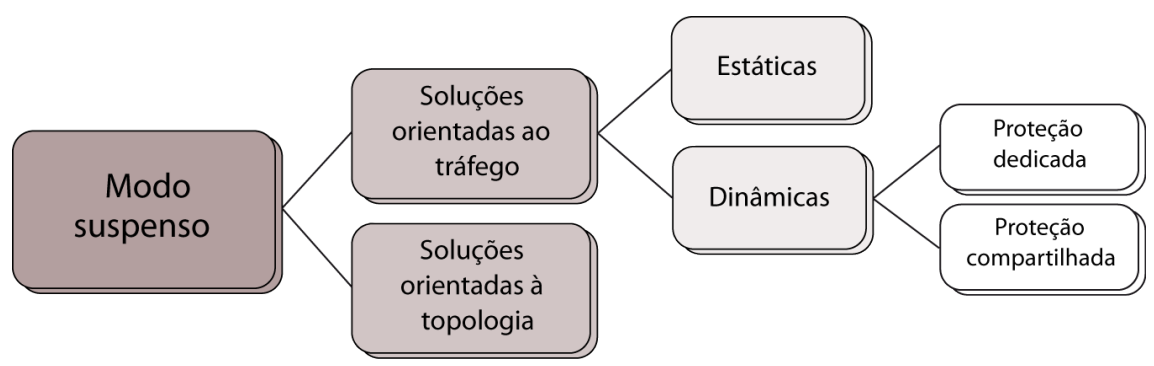

Figura 3.2.: Classificação das soluções baseadas em modo suspenso para rede WDM.

tem requerimentos de tráfego específico como poderiam fazer as soluções dinâmicas no caso anterior. As soluções orientadas à topologia são baseadas em propriedades de grafos, e são menos complexas que as baseadas em tráfego.

Na Figura 3.2 é mostrada uma classificação das soluções baseadas em modo suspenso para rede WDM. A seguir serão detalhadas cada uma das classificações e apresentados os trabalhos mais representativos.

\subsubsection{Modo suspenso: soluções orientadas ao tráfego}

Através de engenharia de tráfego essas soluções determinam quais são os enlaces e componentes mais adequados a serem postos em modo suspenso para conseguir maximizar a economia de energia. Baseando-se na análise de tráfego essas soluções podemos determinar, por exemplo, os enlaces menos utilizados nas redes ópticas. O objetivo é minimizar o consumo de energia através da maximização dos enlaces e dispositivos a serem postos em modo suspenso. As soluções encontradas na literatura aproveitam o fato da redundância e sobredimensionamento nas redes para conseguir seu objetivo.

As soluções orientadas ao tráfego podem ser divididas em duas categorias: soluções de análise de tráfego offline ou estáticas, e soluções de análises de tráfego online ou dinâmicas [3].

No primeiro caso, a análise de tráfego é baseada em dados históricos. Este tipo de soluções apontam ao planejamento das redes. São chamadas também estratégias estáticas de provisionamento de tráfego [66]. As soluções online analisam o tráfego em tempo real, e com essa informação é planejada a distribuição do tráfego de maneira dinâmica.

O problema de planejamento estático é um problema NP completo que pode ser resolvido com programação linear inteira Integer Linear Programing (ILP) ou mista [73]. O ILP pode encontrar uma solução ótima, porém não é um método escalável dada sua complexidade computacional. É por isso que são propostas heurísticas que se aproximam à solução ótima e a salvar os problemas de escalabilidade. Quer dizer que encontram possíveis soluções em menor tempo e custo computacional.

Muhammad et al. [67] propõem uma planificação estática energeticamente eficiente 
para redes WDM fazendo uso do modo suspenso. Para seu estudo considera uma rede com proteção dedicada de caminho 1:1. O que significa que cada caminho óptico principal (working ligthpath) tem um caminho óptico de proteção (Ver Seção 2.1). Esses caminhos não compartilham o mesmo enlace físico que seu respectivo caminho principal (chamados também enlaces disjuntos). Os autores modelam a rede usando teoria de grafos, e propõem resolver o problema com ILP, aproveitando a característica de redundância da rede. A função objetivo é minimizar a energia total consumida pela rede. Essa energia é dada pela somatória da energia consumida pelos enlaces e dispositivos em modo ativo da rede.

Considerando que os dispositivos que conformam a rede suportem os estados descritos anteriormente: ativo, desligado e suspenso, quanto menos dispositivos estejam em modo ativo, menor será a quantidade de energia consumida. É por isso que os enlaces e nós que servem só como caminhos de proteção devem ser postos em modo suspenso. Portanto para minimizar o consumo de energia, deve-se maximizar o número de enlaces e nós que sirvam só como caminho óptico de proteção. Repare que as soluções offline, orientadas ao tráfego, tem conhecimento prévio do tráfego que passará pela rede.

Em suma os autores de [67] propõem que para minimizar o consumo de energia é necessário rotear os caminhos ópticos de maneira que o número de nós e enlaces que suportem exclusivamente caminhos ópticos de proteção seja maximizado, com o intuito de serem colocados em modo suspenso. A proposta é comparada com soluções que não usam o modo suspenso como estratégia de economia de energia.

Posteriormente Monti et al. [66] sugerem uma heurística baseada nas mesmas características da solução anterior. A finalidade é melhorar a escalabilidade da proposta anterior sem comprometer em alto grau a quantidade de energia economizada. O algoritmo também modela a rede com teoria de grafos. Assim $G=(N, E)$ representa o grafo da rede, e os pesos das arestas são as distâncias geográficas entre os enlaces.

Na proposta de [66] são calculados dois caminhos ópticos mais curtos para cada uma das demandas de tráfego dadas. Um deles será o caminho principal e o outro o de proteção (lembrando que não devem compartilhar a mesma rota física). As demandas são ordenadas de forma crescente, de acordo com o peso dos caminhos ópticos encontrados para cada uma delas. Em seguida é gerado um grafo auxiliar $G_{p}=(N, E)$ onde os pesos das arestas são inicialmente nulos. Após, são calculados novamente os caminhos ópticos, principais e de proteção, segundo a lista ordenada de demandas, mas desta vez com relação ao grafo $G_{p}$. Em cada cálculo serão atribuídos pesos para os caminhos ópticos encontrados. O peso das arestas será maior para os caminhos de proteção. O objetivo é diminuir a eleição, como rotas principais, de rotas que já sejam caminhos ópticos de proteção, para maximizar a quantidade de enlaces que trabalham só como rotas de proteção e colocar elas em modo suspenso. 

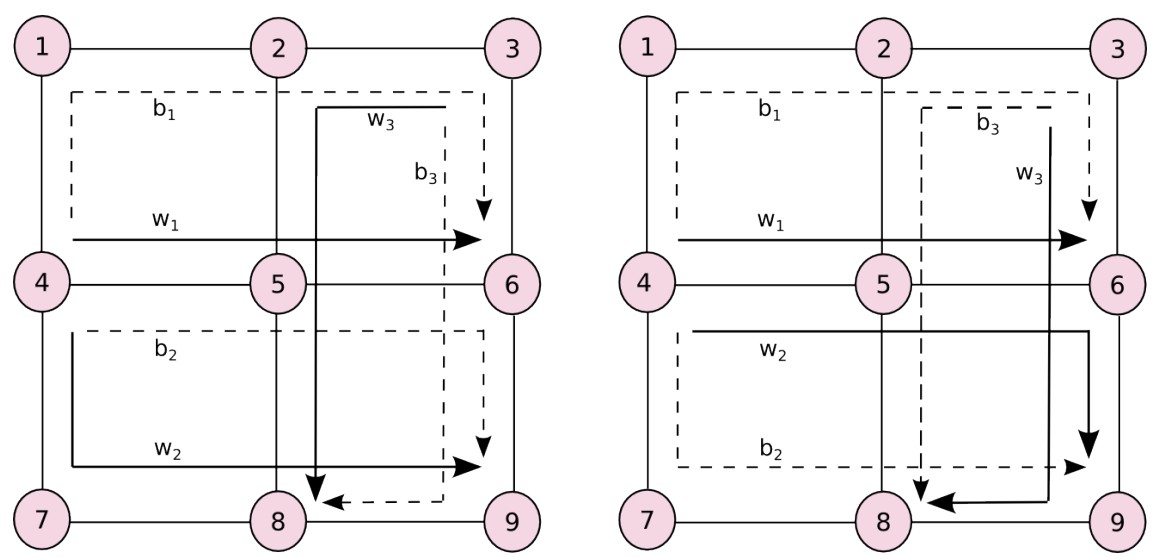

Figura 3.3.: Comparação entre roteamento sem economia de energia e roteamento com economia de energia [71].

Na Figura 3.3 é exemplificada e comparada a solução orientada ao tráfego usando modo suspenso com o encaminhamento clássico, num cenário de redes com proteção dedicada de caminhos ópticos [71]. Tem-se três demandas de tráfego, $d_{1}(4,6), d_{2}(4,9)$ e $d_{3}(3,8)$, a serem transmitidas pela rede representada pelo grafo na figura. Considerando que as arestas do grafo têm pesos iguais, são calculadas as rotas para os caminhos ópticos principais $w_{i}$ e de proteção $b_{i}$ (os caminhos devem ser fisicamente separados). No caso do encaminhamento clássico, que não considera a economia de energia, esses caminhos serão os mais curtos. Desse modo são atribuídos os caminhos $w_{1}$ (4-5-6), $b_{1}$ (4-1-2-3-6) para $d_{1}$; $w_{2}$ (4-7-8-9), $b_{2}(4-5-6-9)$ para $d_{2}$; é $w_{3}(3-2-5-8), b_{3}(3-6-9-8)$ para $d_{3}$.

No caso do encaminhamento com economia de energia, os caminhos ópticos podem ser atribuídos da seguinte maneira. Como no caso anterior, são calculados os caminhos mais curtos, $w_{1}$ e $b_{1}$, para $d_{1}$. Depois, para $d_{2}$, trata-se de utilizar a mesma rota $w_{1}$ da demanda anterior, para minimizar os enlaces e nós trabalhando como rotas principais. Em consequência, estabelecem-se $w_{2}$ (4-5-6-9) e $b_{2}$ (4-7-8-9) como as rotas para os caminhos ópticos de $d_{2}$. Igualmente são calculadas as rotas para $d_{3}$, encaminhando $w_{3}$ pelos enlaces que fazem parte das rotas já escolhidas como caminhos ópticos principais para as anteriores demandas. Resultando para $d_{3}, w_{3}(3-6-9-8)$ e $b_{3}(3-2-5-8)$ como o caminho principal e de proteção respectivamente.

Se os dispositivos da rede mostrada na Figura 3.3 não suportassem o modo suspenso, teria-se os 9 nós e 12 enlaces que compõem a rede, em modo ativo (consumindo energia). No caso de encaminhamento clássico com suporte de modo suspenso, 1 nó e 4 enlaces estariam em modo suspenso. Finalmente no caso das soluções baseadas em economia de energia orientadas ao tráfego com modo suspenso, 3 nós e 7 enlaces poderiam ser postos em modo suspenso. Portanto, menor energia consumida é atingida maximizando a quantidade de nós e enlaces em modo suspenso [71]. 
No provisionamento ou planejamento das redes WDM o roteamento das demandas de tráfego pode ser realizado de maneira dinâmica (roteamento online). As demandas de tráfego vão mudando ao longo do tempo, segundo a necessidade de transmissão de dados. Por isso os caminhos ópticos que satisfaçam as demandas de tráfego deverão ser calculados em tempo real. O desafio é ir planejando a rede na medida em que o tráfego vai sendo analisado. O roteamento dinâmico, assim como o estático, deve garantir a disponibilidade da rede para preservar a qualidade de serviço. Portanto essa estratégia de planejamento também precisa considerar requerimentos de proteção no caso de falhas de conexão na rede. Dentro das estratégias que garantem a disponibilidade da rede temse a proteção dedicada de caminhos (DPP) e a proteção compartilhada (SPP). Ambos esquemas de proteção foram explicados na Seção 2.1.

Manter em modo ativo os componentes dos caminhos ópticos de redundância não é um uso eficiente da energia, ainda mais quando os caminhos de proteção não são utilizados a maioria do tempo, e consomem mais energia por ter maior comprimento que os caminhos principais [71]. Assim, pode-se diminuir eficientemente a quantidade de energia consumida pondo em modo suspenso esses caminhos de proteção. É assim que vários autores propuseram soluções orientadas ao tráfego para cenários dinâmicos, usando o modo suspenso como método de economia de energia [18, 71, 74]. Encontramos na literatura soluções para dois cenários de redes WDM: com proteção de caminhos dedicada e com proteção compartilhada.

O cenário de rede considerado por Jirattigalachote et al. [71], é uma rede WDM com proteção caminho 1:1, DPP. Depois de testar possíveis soluções, os autores concluíram que a solução a ser proposta deveria ser capaz de diferenciar entre os enlaces usados por caminhos ópticos principais e os usados por caminhos de proteção. Também, constataram que, tendo como único objetivo diminuir a energia consumida, foram descuidadas outras métricas da rede, e a probabilidade de bloqueio aumentou.

Os autores propuseram três algoritmos que têm como objetivo a minimização da energia consumida pela rede [71]. Um deles é chamado Energy Aware-Dedicated Path Protecction (EA-DPP). Esse algoritmo encaminha as demandas de tráfego tendo em conta a economia de energia, em cenários de rede que não suportam o modo suspenso. Esse algoritmo foi proposto para comparar a eficiência dele com métodos que suportam o modo suspenso.

O segundo algoritmo é desenvolvido sobre o mesmo cenário dinâmico de rede, mas com dispositivos que suportam o modo suspenso. Energy Aware-Dedicated Path Protecction with Differentation (EA-DPP-Dif) está focado em minimizar o consumo de energia mediante a diferenciação entre caminhos ópticos principais e de proteção, para evitar ter enlaces que sejam usados como caminhos principais e como caminhos de proteção ao mesmo tempo, para demandas diferentes. O algoritmo atingiu resultados satisfatórios 
com relação à economia de energia, mas aumentou a probabilidade de bloqueio.

Para minimizar a probabilidade de bloqueio foi realizada uma modificação no algoritmo anterior, e os autores de [71] propuseram o algoritmo Energy Aware-Dedicated Path Protecction with Mixing (EA-DPP-MixS). Esse algoritmo permite a mistura de caminhos ópticos de proteção com os caminhos ópticos principais. EA-DPP-MixS permite que alguns caminhos de proteção sejam roteados por enlaces que suportam caminhos principais. Isto foi conseguido relaxando a restrição de diferenciação de caminhos. Esse algoritmo com restrições relaxadas diminuiu a probabilidade de bloqueio, mas a porcentagem de energia economizada também diminuiu. Os experimentos permitiram concluir que existe um compromisso entre economia de energia e probabilidade de bloqueio. Portanto é necessário encontrar um balanço para garantir da melhor maneira a qualidade de serviço das redes verdes.

O outro cenário dentro das soluções dinâmicas orientadas ao tráfego para economia de energia, como já foi mencionado, são as redes wavelength division multiplexing (WDM) com proteção compartilhada de caminhos shared path proteccion (SPP). Bao et al. [18] propõem uma solução baseada em modo suspenso para esse cenário. O algoritmo Power Aware Shared Path Protecction (PASPP) procura que os caminhos ópticos principais e os de proteção passem por fibras diferentes. Mas essa restrição não é mandatória, se a restrição não pudesse ser cumprida tais caminhos ópticos poderiam convergir numa mesma fibra, e assim diminuir o bloqueio. Para o encaminhamento, o algoritmo faz uso de custos por enlace e custos por fibra, e de atribuição e liberação de recursos. A proposta procura melhorar a complexidade e custo da fase inicial de pré-cálculo dos caminhos ópticos principais e de proteção para todas as possíveis fontes e destinos, que são sugeridas em [71]. Os autores de [18] consideram este precálculo como uma desvantagem, visto que se ocorressem mudanças na topologia da rede, essa etapa afetaria a flexibilidade e escalabilidade da solução.

\subsubsection{Modo suspenso: soluções orientadas à topologia}

A primeira solução através de topologia de rede foi proposta em [75]. A proposta faz uso do Open Shortest Path First (OSPF), baseado numa versão modificada do algoritmo Dijkstra. Cuomo et al. [73] propõem uma solução orientada à topologia baseada em propriedades algébricas de conectividade e métricas de grafos como betweenness ou centralidade de intermediação.

A razão considerada pelos autores para escolher soluções orientadas à topologia, ao invés das orientadas ao tráfego, é sua menor complexidade. Assim, estas soluções podem ser integradas de maneira mais simples no protocolo de roteamento IP. As soluções que implicam conhecimento de tráfego precisam de sistemas de monitoramento, controle e 
gerenciamento para a aplicação de suas soluções. Além disso, esta solução de topologia pode ser aplicada sem necessidade de conhecimento de tráfego.

Baseando-se no fato de ter enlaces e componentes de rede subutilizados, devido ao sobredimensionamento da rede, [73] analisa a possibilidade de modificação temporal da topologia da rede. Os autores propõem uma heurística chamada Energy Saving based on TOPology (ESTOP) que identifica os enlaces pouco usados através de propriedades de grafos. A finalidade é excluir esses enlaces e colocá-los em modo suspenso. A proposta é uma combinação de propriedades de topologia de rede e cálculo de caminhos de roteamento. O algoritmo foi testado com cargas de tráfego real e comparado com soluções que dependem do tráfego. A seguir serão explicadas as propriedades levadas em conta para a solução.

Como foi visto na Seção 2.2, as redes podem ser descritas por teoria de grafos, onde os nós são representados como vértices $N$ e os enlaces como arestas $E$, daí o grafo da rede é $G=(N, E)$. ESTOP faz uso de duas propriedades de teoria de grafos, a centralidade de intermediação (betweenness), $B_{l}$, e a conectividade. A primeira é o número de caminhos de todos os nós para todos os nós, que passa por uma aresta. O algoritmo utiliza uma versão simplificada da centralidade de intermediação. Assim $B_{l}$ só leva em conta os caminhos mais curtos, de todos os nós para todos os nós, que passam pelo enlace $l$. A origem do caminho é representada por $s$ e o destino por $d$. Desse modo a centralidade de intermediação usada no algoritmo é definida como:

$$
B_{l}=\sum_{(s, d) \in s \neq d} S P_{l}(s, d)
$$

onde $S P_{l}(s, d)$, são os caminhos mais curtos entre $s$ e $d$. O valor mais alto para $B_{l}$ será para o enlace, $l$, pelo que passe a maior quantidade de caminhos mais curtos.

A outra métrica empregada por ESTOP é a conectividade, que usa a matriz Laplaciana do grafo, $L(G)$ (Ver Seção 2.2.) O conjunto de autovalores $\lambda(G)$ com que $L(G)$ pode ser definida é ordenado de forma crescente. Devido à bidirecionalidade do grafo, $L(G)$ é simétrica, e o primeiro autovalor será $\lambda_{1}(G)=0$. O seguinte autovalor $\lambda_{2}(G)$ é chamado conectividade algébrica ou fielder eigenvalue. Esse segundo autovalor representa o mínimo número de enlaces que desconectam o grafo ao serem removidos.

Essas características de grafos servem como indicadores para o algoritmo. A centralidade de intermediação $B_{l}$ é usada para encontrar os enlaces menos utilizados, ou seja, os possíveis candidatos a serem postos em modo suspenso. O segundo autovalor $\lambda_{2}$ é usado como uma medida de controle, que mostra como a poda de enlaces afeta a conectividade da rede. 


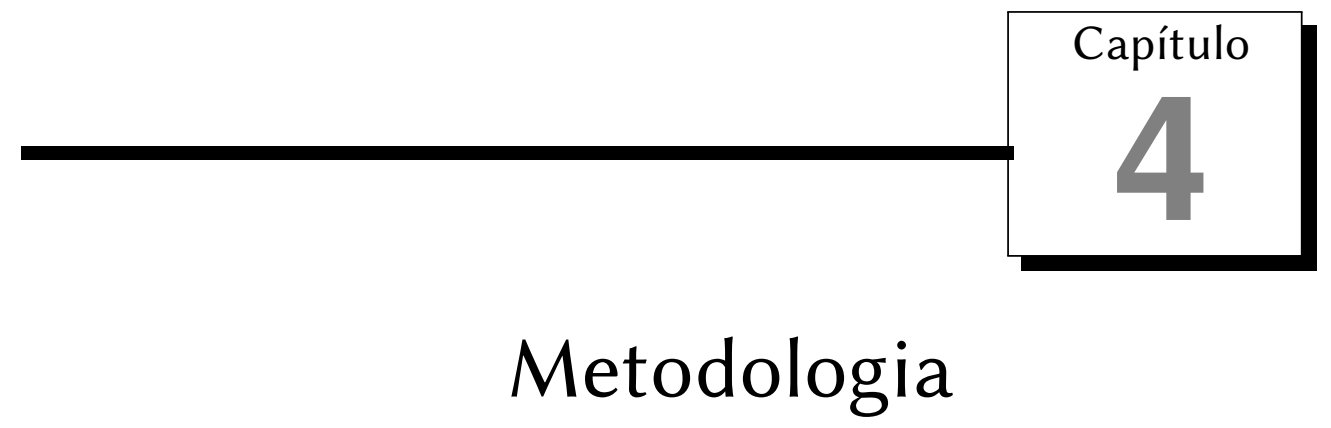

\subsection{Objetivo e Metas}

O objetivo do trabalho é desenvolver um algoritmo de roteamento energeticamente eficiente e com bom desempenho em relação às demandas de tráfego atendidas, isso para redes WDM com proteção dedicada de caminhos. O intuito é melhorar a qualidade de serviço das estratégias encontradas na literatura. $\mathrm{O}$ algoritmo está baseado em diferenciação de caminhos, e visa pôr em modo suspenso elementos da rede que somente transportem caminhos de proteção.

A seguir são descritas as metas para atingir o objetivo deste projeto.

1. Relacionar as classificações de soluções em economia de energia para redes de telecomunicações relatadas na literatura e integrá-las numa única classificação baseada no tipo de abordagem e no cenário de rede.

2. Realizar um estudo das soluções baseadas em modo suspenso para redes WDM e determinar a solução a ser implementada.

3. Implementar os algoritmos das estratégias de roteamento de tráfego da solução escolhida.

4. Comparar e avaliar as estratégias implementadas, de acordo com métricas de desempenho, como porcentagem de energia economizada e probabilidade de bloqueio. 
5. Desenvolver nossa proposta de roteamento de tráfego de acordo com os resultados da análise anterior.

6. Avaliar a proposta de roteamento intensivo usando cada uma das estratégias estudadas.

\subsection{Metodologia}

Considerando como nosso objetivo a economia de energia em redes ópticas WDM, é preciso determinar a quantidade de energia que está sendo economizada a fim de comprovar a eficiência das propostas. Nosso primeiro passo é avaliar o consumo de energia na rede. Dada uma rede WDM, devemos determinar quais são os componentes da rede que consomem energia, e a quantidade de energia que consomem. Esses cálculos de energia consumida serão chamados de modelo de consumo de energia.

Além disso, é necessário determinar as redes de teste que serão usadas para a avaliação das abordagens de modo suspenso. Também é preciso determinar os parâmetros que serão levados em conta para a geração de tráfego, assim como as métricas para fazer as comparações entre a eficiência das abordagens a serem avaliadas. A ferramenta de análise será simulação computacional, sendo usado o sistema Matlab para tais fins.

\subsubsection{Modelo de consumo de energia em redes WDM}

O método usado para o cálculo do modelo de consumo de energia na rede está baseado nos modelos propostos por Tucker, [33], Jirattigalachote et al. [71] e Bao et al. [18]. A potência consumida pela rede será medida em watts e, para quantificar a energia consumida, se usará a energia por bit, que pode ser expressa em unidades de potência por taxa de bit $W / b / s$ ou $W / G b / s$.

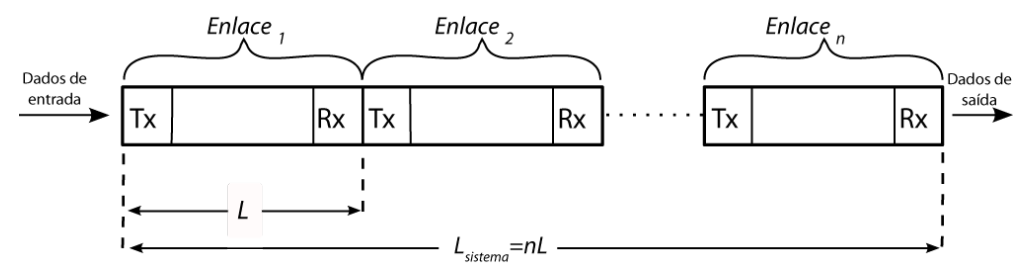

Figura 4.1.: Sistema WDM com vários enlaces [33].

Com a finalidade de avaliar o consumo de energia é necessário definir o modelo de rede WDM. A rede é formada por um conjunto de conexões ou sistemas WDM. O modelo para análise dos sistemas WDM será tomado de [33]. Na Figura 4.1 é mostrado um sistema WDM com vários enlaces. O sistema tem $n$ enlaces com comprimento $L$, com 
comprimento total $n L$. Cada enlace possui um transmissor, $T_{x}$, que regenera o sinal para cada comprimento de onda, e um receptor, $R_{x}$. Assim os sinais transmitidos pelo sistema passam pelos $n$ enlaces e são regenerados no $T_{x}$ em cada enlace.

Na Figura 4.2 é representado o esquema de um dos $n$ enlaces. O enlace é composto por um $T_{x}$ na entrada, um $R_{x}$ na saída e $m$ amplificadores que suportam $k$ comprimentos de onda. Os amplificadores considerados são $(m-1)$ amplificadores de linha e um préamplificador na entrada do receptor. Cada enlace está dividido em $m$ trechos de amplificação, com comprimento $L_{\text {trec } h o}$. Assim o comprimento total do enlace é $L=m L_{\text {trecho }}$.

A potência total consumida por um enlace, $P_{\text {enlace }}$, pode ser definida como a soma da potência do transmissor e receptor $P_{T x / R x}$ mais a potência consumida pelos amplificadores $P_{a m p}$.

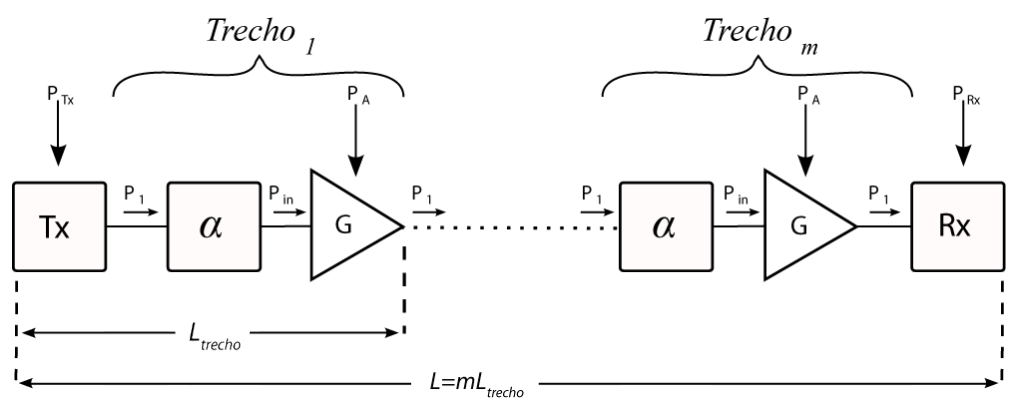

Figura 4.2.: Enlace WDM opticamente amplificado [33].

No caso de uma rede com sistemas WDM sem repetidores, ou seja, um sistema composto por um só enlace, a potência consumida pela rede pode ser resumida pela soma da potência consumida nos nós e nos enlaces. A potência dos nós é dada pela soma da potência consumida pelos transmissores $T_{x}$ e receptores $R_{x}$, e a potência dos enlaces é dada pela soma da potência consumida pelos amplificadores $P_{A}$ em cada enlace $[18,71]$.

Como a rede WDM pode ser representada pelo grafo $G=(N, E)$, então a potência total da rede pode ser expressa por:

$$
P_{t o t}=\sum_{n \in N}\left(P_{n}^{n o d e} \cdot x_{n}\right)+\sum_{e \in E}\left(P_{e}^{a m p} \cdot x_{e}\right),
$$

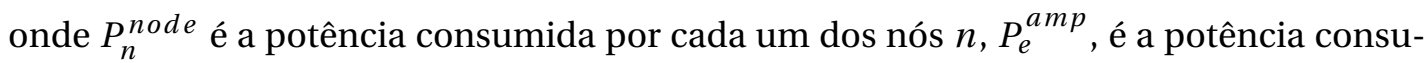
mida pelos enlaces $(e), x_{n}$ é o número de nós e $x_{e}$ o número de enlaces na rede [71].

A fim de avaliar as abordagens com modo suspenso, os nós e os enlaces suportam três estados, ativo, suspenso e desligado. Para os cálculos de potência consumida, as variáveis $x_{n}$ e $x_{e}$ podem ter dos valores 1 ou 0 . São iguais a 1 se os nós ou enlaces estão em modo ativo, e 0 quando são postos em modo suspenso ou quando estão desligados [71].

Após determinar como está constituída a potência geral consumida pela rede, preci- 
samos calcular a potência consumida pelas partes que a compõem (nós e enlaces). A potência consumida pelos nós, $P_{\text {node }}$, depende da sua arquitetura. Jirattigalachote $e t$ al. [71] consideram três componentes: a potência consumida pela matriz de comutação (switching fabric), $P_{O x c}$, a potência do trasmisor $P_{T x}$ e a potência do receptor $P_{R x}$. Bao et al. [18] consideram a arquitetura do nó composta por um sistema de controle Electronic Control System (ECS), um sistema de matriz de comutação baseada em 3D Micro Electromechanical System (MEMS), conversores ópticos de comprimento de onda Wavelength Converter (WC) e transceptores $\left(T_{x} / R_{x}\right)$. O ECS está sempre em estado ativo, e consome uma quantidade constante de potência.

Como foi descrito na Seção 2.1, dentro dos dispositivos que compõem o Optical CrossConnector (OXC) estão considerados os ECS e os MEMS. Também, o OXC pode ter incluso conversores de comprimento de onda, se o nós suportarem essa característica. Dessa maneira consideramos a potência consumida por cada um dos nós que compõem a rede como:

$$
P_{n}^{\text {node }}=P_{o x c}+P_{T_{x} / R_{x}}\left(c_{n}\right),
$$

onde $c_{n}$ é o número de caminhos principais que começam e terminam no nó $n$. No caso de proteção dedicada a potência do nó pode ser expressa como:

$$
P_{n}^{n o d e}=P_{o x c}+P_{T_{x} / R_{x}}\left(c_{n}\right)+P_{T_{x} / R_{x}}\left(d_{n}\right),
$$

onde $d_{n}$ é o número de caminhos de proteção que começam e terminam no nó $n$ [71]. A potência consumida pelos OXC pode ser expressa como:

$$
P_{o x c}=P_{e c s}+\left(P_{m e m s}+P_{w c}\right)\left(c_{n}\right) .
$$

Note-se que a potência consumida pelo sistema de controle $P_{e c s}$ é independente do número de caminhos $c_{n}$ que passam pelo nó.

A seguir é descrito o outro componente da potência total consumida pela rede, a potência dos enlaces. Essa potência depende da energia que os amplificadores consomem, $P_{e}^{a m p}$. A potência dos amplificadores num enlace pode ser expressa como o número total de amplificador $k_{a m p}$, multiplicado pela potência consumida por cada amplificador [71], assim:

$$
P_{e}^{a m p}=k_{a m p} P_{a m p} .
$$

$\mathrm{Na}$ literatura encontramos diversas maneiras de calcular o número de amplificadores necessários segundo o comprimento do enlace. O desempenho de uma rede óptica de transporte está ligada com a sensibilidade de recepção, definida pelo limite de Shannon. Fatores como a modulação, perdas na fibra, e ruído Amplified Spontaneous Emis- 
sion (ASE), determinam o mínimo número necessário de amplificadores [4, 33]. Em [18] o número de amplificadores $k_{a m p}$ para cada enlace é calculado por meio de:

$$
k_{a m p}=\left(\frac{L}{L_{\text {trecho }}}\right)+2 \text {, }
$$

onde $L$ é o comprimento do enlace, $L_{\text {trecho }}$ é o comprimento do trecho de amplificação (ver Figura 4.2). O termo aditivo 2 representa os amplificadores de pré e pós compensação de dispersão. He e Lin [74] consideram distintos valores de consumo de potência para os pré e pós amplificadores e os amplificadores de linha. Para o cálculo de potência consumida pelos amplificadores, primeiro é calculado o número de amplificadores de linha através de:

$$
k_{a m p-l i n}=\left(L / L_{\text {trecho }}\right) .
$$

Depois é adicionada a potência consumida pelo pré e o pós amplificador. Assim a potência total consumida pelos amplificadores num enlace $e$ é:

$$
P_{e}^{a m p}=\left(k_{a m p-l i n}\right) P_{a m p}+P_{p r e}+P_{p o s} .
$$

Adicionalmente será incluída a Tabela 4.1 com valores aproximados da potência consumida por alguns elementos da rede. Esses elementos serão usados como parte da análise de consumo de energia.

Tabela 4.1.: Potência consumida por dispositivos de rede WDM. Valores em watts obtidos de $[18,71,74]$.

\begin{tabular}{llr}
\hline Dispositivo de rede & Símbolo & Potência \\
\hline Transmissor e Receptor (Transponder) & $P_{T_{x} / R_{x}}$ & 14 \\
Amplificador de linha & $P_{a m p}$ & 12 \\
Pré-Amplificador & $P_{\text {pre-amp }}$ & 12 \\
Pós-Amplificador & $P_{\text {pos-amp }}$ & 12 \\
Controlador eletrônico do sitema & $P_{\text {ecs }}$ & 150 \\
3D MEMS & $P_{m e m s}$ & 1,757 \\
Conversor óptico de comprimento de onda & $P_{w c}$ & 1,757 \\
Cross-Conetor Óptico & $P_{\text {oxc }}$ & 6,4 \\
\hline
\end{tabular}

\subsubsection{Modelos de redes para os testes}

As topologias de rede a serem utilizadas na avaliação do desempenho serão a rede europeia COST239 [76], a rede estadunidense USNet [77], e a rede brasileira Ipê [78]. As primeiras foram usadas como modelos de rede em alguns trabalhos que propõem soluções 
em economia de energia utilizando o modo suspenso [18, 71]. Na revisão bibliográfica não foram encontrados trabalhos de uso eficiente de energia na rede óptica brasileira. $\mathrm{O}$ projeto busca analisar o desempenho das soluções baseadas em modo suspenso, e avaliar o impacto da energia economizada na rede brasileira.

A rede COST239 é uma topologia de rede óptica de teste que conecta algumas das principais cidades de Europa. A rede é composta de uma rede núcleo e três subredes. Para nossos testes será considerada a rede núcleo que está constituída por 11 nós e 26 enlaces de fibra [76]. Na Figura 4.3 é mostrada a rede COST239 com as distâncias de seus enlaces em $\mathrm{km}$.

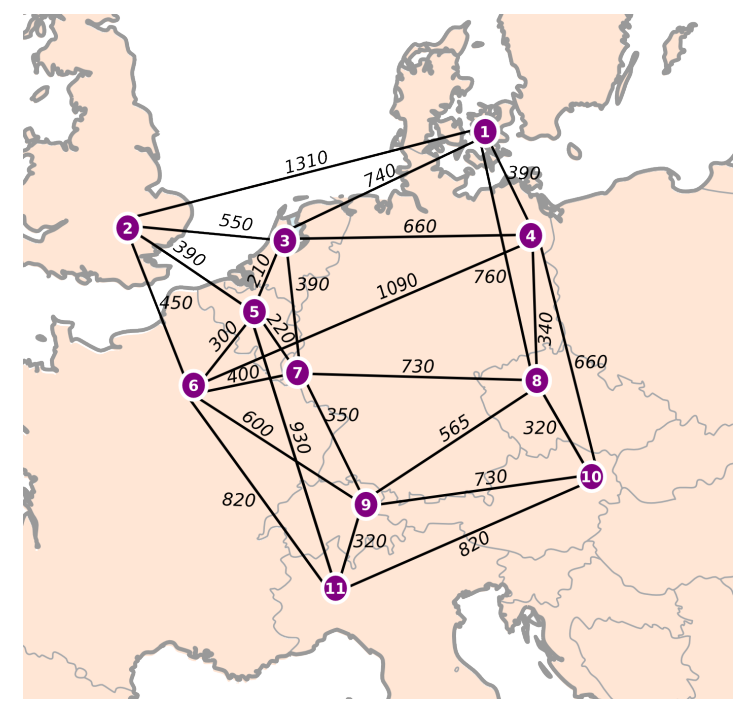

Figura 4.3.: Topología da rede europeia COST239 [76].

Também será utilizada uma mostra da rede backbone estadunidense. USnet é uma rede óptica em malha, constituída por 24 nós, localizados nas principais cidades dos EUA. A rede tem 43 enlaces de fibra que conectam esses nós [77]. Na Figura 4.4 é ilustrada a rede USnet com suas distâncias em $\mathrm{km}$.

Finalmente a rede brasileira Ipê é uma rede óptica nacional acadêmica, inaugurada pela Rede Nacional de Ensino e Pesquisa (RNP) em 2005. A infraestrutura conta com 28 Pontos de Presença, desses pontos 25 correspondem a enlaces WDM. Desses 25 pontos, 3 nós não serão considerados pois eles são parte de rotas sem possibilidade de caminho de proteção. Assim, para nossos testes, a rede brasileira Ipê contará com 22 nós e 27 enlaces. A rede é mostrada na Figura 4.5 [78] com a distância de seus enlaces em $\mathrm{km}$.

\subsubsection{Geração de tráfego}

Para analisar e comparar o desempenho dos algoritmos de roteamento energeticamente eficientes, sejam para cenários estáticos ou dinâmicos, é preciso a geração de tráfego. 


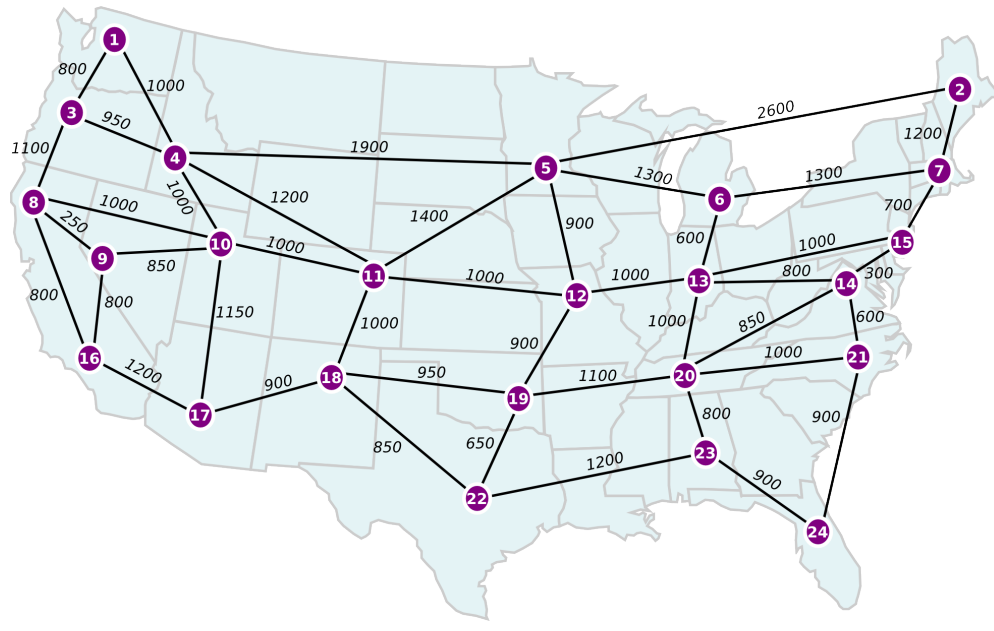

Figura 4.4.: Topología da rede estadunidense USNet [77].

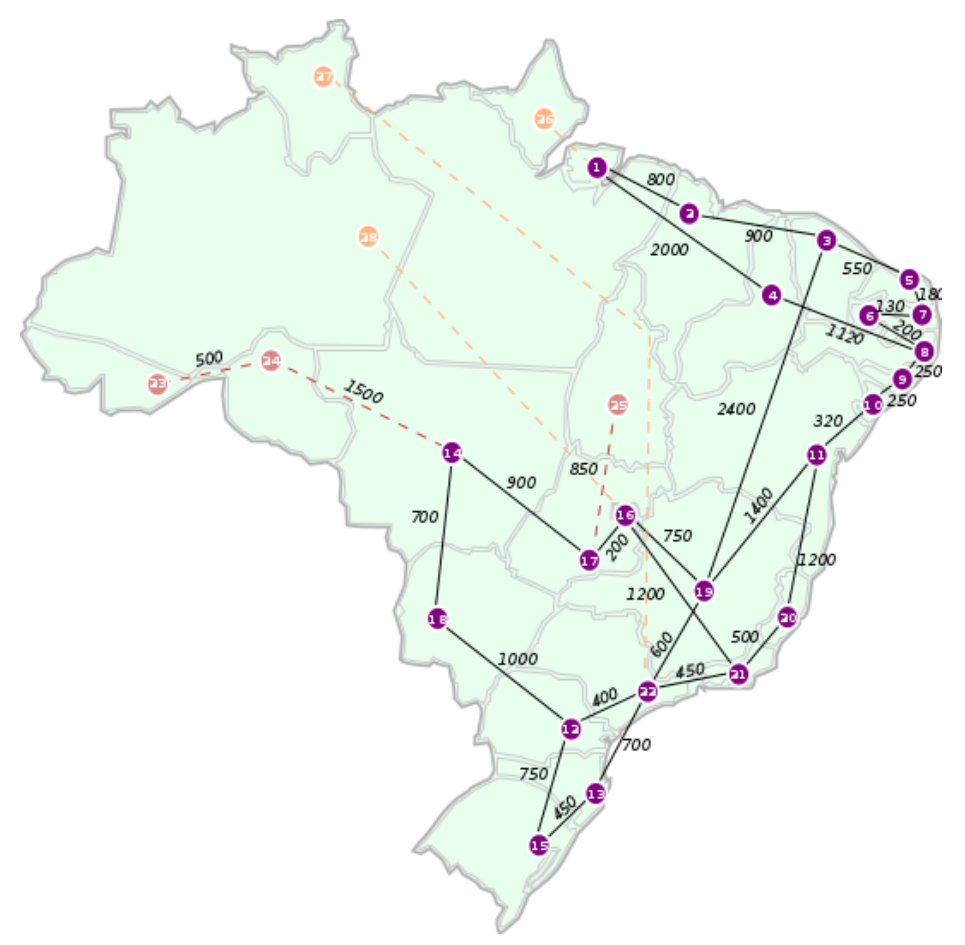

Figura 4.5.: Topología da rede brasileira Ipê [78]. 
O tráfego será gerado sob as redes descritas anteriormente. As demandas de conexão de tráfego seguem certas características que dependem de variáveis como sua origem e destino, a duração das conexões, a carga do tráfego, o número de conexões e o tempo de espera entre conexões [79].

Na nossa simulação, a probabilidade, para cada um dos nós, de ser origem ou destino de uma demanda de conexão será uniforme. Isso significa que as origens e os destinos serão escolhidos aleatoriamente, cada nó terá a mesma probabilidade de ser escolhido. As demandas a serem geradas não têm conhecimento prévio das futuras demandas de conexão. Elas seguem a distribuição de Poisson com taxa de chegada $\lambda$, e tempo médio de duração das conexões $1 / \mu$. A carga média da rede será $\lambda / \mu$ medida em Erlangs $[18,80]$.

Os testes serão feitos com taxas crescentes de carga de tráfego. Essas taxas serão obtidas acrescentando a taxa de chegada em cada interação e mantendo o tempo de conexão seguindo uma distribuição exponencial [71]. Nas avaliações de desempenho dos trabalhos revisados, a carga de tráfego varia entre 30 a 380 Erlangs [18, 71, 74]. Altos valores de carga de tráfego, acima de 800 Erlangs, são rodados para identificar o ponto em que a energia consumida por soluções de roteamento, sem economia de energia e soluções energeticamente eficientes, convergem [71].

Para os testes há redes que não suportam conversão de comprimento de onda, como em [66, 71]. Nesse caso, para cada demanda, será atribuído um comprimento de onda ao longo do caminho óptico calculado. Também serão consideradas redes com nós com capacidade de conversão de comprimento de onda como em [18, 74]. Além disso, cada conexão terá uma largura de banda correspondente à capacidade de um comprimento de onda [71]. O modelo de rede não suporta acomodamento de tráfego, traffic grooming.

Em cada simulação serão gerados 120000 conexões, as primeiras 20000 não serão consideradas, para que a rede atinja um estado estável [79].

\subsubsection{Métricas de desempenho}

Com o objetivo de comparar as abordagens, são determinadas algumas métricas, focadas tanto na energia economizada como na qualidade de serviço que garante as soluções. As métricas serão tomadas de [18, 71, 74, 79].

Para avaliar e comparar a eficiência em economia de energia das soluções, é preciso conhecer quanto é que consomem as redes sem economia de energia, isto é, as redes que não suportam o modo suspenso e também não usam roteamento verde (energeticamente eficiente). Os cálculos de potência consumida serão realizados mediante as equações apresentadas, no modelo de consumo de energia, suportando diferentes cargas de tráfego. Sob as mesmas cargas de tráfego será calculada a potência consumida para as soluções revisadas na Seção 3.3, de tal modo que será comparada a potência de consumo 
normalizada em função da carga de tráfego da rede em erlangs. Os valores de potência consumida serão normalizados em função do valor de consumo mais alto calculado.

Outra das métricas a ser usada é a utilização de enlaces. Essa métrica contabiliza quantos enlaces estão sendo usados só como caminhos ópticos principais, quantos suportam só caminhos de proteção e o número de enlaces que suportam ambos caminhos. Quanto mais enlaces suportem só caminhos de proteção, maior será a efetividade da solução, pois esses enlaces podem ser postos em modo suspenso. A análise será uma função entre a carga de tráfego e a métrica anteriormente descrita (utilização de enlace).

A probabilidade de bloqueio será a métrica usada para medir a Quality of Service (QoS) resultante da aplicação das técnicas em economia de energia. A probabilidade de bloqueio é a relação entre o número de conexões rejeitadas e o número total de conexões. Essas conexões não são atendidas devido à falta de recursos na rede, por exemplo quando não se tem comprimentos de onda disponíveis para o roteamento do tráfego. O cálculo dessa métrica é importante já que a diminuição da energia consumida mediante modo suspenso pode ocasionar maiores taxas de bloqueio. Então devemos encontrar um compromisso entre a energia economizada e a quantidade de conexões rejeitadas. A comparação entre as soluções será feita medindo a probabilidade de bloqueio através da carga da rede (Erlang). 



\title{
Capítulo
}

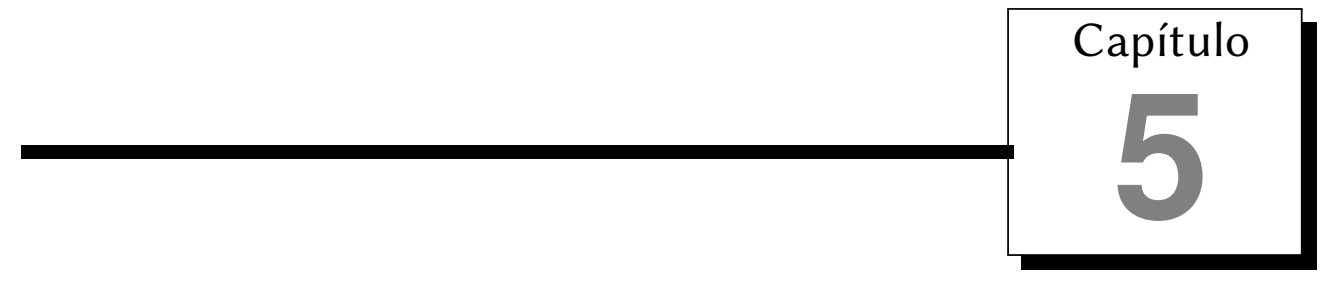

\section{Roteamento de tráfego com base em economia de energia usando modo}

\author{
suspenso
}

O modelo escolhido para economizar energia em redes WDM com proteção dedicada de caminhos é o proposto por [71]. O processo de roteamento sugerido por esse modelo está dividido em uma fase de pré-cálculo e duas etapas. A primeira etapa procura alocar o caminho principal. Depois de escolhida a rota principal a segunda etapa visa alocar o caminho de proteção. Nessas fases, os autores [71] propõem algumas estratégias para incrementar a quantidade de enlaces e nós que podem ser postos em modo suspenso. Quanto maior a quantidade de elementos em modo suspenso, maior a energia economizada.

Nesse capitulo serão apresentados os pseudocódigos dos algoritmos utilizados na implementação e o pseudocódigo da nossa proposta de roteamento intensivo. Os pseudocódigos apresentados correspondem às etapas consideradas para o roteamento de tráfego e alocação de recursos para redes com proteção dedicada de caminhos.

O primeiro algoritmo corresponde à fase de pré-cálculo de rotas candidatas para caminhos principais e de proteção. O segundo pseudocódigo é o algoritmo de roteamento de tráfego para redes com proteção dedicada de caminhos. Depois, é apresentado o algoritmo para a proposta de roteamento intensivo, que realiza uma maior busca de recursos. Também são detalhados os algoritmos de busca de recursos para alocar o caminho prin- 
cipal e de busca de recursos para o caminho de proteção. Finalmente, são apresentados os algoritmos de alocação e desalocação de demandas de tráfego.

Além disso, no capitulo são descritas as estratégias de roteamento baseado em economia de energia e explicado o objetivo de cada uma delas. Baseados nesses objetivos é esperado que a estratégia com menor consumo de energia seja a EA-DPP-Dif, assim como, é esperado que ela apresente maior probabilidade de bloqueio. Espera-se também que o roteamento intensivo proposto diminua significativamente a probabilidade de bloqueio sem sacrificar a quantidade de energia economizada.

\subsection{Fase de pré-cálculo de caminhos}

Na fase de pré-cálculo é calculado um determinado número de caminhos principais com seus correspondentes caminhos de proteção, entre todos os nós. Lembrar que os caminhos principais e os de proteção devem ser caminhos disjuntos. Esses caminhos são armazenados em listas ou bases de dados para serem utilizados nas etapas seguintes. Os caminhos são calculados utilizando o algoritmo de Yen’s [81]. A quantidade de caminhos principais a serem calculados será representada por $u$ e a quantidade de caminhos de proteção por $v$. O algoritmo de pré-cálculo de caminhos principais e de proteção é presentado em Algoritmo 1.

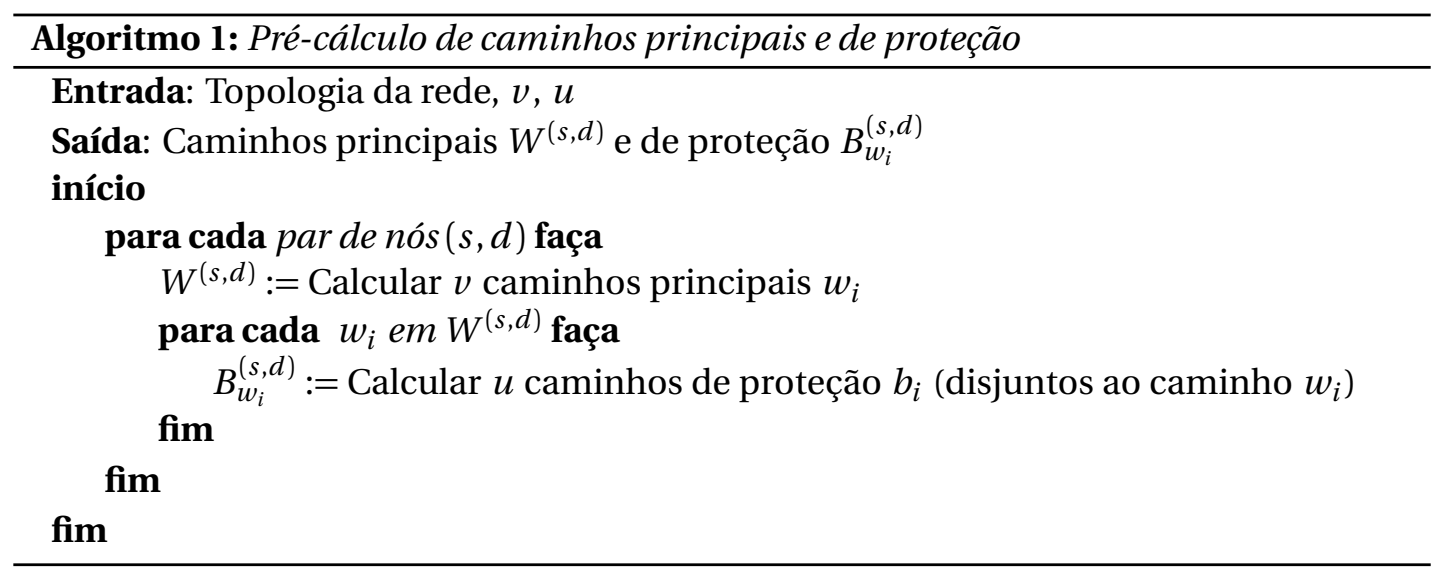

Os autores [71] propõem calcular 20 caminhos principais entre cada par de nós, e 10 caminhos de proteção para cada um dos caminhos principais. Implementamos esse algoritmo baseados no código obtido de [82], que retorna os $k$ caminhos mais curtos entre uma fonte e destino, usando o algoritmo de Yen's. Esse código [82] foi modificado para, além dos 20 caminhos principais, achar também os 10 caminhos de proteção. Seção $\$ 4.2 .4$ 


\subsection{Roteamento com proteção dedicada de caminhos}

O Algoritmo 2 mostra a sequência de instruções a ser executadas para o roteamento de demandas de tráfego com base em economia de energia. O primeiro passo é geração das demandas de tráfego $E v$, em forma de eventos $e v_{i}$. Esses eventos podem ser de alocação ou desalocação.

Se o evento é de alocação então, são procurados recursos para o caminho principal $W_{\text {path }}$. Dependendo do caminho escolhido são procurados recursos para o caminho de proteção $B_{\text {path }}$. Eles são alocados somente se houver recursos para ambos os caminhos. Se não for o caso, o evento é bloqueado. Se o evento é de desalocação e ele foi previamente alocado, são desalocados tanto o caminho principal como o secundário que foram atribuídos no evento de alocação. Quando é gerado o tráfego, a cada evento de alocação associa-se a um evento de desalocação. Se o evento de alocação derivou em bloqueio, quando é o turno do evento de desalocação associado a esse evento de alocação, não terá-se caminhos a desalocar.

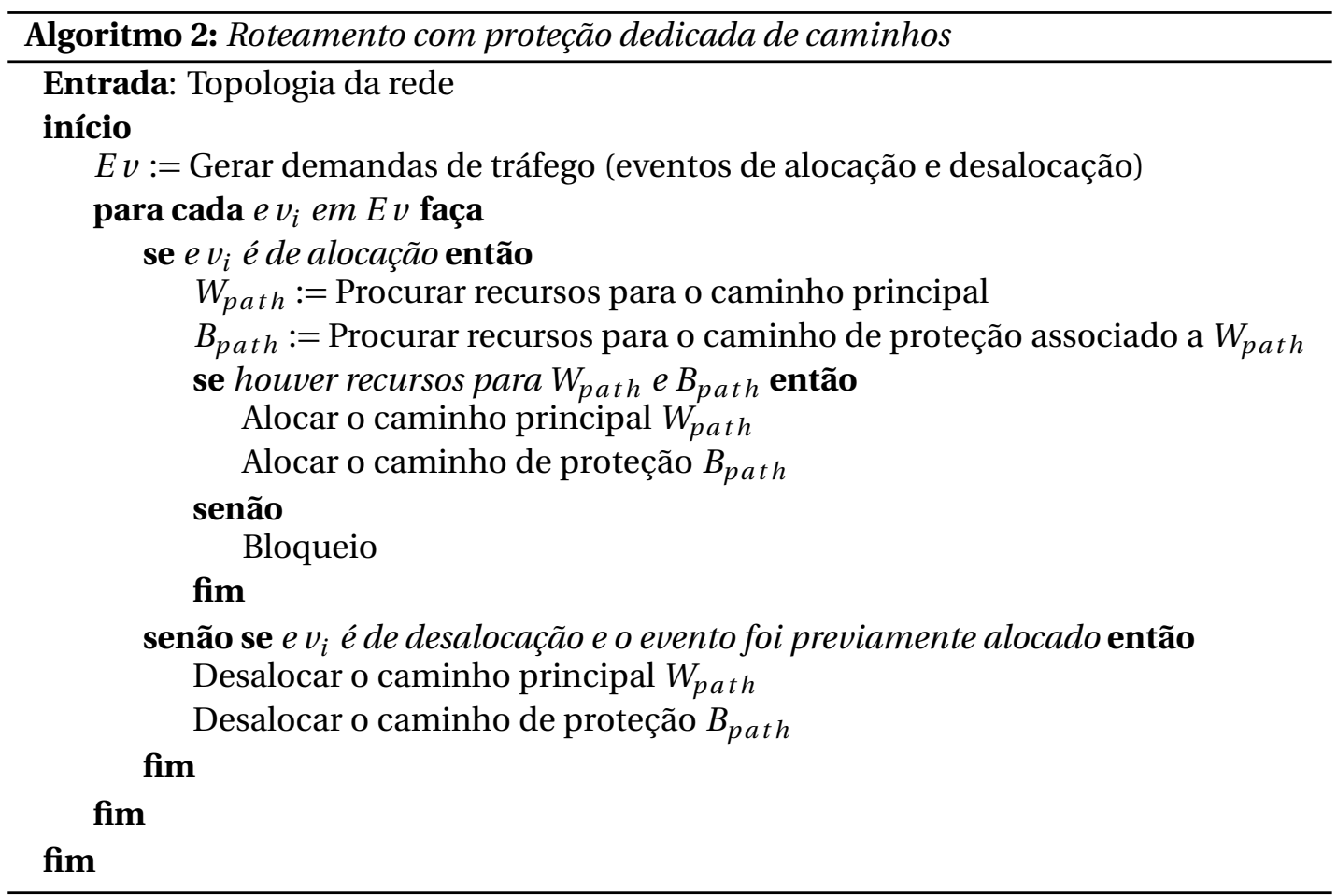




\subsection{Proposta de roteamento intensivo com proteção dedicada de ca- minhos}

Com o objetivo de diminuir a probabilidade de bloqueio, propomos uma modificação na estratégia de busca de recursos do Algoritmo 2. Nossa proposta é descrita no Algoritmo 3, as linhas na cor verde destacam a diferença entre os algoritmos 2 e 3 . Como no Algoritmo 2, depois de gerada a demanda de tráfego, os eventos são processados segundo seu tipo (alocação ou desalocação). Se o evento é de alocação é feita uma lista das rotas principais com recursos disponíveis. Se a lista não estiver vazia, quer dizer tem-se pelo menos uma rota com recursos para alocar o caminho principal, $W_{\text {path }}$ será a rota com menor custo. A atribuição de custos será explicada no Algoritmo 4. Depois são procurados recursos para o caminho de proteção $B_{\text {path }}$, segundo o Algoritmo 5 . Se houver recursos para o caminho de proteção o algoritmo aloca os dois caminhos. Se não houver recursos para $B_{\text {path }}, W_{\text {path }}$ é eliminado da lista de rotas disponíveis. A rota seguinte com menor custo é atribuída a $W_{p a t h}$ e o algoritmo volta a procurar recursos para o caminho de proteção.

O intuito é ampliar a possibilidade de achar recursos para alocar a demanda. Assim, se não houver recursos para o caminho de proteção do caminho principal escolhido, um outro caminho principal é procurado. Como novas rotas de proteção são examinadas, amplia-se a chance de que haja recursos disponíveis para alguma delas. Se já não há mais rotas principias e não foram encontrados recursos para o caminho de proteção, a demanda não é alocada, sendo bloqueada. Por último, se o evento é de desalocação e seu respectivo evento de alocação foi atendido, são desalocados os caminhos principal e secundário.

A nossa proposta de roteamento intensivo será executada para todas as estratégias, assim se o nome da estratégia é seguido por "Intensivo" quer dizer, trata-se de alguma estratégia usando a proposta de roteamento, por exemplo, EA-DPP-Dif-Intensivo.

\subsection{Etapa de busca de recursos para o caminho principal}

A finalidade do Algoritmo 4 é achar o candidato com menor custo, que esteja disponível, para ser o caminho principal. Os custos por enlace são atribuídos segundo a estratégia escolhida, EA-DPP-Dif, EA-DPP-MixS, EA-DPP ou Shorthest Path-Dedicated Path Protecction (SP-DPP). A atribuição de custos e o objetivo de cada uma das estratégias serão explicadas na Seção \$5.7. Assim, dado um evento de alocação, com nó fonte $s_{e v i} \mathrm{e}$ nó destino $d_{e v i}$, são extraídas as rotas principais, entre $s$ e $d$, encontradas na fase de précálculo 1. As disponibilidade de cada uma das $v$ rotas é avaliada. As rotas disponíveis 


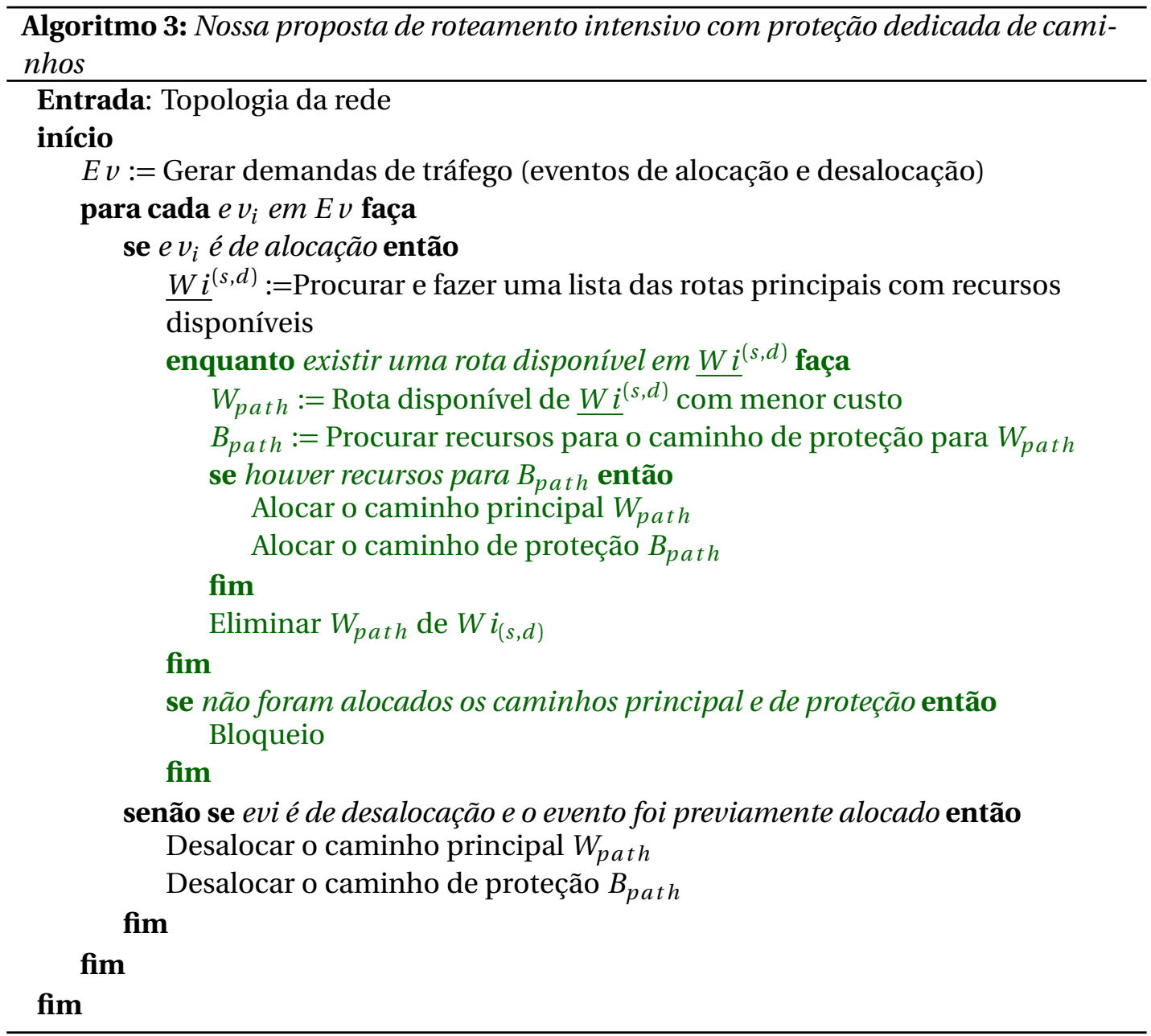


(com o mesmo comprimento de onda) são armazenadas na lista $\underline{W}^{(s, d)}$. Se não houver candidatos a demanda é bloqueada. O passo seguinte é atualizar os custos por enlace na rede. O custo de cada enlace é calculado de acordo com a estratégia e a como está sendo usado o enlace.

A utilização do enlace refere-se a se o enlace faz parte somente de caminhos principais $W B^{\prime}$, somente caminhos de proteção $B W^{\prime}$, ambos os tipos de caminhos $W \& B$, ou o enlace está livre $(W \| B)^{\prime}$ (W: working, B:protection). Assim, neste algoritmo dependendo da estratégia, por exemplo EA-DPP-Dif, para um enlace que faz parte somente de caminhos principais, $W B^{\prime}$, o custo atribuído para esse enlace será 0 . Depois são calculados os custos de cada uma das rotas disponíveis da lista $\underline{W}^{(s, d)}$. Esse cálculo é feito somando o custo de cada um dos enlaces que compõem a rota. São escolhidas as rotas com o menor custo. Se há apenas uma rota, essa será o caminho principal $W_{p a t h}$. Se houver empate de custos entre duas ou mais rotas, a maneira de escolher o caminho principal varia de acordo com a estratégia usada. No caso de EA-DPP-Dif ou EA-DPP-MixS, é escolhida a rota com o maior número médio de rotas principais que fazem parte dela. Essa média é calculada somando o número de caminhos principais que já estejam fazendo parte de cada um dos enlaces da rota, dividido entre o número de saltos da rota. Caso seja a estratégia EA-DPP ou SP-DPP é escolhida a rota com o menor comprimento físico.

\subsection{Etapa de busca de recursos para o caminho de proteção}

Na segunda etapa são procurados comprimentos de onda para alocar o caminho de proteção. Somente passa-se à segunda etapa quando é achado um caminho principal disponível na etapa anterior. São extraídas da fase de pré-processamento as $u$ rotas (disjuntas) de proteção que correspondem à rota principal escolhida.

Da mesma maneira que na etapa anterior é feita uma lista, $\underline{B}_{w i}^{(s, d)}$ com as rotas de proteção com recursos disponíveis. Se não houver rota disponível a demanda é bloqueada. Depois são atualizados os custos para cada enlace na rede. Esses custos dependerão, também, da estratégia escolhida é de acordo á utilização do enlace $(W / B)$. Para cada uma das rotas na lista $\underline{B}_{w i}^{(s, d)}$ é calculado o custo total da rota. Finalmente, escolhe-se a rota com o menor custo. Se houver empate (mais de uma rota com o menor custo) a escolha da rota dependerá da estratégia usada. No caso de EA-DPP-Dif e da proposta desse trabalho, será escolhida como caminho de proteção, $B_{\text {path }}$, a rota com o maior número médio de rotas de proteção que fazem parte dela. No caso de EA-DPP-MixS, EA-DPP e SP-DPP $B_{\text {path }}$ será a rota com o menor comprimento físico.

Nas duas etapas o comprimento de onda escolhido é o primeiro que estiver disponível, (método first-fit). 


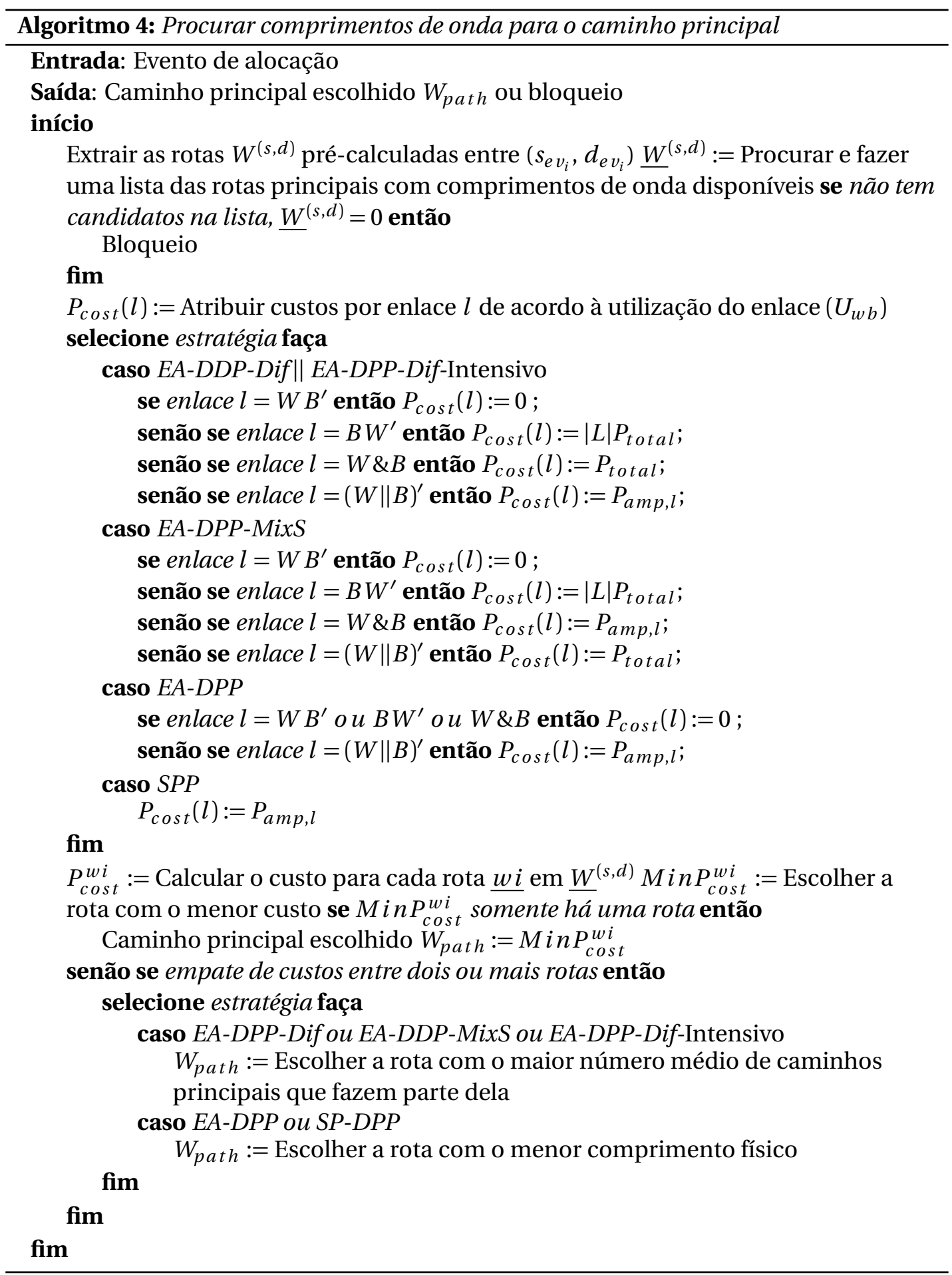




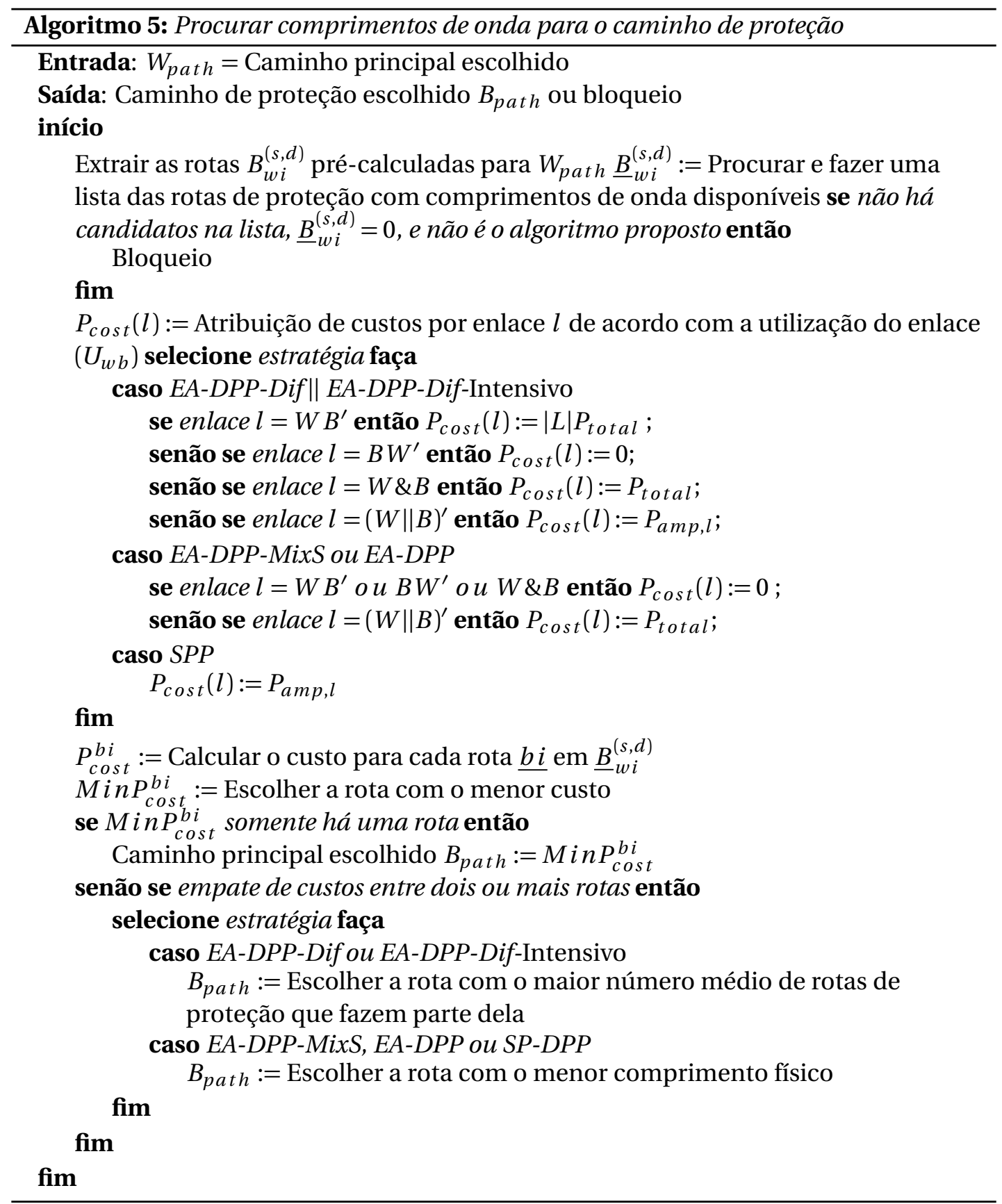




\subsection{Alocação e desalocação de eventos}

Para cada demanda de alocação tráfego, o caminho principal e de proteção escolhidos, de acordo com a estratégia de economia de energia usada, devem ser devidamente alocados. O Algoritmo 6 executa esse processo. Esse algoritmo será utilizado somente se o evento for de alocação e se foram achados comprimentos de onda disponíveis para ambos os caminhos. A alocação consiste em marcar como ocupado cada enlace dos caminhos escolhidos. Os enlaces são marcados na respectiva matriz de tráfego, segundo o comprimento de onda encontrado nos Algoritmos 4 e 5. Além disso, a matriz de tipo de utilização de enlace, $U_{w b}$, deve ser atualizada. No caso do caminho principal, se o enlace a ser alocado estiver carregando só caminhos principais, $W B^{\prime}$, o enlace na matriz de utilização continuara sendo $W B^{\prime}$. Quer dizer, o enlace continua fazendo parte somente de caminhos principais. Se o enlace pertence somente a caminhos de proteção, $B W^{\prime}$, passaria a ser um enlace misto, $W \& B$. Se o enlace é misto, seguirá sendo misto. Por último, se o enlace estiver desocupado, $(W \| B)^{\prime}$, agora o enlace será usado por o caminho principal, $W B^{\prime}$.

Na alocação do caminho de proteção a matriz de utilização é marcada de maneira similar. Para cada um dos enlaces que fazem parte do caminho de proteção a ser alocado, o enlace é $W B^{\prime}$ (faz parte só de caminhos principais), o enlace passará a ser misto, $W \& B$. Se é parte somente de caminhos de proteção, $B W^{\prime}$, continuará sendo $B W^{\prime}$. Se é misto, continuará sendo misto $W \& B$. Se estiver desocupado, passará a ser somente de caminhos de proteção $B W^{\prime}$.

O Algoritmo 7 de desalocação é parecido com o algoritmo anterior, só que agora marcaremos como desocupados os saltos dos caminhos a desalocar. Utilizaremos o algoritmo somente se o evento é de desalocação. Lembrar que cada demanda de tráfego esta dividida em dois eventos de alocação e desalocação. O identificador do evento indica se o respectivo evento de alocação foi atendido. Quer dizer, foram encontrados comprimentos de onda disponíveis para o caminho principal e de proteção e eles foram alocados. Ao identificar o evento de alocação respectivo, são extraídos os caminhos $W_{p a t h}, B_{p a t h}$ e os comprimentos de onda designados. Cada comprimento de onda é marcados como desocupado na matriz de tráfego. Ademais, deve ser atualizada a matriz de utilização de enlaces $U_{w b}$. Na desalocação do caminho principal tem-se dois casos que modificam a matriz $U_{w b}$. Se o comprimento de onda desalocado faz parte de um enlace que tem atribuído somente um caminho principal, $W B^{\prime}$, o enlace será marcado como desocupado ou vazio, $(W \| B)^{\prime}$. Isso é, porque o único caminho que faz parte de esse enlace é o caminho que está sendo desalocado. Caso o enlace fosse misto $W \& B$, e faz parte de caminhos de proteção e somente de um caminho principal, o enlace agora será marcado como enlace somente de proteção, $B W^{\prime}$, porque o caminho que fazia o enlace ser misto é o caminho 


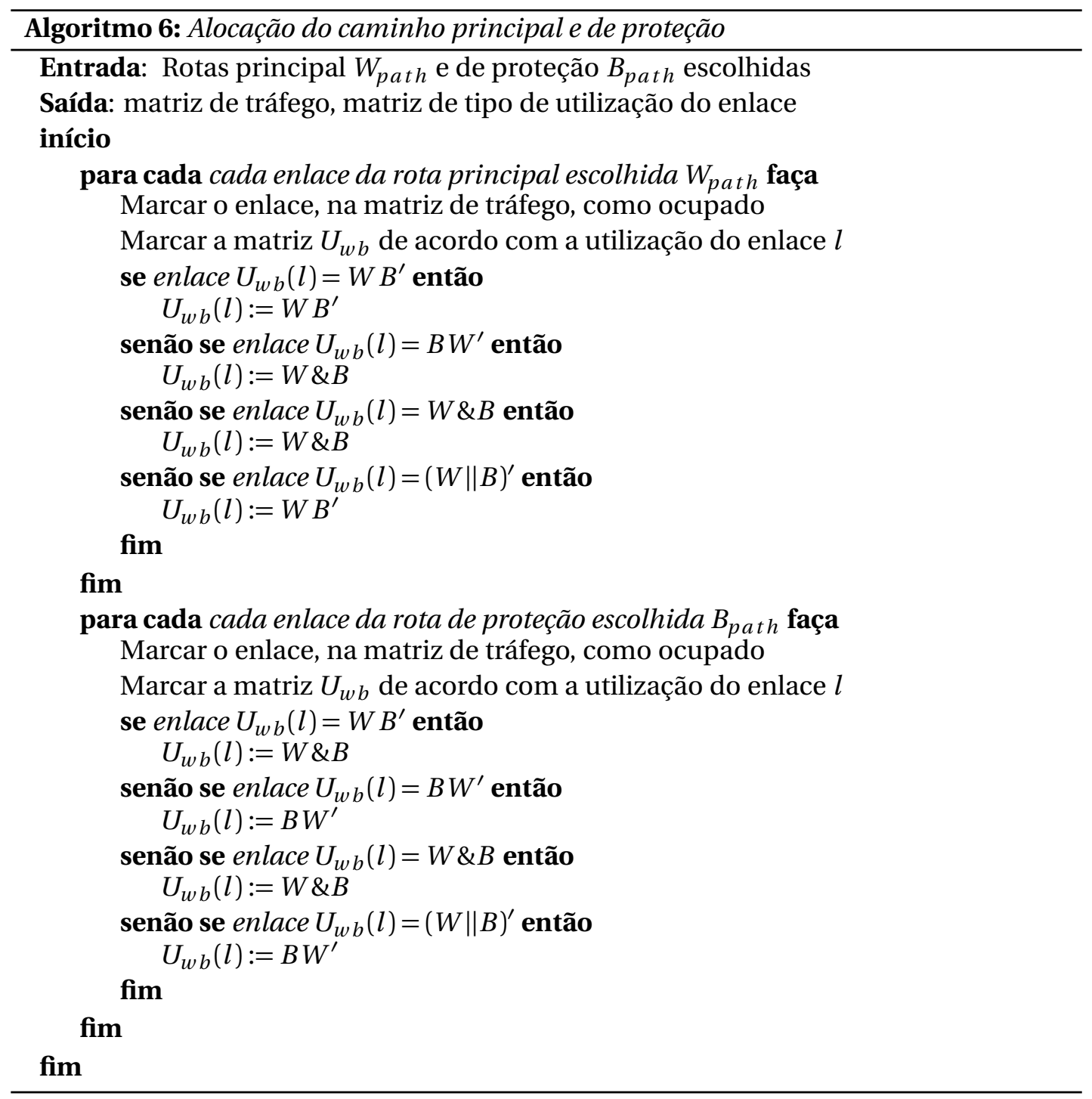


que será desalocado.

Quando o caminho de proteção é desalocado há também dois casos que modificam a matriz de utilização. Se o enlace é $B W^{\prime}$ e há somente um caminho de proteção que faz parte dele, o enlace será marcado como vazio, $(W \| B)^{\prime}$. Se o enlace é misto e, além dos caminhos principais, há somente um caminho de proteção que faz parte dele, o enlace será marcado como $W B^{\prime}$, pois ele agora somete faz parte de caminhos principais.

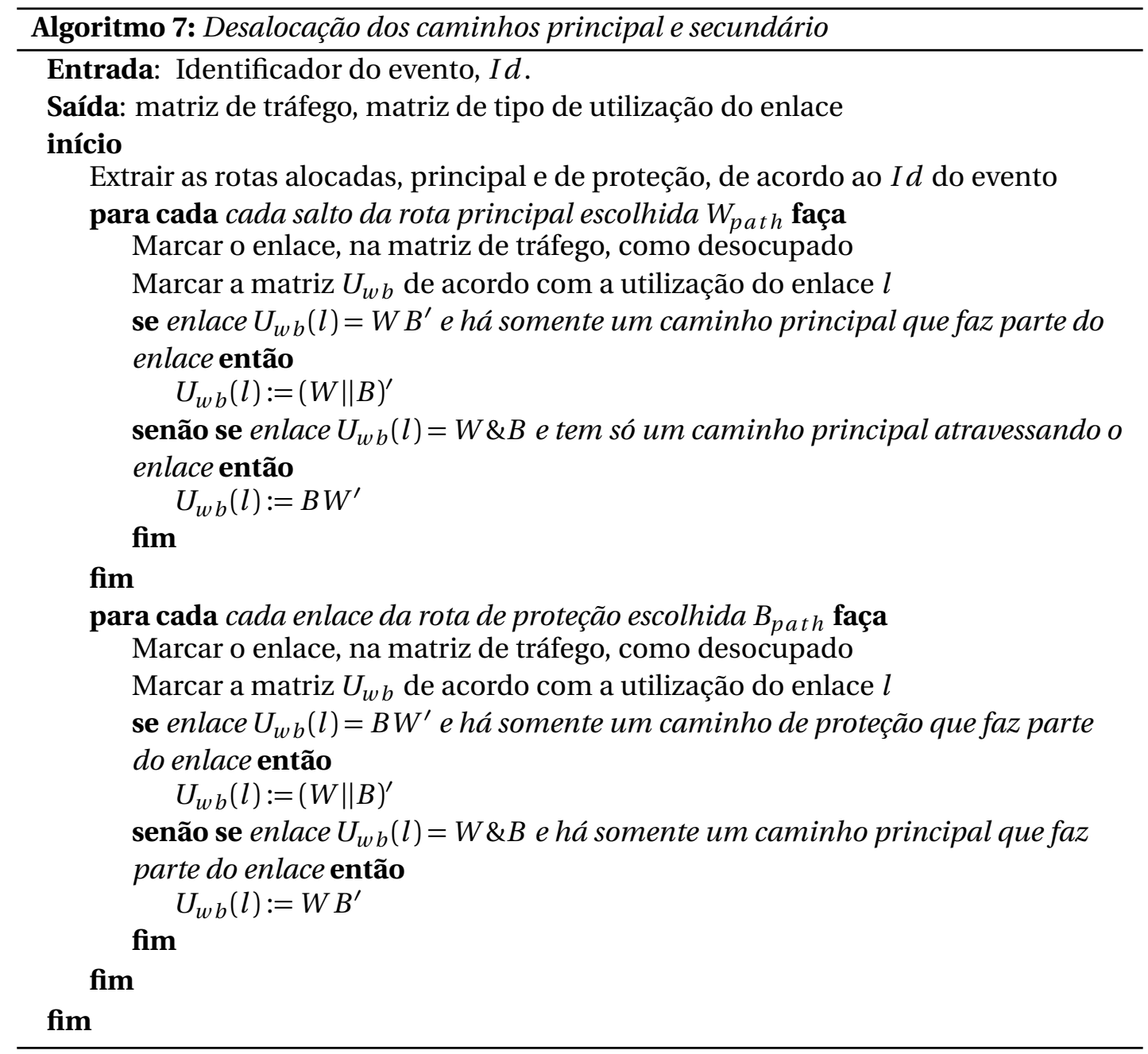

A seguir é apresentado um fluxograma (Figura 5.1) que resume o roteamento de tráfego com base em economia de energia. Nele são mostradas a fase de pré-cálculo de caminhos e as etapas de busca e alocação de recursos para ambos os tipos de caminhos, principal e de proteção. Na Figura 5.1 podemos observar a sequência de instruções apresentadas nos algoritmos 1, 4 e 5. Além disso, a seção em verde representa o roteamento intensivo (algoritmo 3), proposto principalmente para diminuir a probabilidade de bloqueio dada pelas estratégias de economia de energia. 


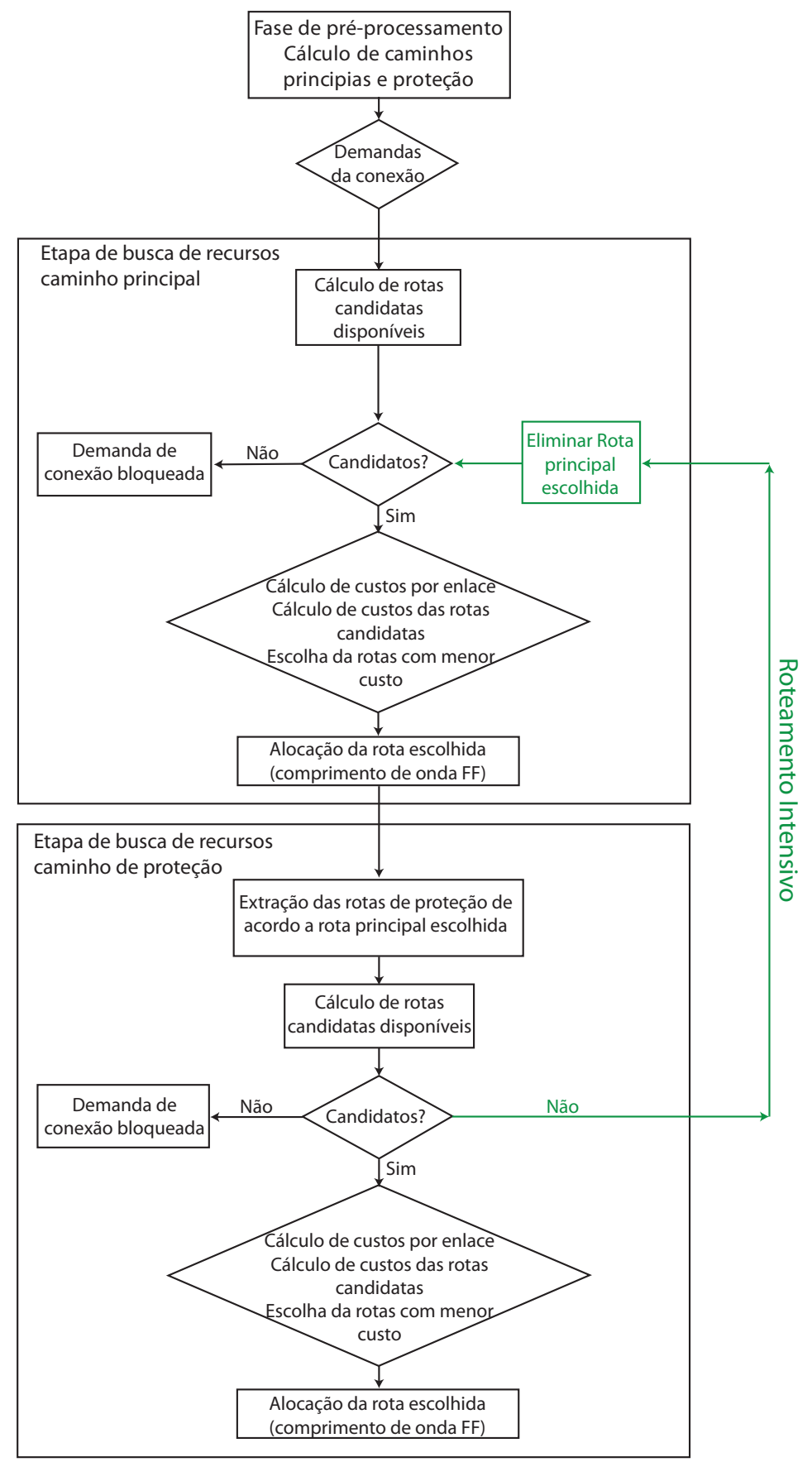

Figura 5.1.: Fluxograma do roteamento de tráfego com base em economia de energia. 


\subsection{Estratégias de economia de energia}

O intuito do modelo desenvolvido para economizar energia em redes com proteção dedicada de caminhos, dedicated path protection (DPP), é que os elementos da rede (enlaces e nós) que pertencem somente a caminhos de proteção podem ser postos em modo suspenso. Dessa maneira, o objetivo das estratégias de economia de energia implementadas é ampliar a quantidade de enlaces e nós que estão sendo usados somente por caminhos de proteção, assim como diminuir a quantidade de enlaces mistos, que são parte de ambos os tipos de caminhos, pois eles não podem ser postos em modo suspenso. As estratégias apresentadas em [71] baseiam-se na atribuição de diferentes custos por enlace, tanto na etapa de busca de caminho principal como na de busca de caminho de proteção. A seguir explicaremos as estratégias propostas.

A primeira estratégia energy-aware dedicated path protection with differentiation (EA-DPP-Dif) tem como finalidade separar o roteamento de caminhos principais dos de proteção. Quer dizer, ela tenta que os caminhos de proteção não sejam atribuídos a enlaces que já são parte de caminhos principais. A estratégia consegue diferenciar entre os dois tipos de caminhos mediante os custos por enlace que atribui. Assim, na busca de recursos para o caminho principal (algoritmo 4) para EA-DPP-Dif, os custos por enlace:

$$
P_{\text {cost }}(l)= \begin{cases}0 & \text { se } U_{w b}(l)=W B^{\prime} \\ n_{\text {links }} P_{t o t} & \text { se } U_{w b}(l)=B W^{\prime} \\ P_{\text {tot }} & \text { se } U_{w b}(l)=W \& B \\ P_{a m p} k(l) & \text { se } U_{w b}(l)=(W \| B)^{\prime}\end{cases}
$$

Os custos atribuídos dependem da utilização do enlace, que pode ser usado somente por caminhos principais $W B^{\prime}$, somente por caminhos de proteção $B W^{\prime}$, misto $W \& B$, ou estar vazio $(W \| B)^{\prime}$. Os custos por enlace podem tomar quatro valores: $0, n_{\text {links }} P_{\text {tot }}, P_{\text {tot }}$ ou $P_{a m p} k(l)$.

Nessa estratégia o menor custo, 0 , é atribuído aos enlaces que são parte somente de caminhos principais, $W B^{\prime}$. Assim fomentar que o caminho a ser alocado passe por esses enlaces. Lembrar que, em busca de recursos, o caminho escolhido será aquele que tenha o menor custo. Quando a rota escolhida, para o caminho principal, é aquela que tem a maior quantidade de enlaces que pertencem somente a caminhos principais, a quantidade de enlaces mistos diminui.

O maior custo é atribuído a enlaces que pertencem somente a caminhos de proteção $B W^{\prime}$. A intenção é desestimular a escolha desses enlaces como parte da rota do caminho principal a ser alocado. O maior custo é dado por $n_{l i n k s} P_{t o t}$, que representa o número de enlaces na rede multiplicado pela potência total gasta pela rede. Essa potência total 
refere-se a potência consumida quando todos os elementos da rede estão em estado ativo. $P_{t o t}$ é atribuído ao enlaces mistos. E $\operatorname{Pa} m p k(l)$, que é a potência gasta pelo enlace em estado ativo, é atribuído a os enlaces que não etão sendo usados. A potência do enlace em estado ativo e calculado pela quantidade de amplificadores que ele tem, $k(l)$, pela potência que consome cada amplificador.

Seguindo com a estratégia EA-DPP-Dif, na busca de recursos para o caminho de proteção (algoritmo 5) os custos por enlace são:

$$
P_{\text {cost }}(l)= \begin{cases}n_{\text {links }} P_{\text {tot }} & \text { se } U_{w b}(l)=W B^{\prime} \\ 0 & \text { se } U_{w b}(l)=B W^{\prime} \\ P_{t o t} & \text { se } U_{w b}(l)=W \& B \\ P_{a m p} k(l) & \text { se } U_{w b}(l)=(W \| B)^{\prime}\end{cases}
$$

Nesse caso o maior custo $n_{\text {links }} P_{\text {to }}$ é atribuído aos enlaces que pertencem somente a caminhos principais. Assim, tenta-se que o caminho de proteção a ser alocado não utilize esses enlaces, $W B^{\prime}$. Para os caminhos que são somente caminhos de proteção é atribuído o menor custo, 0 . O intuito é promover que os caminhos de proteção sejam atribuídos a enlaces $B W^{\prime}$ e diminuir a simultaneidade de caminhos principais e de proteção nos enlaces. Como no caso anterior, os custos atribuídos aos enlaces mistos e em desuso são $P_{t o t}$ e $P_{a m p} k(l)$, respectivamente.

A segunda estratégia energy-aware dedicated path protection with mixing (EA-DPP-MixS) foi proposta em [71] para diminuir a probabilidade de bloqueio resultante da estratégia anterior, EA-DPP-Dif. A EA-DPP-MixS permite a simultaneidade de caminhos de potecão e principais num mesmo enlace. O objetivo dessa estratégia é não sobrecarregar os enlaces, o que pode resultar em maior probabilidade de bloqueio. Além disso, tenta diminuir a escolha de rotas longas ou seja, com muitos saltos. Durante a busca de recursos para o caminho principal no algoritmo 4, os custos por enlace são:

$$
P_{\text {cost }}(l)= \begin{cases}0 & \text { se } U_{w b}(l)=W B^{\prime} \\ n_{\text {links }} P_{t o t} & \text { se } U_{w b}(l)=B W^{\prime} \\ P_{a m p} k(l) & \text { se } U_{w b}(l)=W \& B \\ P_{t o t} & \text { se } U_{w b}(l)=(W \| B)^{\prime}\end{cases}
$$

Nessa estratégia, diferentemente da anterior, os enlaces mistos $W \& B$ são atribuídos com um custo menor que os enlaces vazios $(W \| B)^{\prime}$. Assim, os enlaces $W B^{\prime}$ e $B W^{\prime}$ mantêm os mesmos custos da estratégia anterior. Para os enlaces mistos, o custo será $P_{a m p} k(l)$ e para os vazios, $P_{\text {tot }}$. Com esses novos custos, procura-se desestimular a utilização de recursos que ainda não foram usados. Adicionalmente a estratégia mantém a ideia de 
atribuir caminhos principais a enlaces que têm caminhos principais anteriormente alocados.

Quando são procurados recursos para o caminho de proteção (algoritmo 5), os custos por enlace são:

$$
P_{\text {cost }}(l)= \begin{cases}0 & \text { se } U_{w b}(l)=W B^{\prime} \text { ou } B W^{\prime} \text { ou } W \& B \\ P_{a m p} k(l) & \text { se } U_{w b}(l)=(W \| B)^{\prime}\end{cases}
$$

Em EA-DPP-MixS a atribuição de custos por enlace na busca do caminho de proteção não vai depender de que tipo de caminhos já são parte desse enlace. Para atribuir os custos a estratégia só precisa diferenciar entre enlaces que estejam sendo usados dos que estejam vazios. Assim, o maior custo $P_{a m p} k(l)$ será atribuído para os enlaces sem uso $(W \| B)^{\prime}$ e a todos os outros enlaces será atribuído custo 0 . Nessa estratégia não é relevante se o caminho de proteção será parte de enlaces mistos. Com isto tenta-se diminuir tanto a probabilidade de bloqueio como também a o comprimento das rotas escolhidas como caminho de proteção.

A terceira estratégia energy-aware dedicated path protection (EA-DPP), tem como objetivo desestimular a atribuição de caminhos principais ou de proteção a elementos da rede que ainda estejam sem ser usados. Quer dizer, que o tráfego tentará ser roteado por enlaces que já estejam em estado ativo. O intuito é manter a maior quantidade de elementos inativos com a finalidade de economizar energia. Assim, a atribuição de custos por enlaces em ambos nos dois casos (busca de recursos para caminhos principais e de proteção) é

$$
P_{\text {cost }}(l)= \begin{cases}0 & \text { se } U_{w b}(l)=W B^{\prime} \text { ou } B W^{\prime} \text { ou } W \& B \\ P_{a m p} k(l) & \text { se } U_{w b}(l)=(W \| B)^{\prime}\end{cases}
$$

Da mesma maneira que EA-DPP-MixS, a estratégia EA-DPP atribui dois tipos de custos quando procura recursos para o caminho de proteção. O menor custo, 0 , é atribuído aos enlaces usados, $W B^{\prime}$ ou $B W^{\prime}$ ou $W \& B$. O maior custo a os enlaces vazios. Assim, é promovido o uso de enlaces ativos no lugar dos sem uso.

E implementada uma outra estratégia shortest path dedicated path protection (SP-DPP), para comparações. No caso de SP-DPP (roteamento pelo caminho mais curto), o custo do enlace é baseado na distância física do enlace. Assim, a rota escolhida é aquela que a soma das distâncias dos enlaces que a compõem é a menor. O custo por enlace para essa estratégia é $P_{a m p} k(l)$, para todos os casos, posto que $P_{a m p} k(l)$ está direitamente relacionado com o comprimento do enlace. Se o comprimento de um enlace é maior que o comprimento de outro enlace, ele terá também maior quantidade de amplificadores, 
$k(l)$. Assim, o custo para a estratégia SP-DPP é

$$
P_{\text {cost }}(l)=\left\{P_{a m p} k(l) \quad \text { se } U_{w b}(l)=W B^{\prime} \text { ou } B W^{\prime} \text { ou } W \& B \text { ou }(W \| B)^{\prime}\right.
$$

Para uma melhor compreensão da diferença de custos nas estratégias usadas é apresentada a Tabela 5.1. Na tabela são mostrados os custos segundo o tipo de caminho a ser alocado e segundo a utilização do enlace $\left(W B^{\prime}, W \& B, B W^{\prime}\right.$ e $\left.(W \| B)^{\prime}\right)$.

Tabela 5.1.: Custos por enlace segundo a estratégia.

\begin{tabular}{lcccc}
\hline Caminho principal & $W B^{\prime}$ & $W \& B$ & $B W^{\prime}$ & $(W \| B)^{\prime}$ \\
\hline EA-DPP-Dif & 0 & $P_{\text {tot }}$ & $n_{\text {links }} P_{\text {tot }}$ & $P_{a m p} k(l)$ \\
EA-DPP-MixS & 0 & $P_{a m p} k(l)$ & $n_{\text {links }} P_{\text {tot }}$ & $P_{\text {tot }}$ \\
EA-DPP & 0 & 0 & 0 & $P_{a m p} k(l)$ \\
SP-DPP & $P_{a m p} k(l)$ & $P_{a m p} k(l)$ & $P_{a m p} k(l)$ & $P_{a m p} k(l)$ \\
\hline Caminho de proteção & $W B^{\prime}$ & $W \& B$ & $B W^{\prime}$ & $(W \| B)^{\prime}$ \\
\hline EA-DPP-Dif & $n_{l i n k s} P_{t o t}$ & $P_{t o t}$ & 0 & $P_{a m p} k(l)$ \\
EA-DPP-MixS & 0 & 0 & 0 & $P_{a m p} k(l)$ \\
EA-DPP & 0 & 0 & 0 & $P_{a m p} k(l)$ \\
SP-DPP & $P_{a m p} k(l)$ & $P_{a m p} k(l)$ & $P_{a m p} k(l)$ & $P_{a m p} k(l)$ \\
\hline
\end{tabular}

Nessa seção foi apresentado o pseudocódigo dos algoritmos implementados: algoritmo de pré-cálculo de candidatos a caminhos principais e de proteção (1), algoritmo de roteamento de tráfego (2), a nossa proposta de roteamento intensivo (Algoritmo 3), algoritmos de atribuição de enlaces baseado em economia de energia para caminhos principais (4) e para caminhos de proteção (5) e os algoritmos de alocacao(6) e desalocação (7) de tráfego. Assim também, foram apresentadas as estratégias de economia de energia EA-DPP-Dif, EA-DPP-MixS e EA-DPP baseadas no cálculo de custo por enlace de acordo com a utilização dele. Quer dizer, se no momento da avaliação, o enlace é parte somente de caminhos principais, somente de caminhos de proteção, ambos ou não está sendo usado. E finalmente foi apresentada a estratégia SP-DPP como benchmark para comparar com os resultados das estratégias de economia de energia. 


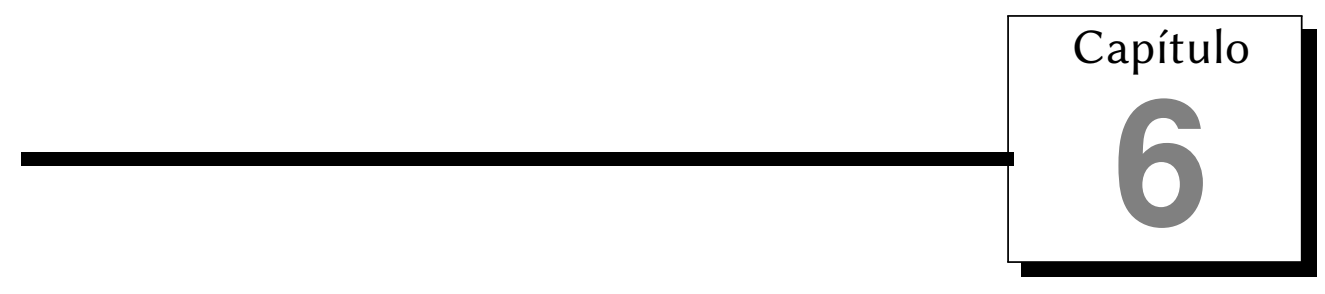

\section{Simulações e resultados}

Nesta seção serão apresentadas e discutidas as simulações e seus resultados. Como foi descrito na Seção \$4.2.2 serão usadas três redes para os testes, a rede Cost239 [76], a rede UsNet [77] e a rede brasileira Ipê [78]. O modelo de consumo de energia que será usado na avaliação também foi descrito na Seção \$4.2.1.

Com o intuito de validar os algoritmos de roteamento baseados em economia de energia implementados, o desenvolvimento passo a passo está apresentado no Apêndice A.

\subsection{Avaliação do desempenho das estratégias}

Com a finalidade de avaliar e comparar as estratégias descritas na Seção 55.7 serão desenvolvidas algumas métricas. Essas métricas permitirão avaliar o desempenho das estratégias sob diferentes critérios. As estratégias serão testadas sob as mesmas condições como carga de rede, número de conexões e quantidade de testes por experimento. Os algoritmos foram testados sob cargas de 108 a 324 erlangs. Usamos 100000 conexões por cada uma das cargas testadas. Cada simulação foi repetida 10 vezes. As métricas avaliadas serão a probabilidade de bloqueio, potência consumida pela rede e tipo de utilização do enlace $W / B$, explicadas na Seção \$4.2.4. 


\subsubsection{Potência total consumida}

Sendo o objetivo principal do trabalho melhorar a eficiência do consumo de energia é necessário medir como ela é consumida. O modelo de consumo de energia (Seção §4.2.1) que será usado para fazer a avaliação e comparação das estratégias (Seção §5.7) é expresso por:

$$
P_{t o t}^{e v}=\sum_{n \in N}\left(P_{n}^{\text {node }} x_{n}\right)+\sum_{e \in E}\left(P_{e}^{a m p} x_{e}\right),
$$

que é a mesma equação que equação (4.1), mas o cálculo de potência é feito em cada evento $(e v)$.

A potência total consumida é a soma da potência consumida pelos nós em estado ativo, $x_{n}$, e enlaces em estado ativo, $x_{e}$. O cálculo da potência consumida é realizado em cada evento (de alocação ou de desalocação), pela análise do estado de cada nó e enlace na rede. Em seguida, é feita uma média das potências consumidas em todos os eventos e uma média da potência total considerando todos os testes. Consideramos duas abordagens para o cálculo de potência consumida por elementos da rede (nós e enlaces). A primeira considera todos os elementos da rede que sejam parte de caminhos principais e de proteção em estado ativo (consumindo energia). A segunda considera o modo suspenso como o estado dos elementos que são parte somente de caminhos de proteção. Quer dizer, que no momento do cálculo eles não são considerados como elementos em estado ativo pelo que não consumirão energia. Para referirmos à primeira abordagem será usado somente o nome da estratégia e para a segunda o nome da estratégia usada seguido de sleep.

A seguir serão apresentadas os gráficos com os resultados da potência consumida para a rede Cost239 [76], a rede UsNet [77] e a rede brasileira Ipê [78] para diferentes cargas de tráfego que a rede suporta. A potência será normalizada segundo a potência máxima que a rede pode consumir durante um evento, isto é a potência consumida com todos os elementos da rede em estado ativo.

Na Figura 6.1a é mostrada a potência consumida pela rede Cost239 usando a primeira abordagem de medição de potência (sem modo suspenso) e a potência consumida quando é suportado o modo suspenso para caminhos de proteção usando a estratégia EA-DPP-Dif. Incluiremos também o resultado do cálculo de potência consumida com modo suspenso quando é utilizada a proposta de roteamento intensivo para essa estratégia EA-DPP-Dif Intensivo. Na Figura 6.1b são mostradas as mesmas potências consumidas para a estratégia EA-DPP-MixS. Os resultados de potência consumida para a estratégia EA-DPP são ilustrados na Figura 6.1c, assim como, os resultados para a estratégia SP-DPP na Figura 6.1d. 


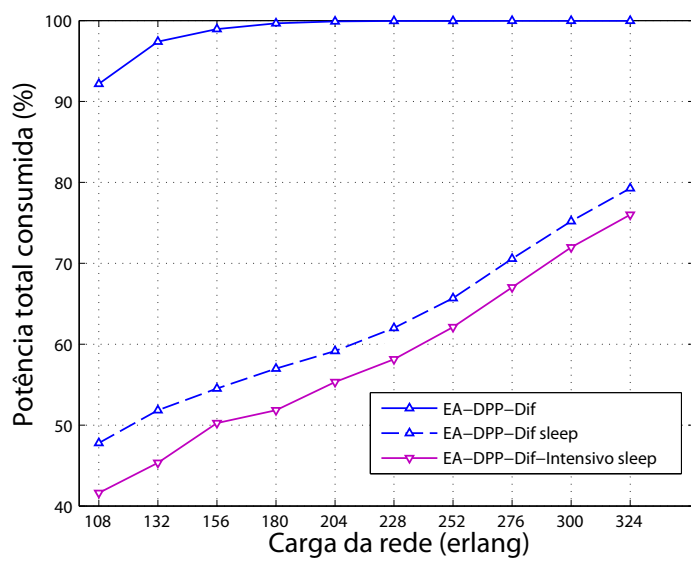

(a) Estratégia EA-DPP-Dif.

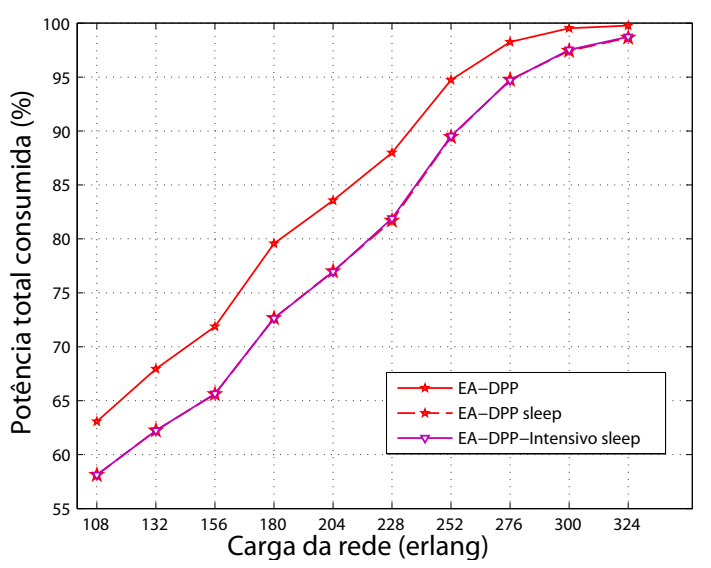

(c) Estratégia EA-DPP.

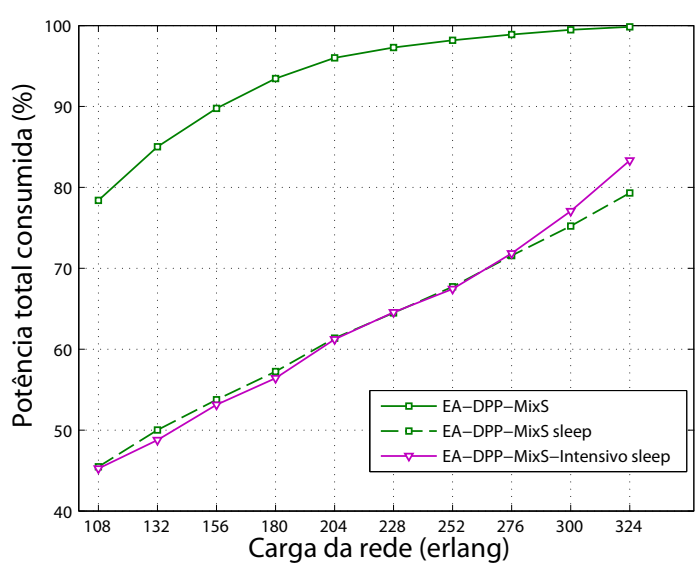

(b) Estratégia EA-DPP-MixS.

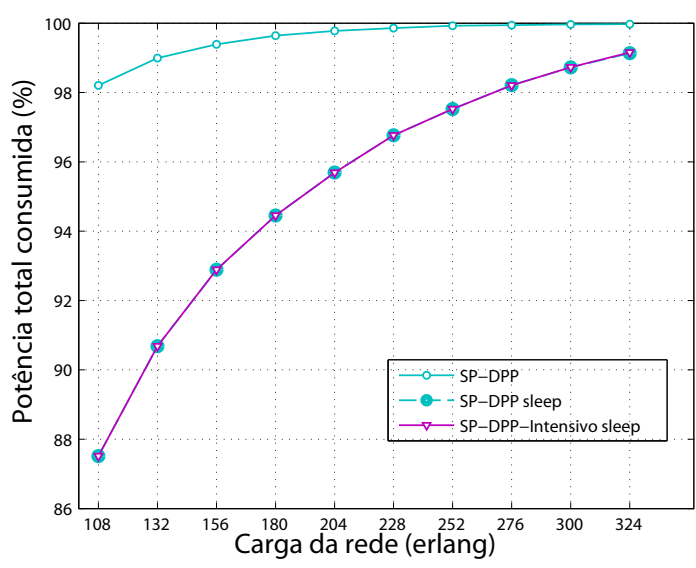

(d) Estratégia SP-DPP.

Figura 6.1.: Potência total consumida pela rede Cost239 versus carga de rede para às estratégias testadas. 
Como pode ser observado utilizar o modo suspenso nos enlaces e nós que são parte dos caminhos de proteção diminui a porcentagem total de potência consumida na rede. Essa redução de potência consumida é observada para todas as estratégias implementadas. No caso de EA-DPP-Dif a percentagem de energia economizada para as cargas de rede testadas varia desde $20 \%$, para as cargas maiores, até $40 \%$ com cargas de rede menores (Figura 6.1a). Com a nossa proposta de roteamento intensivo observamos que para essa estratégia consegue-se economizar $5 \%$ de potência. Para a segunda estratégia EA-DPP-MixS a diferença de percentagem de potência consumida entre a estratégia sem e com modo suspenso varia ao redor de $35 \%$ a $20 \%$ (Figura 6.1 b). Ao aplicar o roteamento intensivo pode-se observar que a quantidade de potência consumida varia muito pouco em comparação a EA-DPP-MixS sleep.

No caso da terceira estratégia EA-DPP a percentagem de potência economizada é menor que com as estratégias anteriores (EA-DPP-Dif e EA-DPP-MixS), variado ao redor de $5 \%$ com respeito à mesma estratégia sem usar modo sleep (Figura 6.1c). No entanto, devemos observar que a potência sem modo suspenso é menor em relação às demais estratégias, e a média de potência utilizada ao longo dos eventos somente chega a 100\% a partir de cargas de rede maiores que 300 erlangs. Isto significa que usando essa estratégia a acomodação de tráfego deixa-se mais recursos da rede sem serem usados, ou seja, não consumindo energia. Além disso, podemos observar que ao aplicar o roteamento intensivo não há nenhuma melhora em termos de potência economizada.

Para a estratégia SP-DPP a utilização de modo suspenso para os caminhos de proteção significou a diminuição de entre $12 \%$ e $1 \%$ da percentagem de potência consumida (Figura 6.1d). Temos que observar que essa diferença de percentagem diminui rapidamente à medida que incrementa-se a carga de tráfego na rede. Como no caso anterior, aplicar o roteamento intensivo com modo suspenso não melhorou a média de potência consumida. Observando os resultados de diferença de percentagem de potência consumida para todas as estratégias podemos inferir que a estratégia que apresenta maior diferença é a EA-DPP-Dif, no entanto a SP-DPP apresenta a menor quantidade de potência economizada. Além disso, pode-se observar que somente a proposta de roteamento intensivo para EA-DPP-Dif apresenta melhora significativa com relação à diminuição de potência em comparação ao roteamento proposto por [71].

Com a finalidade de comparar os resultados de percentagem de potência economizada entre as estratégias, quando é usado o modo suspenso (sleep), é apresentada a Figura 6.2. No gráfico incluímos além das 4 estratégias, EA-DPP-Dif, EA-DPP-MixS, EA-DPP, SP-DPP, o resultado da primeira estratégia usando a nossa proposta de roteamento intensivo (EA-DPP-Dif-Intensivo). Podemos observar que para a rede Cost239 o menor consumo de potência é obtido utilizando a estratégia de diferenciação de caminhos, EA-DPP-Dif, utilizando o roteamento intensivo. A estratégia com pior desempenho de 


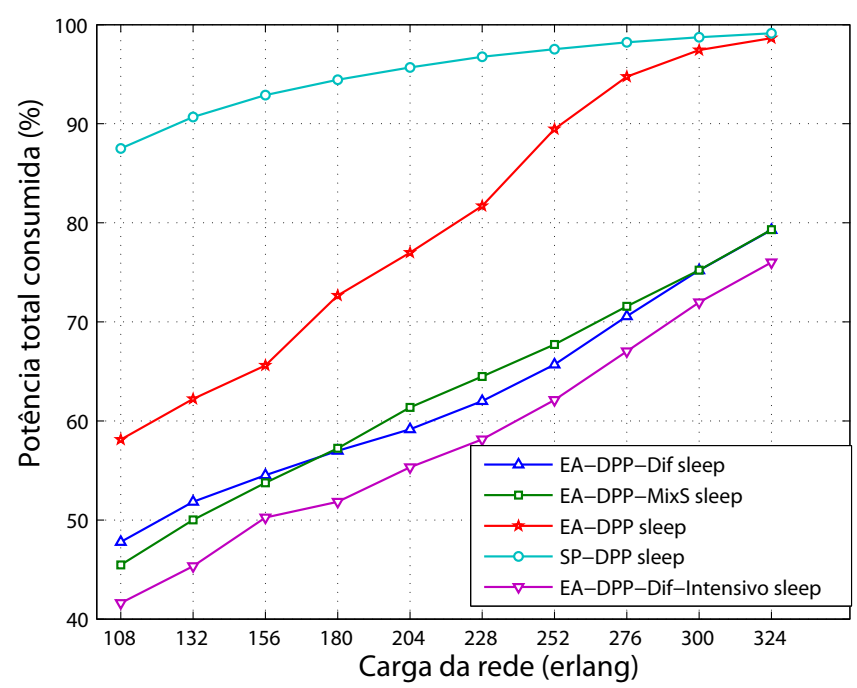

Figura 6.2.: Potência total consumida pela rede Cost239 usando modo suspenso versus carga de rede.

potência consumida (usando o modo suspenso para caminho de proteção) é a estratégia de roteamento por caminho mais curto, SP-DPP.

Os resultados de potência consumida a seguir correspondem à rede USNet [77]. Da mesma maneira que no caso anterior, serão apresentados os gráficos com comparações entre cada uma das estratégias, com e sem modo suspenso, além dos resultados para o roteamento intensivo usando modo suspenso. Na Figura 6.3a é mostrada a comparação de resultados para a estratégia EA-DPP-Dif. Observamos que usando o modo suspenso para os caminhos de proteção consegue-se economizar entre $40 \%$ e $20 \%$ de potência para os erlangs analisados (108 a 324 erlangs). Note-se que para essa estratégia a potência consumida sem modo suspenso tende a ser $100 \%$ desde a carga de tráfego mais baixa. Isto evidencia que, em média, entre os eventos testados, todos os elementos da rede são usados. Ademais, observamos que quando aplicamos o roteamento intensivo, EA-DPP-DifIntensivo, obteve-se percentagens de potência consumida parecidas, para cargas entre 108 e 180 erlangs, com as obtidas para EA-DPP-Dif-sleep. Contudo, para cargas de tráfego maiores, a percentagem de potência economizada diminuiu ao redor de $7 \%$. Ainda assim, a estratégia com roteamento intensivo consegue economizar mais potência.

Na Figura 6.3b são mostradas as comparações para a estratégia EA-DPP-MixS na rede USNet. Quando é usado o modo suspenso para os caminhos de proteção a potência consumida diminui entre $40 \%$ e $8 \%$. O resultado para EA-DPP-MixS-Intensivo mostra que não há melhoria em economia de potência, sendo que a partir de 156 erlangs a potência consumida é maior em comparação a EA-DPP-MixS-sleep.

Os resultados da potência consumida para a estratégia EA-DPP são ilustrados na Fi- 


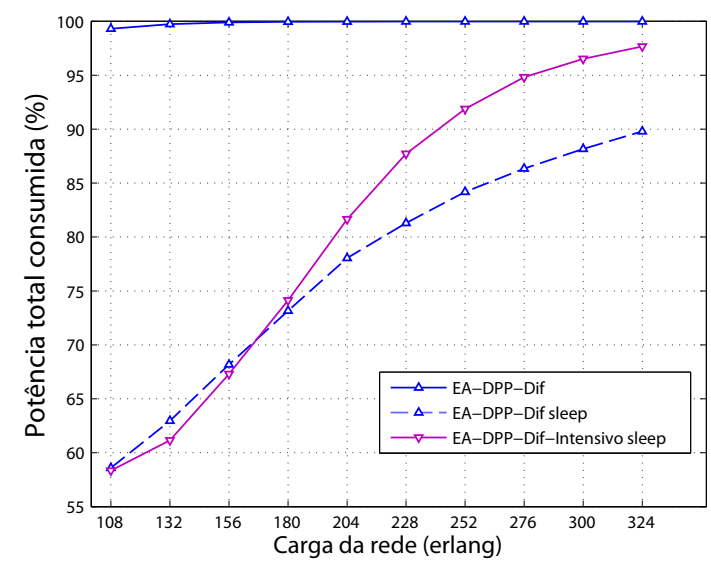

(a) Estratégia EA-DPP-Dif.

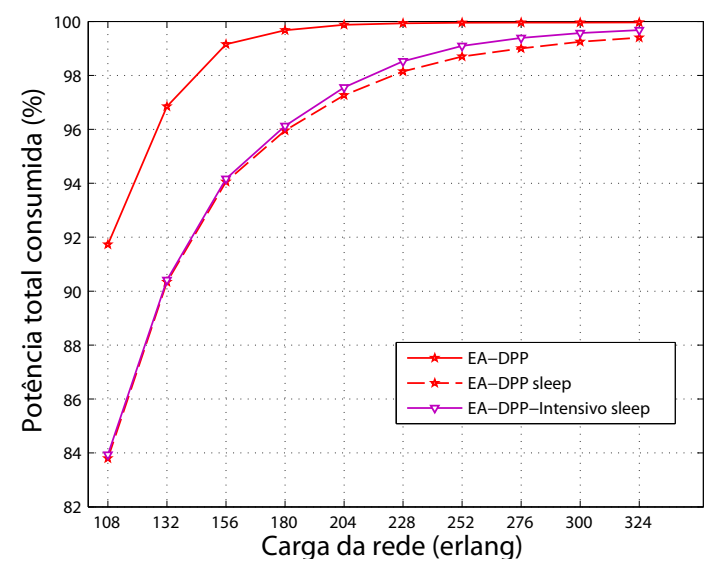

(c) Estratégia EA-DPP.

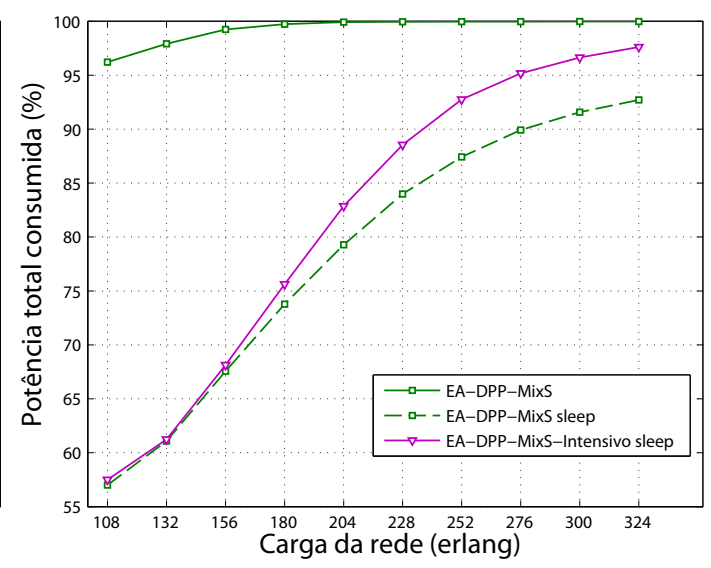

(b) Estratégia EA-DPP-MixS.

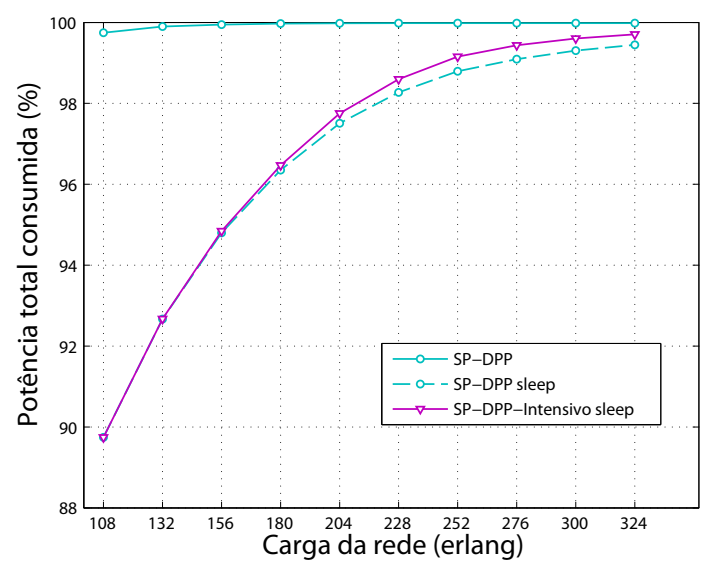

(d) Estratégia SP-DPP.

Figura 6.3.: Potência total consumida pela rede USNet versus carga de rede para às estratégias testadas. 


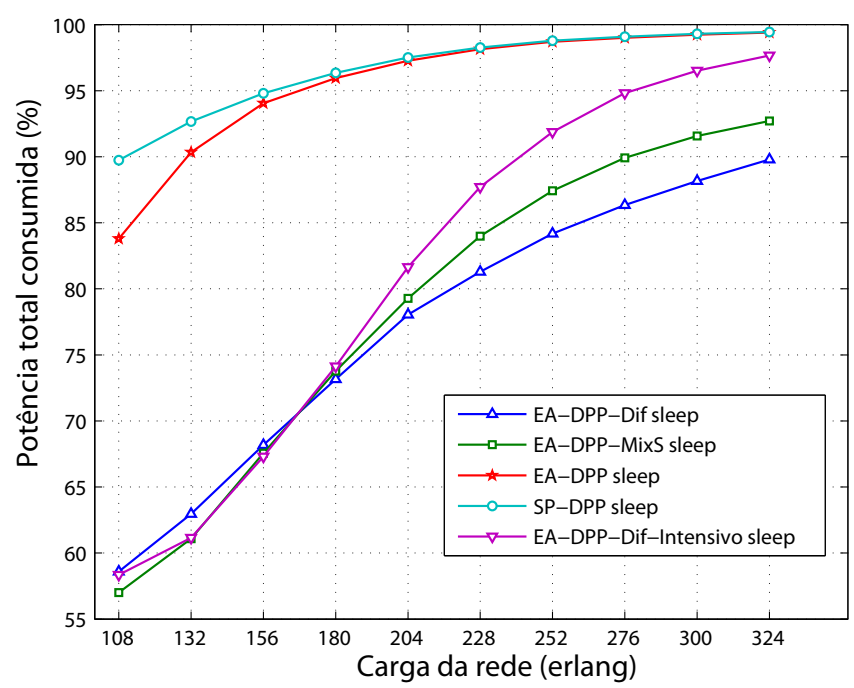

Figura 6.4.: Potência total consumida pela rede USNet usando modo suspenso versus carga de rede.

gura 6.3c. A diferença de percentagem de potência varia de $8 \%$ a 1\%. Observamos, como no caso da rede Cost239, que a potência consumida por essa estratégia sem uso de modo suspenso é menor que a potência consumida pelas outras estratégias (também sem modo suspenso). Ao usar o roteamento intensivo não há melhorias na diminuição de potência.

Para a estratégia SP-DPP os resultados são apresentados na Figura 6.3d. A diminuição de potência consumida varia de $10 \%$ a $1 \%$ e usando o roteamento intensivo não há melhoria.

Com a finalidade de comparar os resultados de percentagem de potência economizada entre as estratégias, quando é usado o modo suspenso (sleep), é apresentada a Figura 6.4. No gráfico incluímos além das quatro estratégias (EA-DPP-Dif, EA-DPP-MixS, EA-DPP e SP-DPP) o resultado da primeira estratégia usando a nossa proposta de roteamento intensivo ( EA-DPP-Dif-Intensivo). Para essa rede podemos observar que a estratégia com menor consumo de energia é a EA-DPP-Dif. As estratégias com maior porcentagem de potência são a EA-DPP e a SP-DPP. A EA-DPP-MixS, para cargas altas, consome até $2 \%$ mais potência que a EA-DPP-Dif. A proposta EA-DPP-Dif-Intensivo, para cargas baixas, ente 108 e 180 erlangs, apresenta melhor desempenho, mas a medida que a carga aumenta é menos eficiente para economizar energia. Embora, EA-DPP-Dif-Intensivo continua sendo melhor que EA-DPP e a SP-DPP.

Os resultados de potência consumida descritos a seguir correspondem à rede brasileira Ipê [78]. Para essa rede também foram testadas cargas menores de rede devido à baixa interconectividade entre os nós que ela apresenta. Na Figura 6.5a são mostrados os resultados para a estratégia EA-DPP-Dif. Observamos que para maioria das cargas a estratégia 


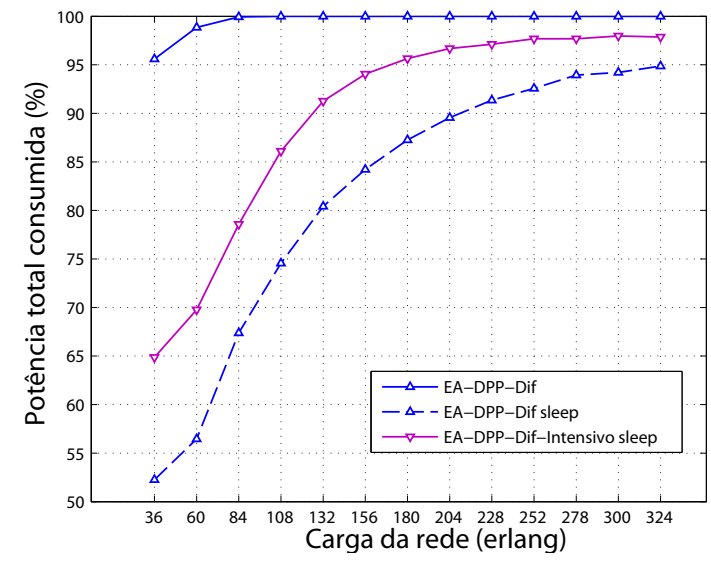

(a) Estratégia EA-DPP-Dif.

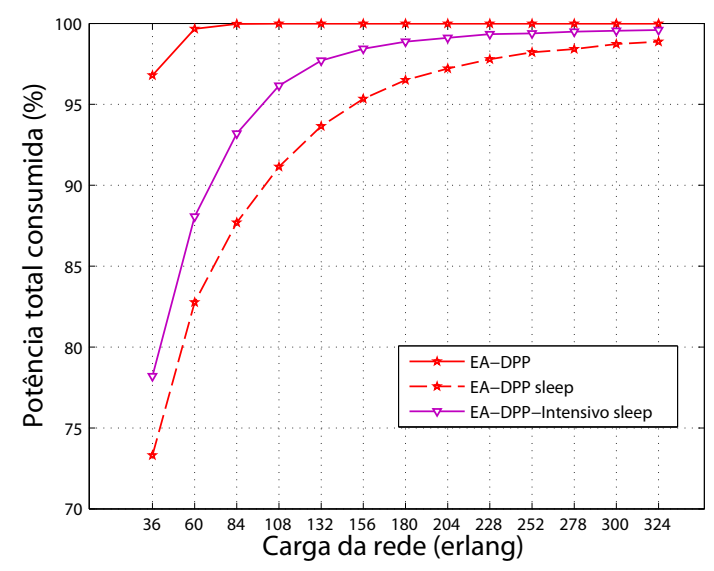

(c) Estratégia EA-DPP.

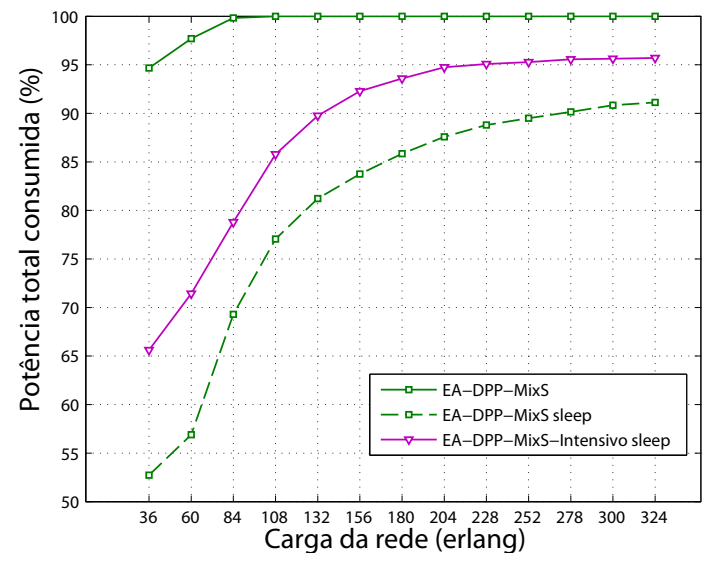

(b) Estratégia EA-DPP-MixS.

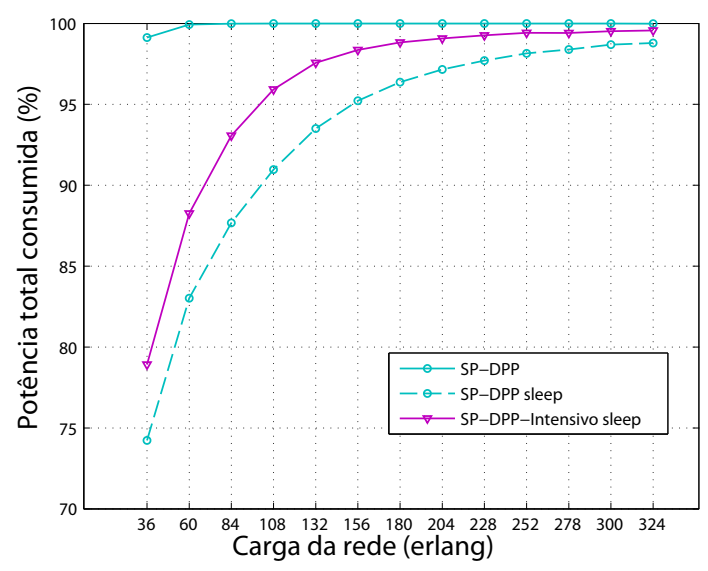

(d) Estratégia SP-DPP.

Figura 6.5.: Potência total consumida pela rede brasileira Ipê versus carga de rede para às estratégias testadas.

sem modo suspenso consome $100 \%$ da potência, em média todos os elementos estão em modo ativo. A diferença para as outras redes a nossa proposta consome mais potência que a EA-DPP-Dif-sleep. O motivo é que um dos objetivos da proposta de roteamento intensivo é diminuir a probabilidade de bloqueio, o que poderia aumentar a potência consumida. Para carga de rede mais baixas a proposta EA-DPP-Dif-Intensivo com modo suspenso consome $65 \%$ de potência enquanto que, EA-DPP-Dif-sleep $52 \%$. Ainda assim, as duas estratégias conseguem economizar energia. Para carga mais alta, 324 erlangs, a EA-DPP-Dif-sleep e a EA-DPP-Dif-Intensivo economizam $5 \%$ e $2 \%$, respetivamente, indicando que para cargas altas utilizar modo suspenso economiza energia.

Na Figura 6.5b mostramos os resultados para a estratégia EA-DPP-MixS para a rede brasileira. Vemos que quando não é usado o modo suspenso, em média, quase todos os elementos da rede estão consumindo energia (potência consumida 100\%). As estratégias 


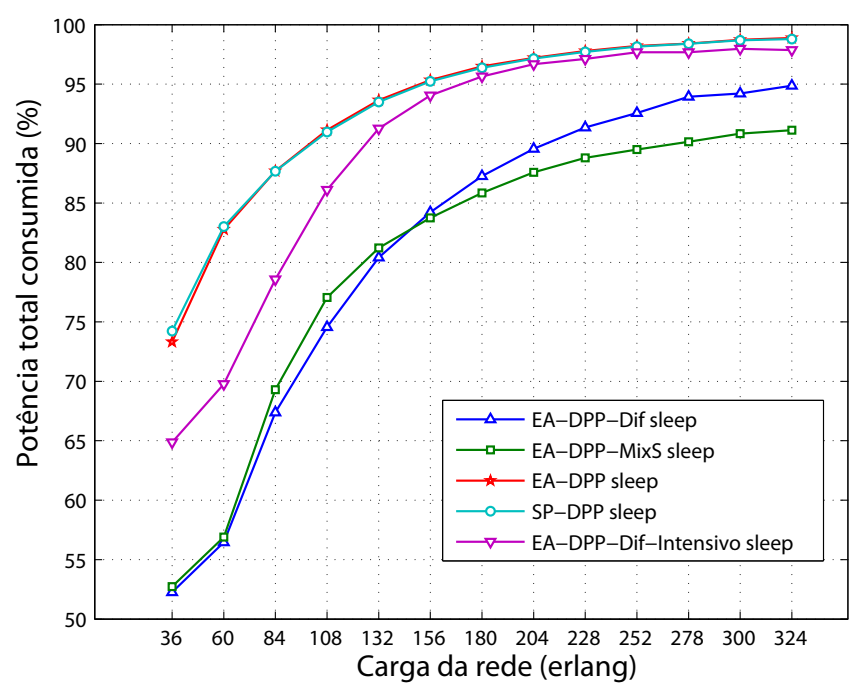

Figura 6.6.: Potência total consumida pela rede brasileira Ipê usando modo suspenso versus carga de rede.

EA-DPP-MixS-Intensivo com modo suspenso consomem entre $65 \%$ e $96 \%$ da potência, enquanto que EA-DPP-MixS-sleep consome entre $54 \%$ e 95\%. Da mesma maneira que a estratégia anterior (EA-DPP-Dif) a proposta gasta maior quantidade de energia que a estratégia de roteamento simples com modo suspenso. Mesmo assim, usando o modo suspenso consegue-se diminuir a potência consumida.

Os resultados para a estratégia EA-DPP podem ser observados na Figura 6.5c. A estratégia sem modo suspenso, da mesma forma que as estratégias anteriores, consome quase $100 \%$ da potência. Quando usamos o modo suspenso (EA-DPP-sleep) a potência economizada varia entre $22 \%$ e $1 \%$. A potência economizada com a proposta de roteamento usando modo suspenso (EA-DPP-Intensivo-sleep) é menor, variando entre 18\% e 0,5\%.

Finalmente, na Figura 6.5d é mostrada a comparação dos resultados para a estratégia SP-DPP para a rede brasileira. A potência consumida segue a mesma distribuição que nas estratégias anteriores. A SP-DPP sem modo suspenso consome $100 \%$ da potência. A proposta SP-DPP-Intensivo sleep consome mais potência que SP-DPP-sleep. A faixa de economia de energia para SP-DPP-sleep é de $25 \%$ e $1 \%$ enquanto para a SP-DPP-Intensivo sleepé de $20 \%$ e $0,5 \%$. Assim, essa estratégia utilizando o modo suspenso também diminui a potência.

Para comparar os resultados de percentagem de potência economizada entre as estratégias, usando o modo suspenso (sleep) para a rede brasileira, é apresentada a Figura 6.6. Assim, podemos observar que para esta rede as estratégias com pior desempenho em relação a economia de energia são a SP-DPP sleep e a EA-DPP-sleep. A EA-DPP-Intensivo sleep melhora a potência consumida mas não de maneira muito significativa (menos de 
5\%). Lembramos que a proposta é computacionalmente mais custosa. A diferença para as redes anteriores (Cost239 e UsNet) é que a estratégia EA-DPP-MixS-sleep é a que apresenta maior eficiência em economia de energia. Isso pode ser explicado pela baixa densidade da topologia da rede (pouca interconectividade entre os nós). Nas redes anteriores a EA-DPP-Dif-sleep exibia desempenho melhor que a EA-DPP-MixS-sleep.

\subsubsection{Probabilidade de bloqueio}

A probabilidade de bloqueio, como foi explicado na Seção \$4.2.4, é o número de conexões não atendidas ou bloqueadas em relação ao número total de conexões. A probabilidade de bloqueio é dada pela insuficiência de recursos para atender a carga de tráfego. No caso dos algoritmos implementados, uma demanda de tráfego é bloqueada quando não há comprimentos de onda disponíveis para alocar os caminhos, principal e de proteção.

Assim, a métrica foi calculada armazenando a quantidade de bloqueios por cada carga de tráfego (erlang). Depois, foi feita uma média aritmética entre as 10 repetições ou testes. Finalmente, o valor resultante foi dividido entre o número de conexões (100000) para obter a probabilidade de bloqueio.

Os resultados para as três redes serão apresentados a seguir.

Na Figura 6.7 é mostrada a probabilidade de bloqueio para a rede Cost239 em função da carga de rede entre 108 e 324 erlangs. Na figura mostramos os resultados para as estratégias de economia de energia (EA-DPP-Dif, EA-DPP-MixS, EA-DPP e SP-DPP), em conjunto à probabilidade de bloqueio para a estratégia EA-DPP-Dif utilizando a proposta de roteamento intensivo. Somente será mostrada a probabilidade de bloqueio para EA-DPP-Dif -Intensivo por ter-se observado resultados de interesse em diminuição potência consumida quando é aplicado o roteamento Intensivo para essa estratégia (Seção \$6.1.1).

Com o intuito de mostrar o comportamento da probabilidade de bloqueio para altas cargas de rede é apresentada a Figura 6.8. Foram testadas as mesmas estratégias mostradas na Figura 6.7 com cargas entre 180 e 3240 erlangs. Podemos observar que a partir de 468 erlangs a probabilidade de bloqueio é igual para todas as estratégias. Isto ocorre porque os recursos da rede são insuficientes para atender essas cargas de tráfego e utilizar qualquer uma das estratégias não faz diferença pois a carga é muito alta para os recursos disponíveis.

A probabilidade de bloqueio para a rede UsNet [77], em função da carga de rede, é apresentada nas Figuras 6.9 e 6.10. São mostrados os resultados para as estratégias EA-DPP-Dif, EA-DPP-MixS, EA-DPP, SP-DPP e EA-DPP-Dif-Intensivo. Na Figura 6.9 são mostrados os resultados de probabilidade de bloqueio para cargas de rede entre 108 e 324 erlangs. Como pode-se observar a estratégia que apresenta maior probabilidade de bloqueio é a EA-DPP-Dif e a estratégia com menor bloqueio é a EA-DPP-Dif-Intensivo (salvo 


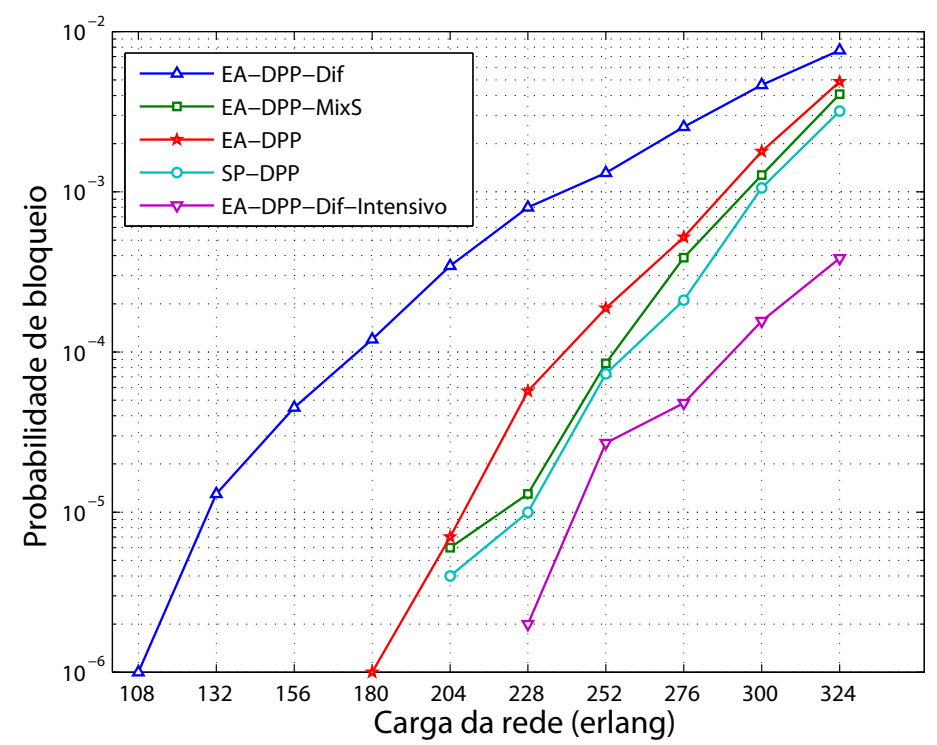

Figura 6.7.: Probabilidade de bloqueio vs. carga da rede para Cost239.

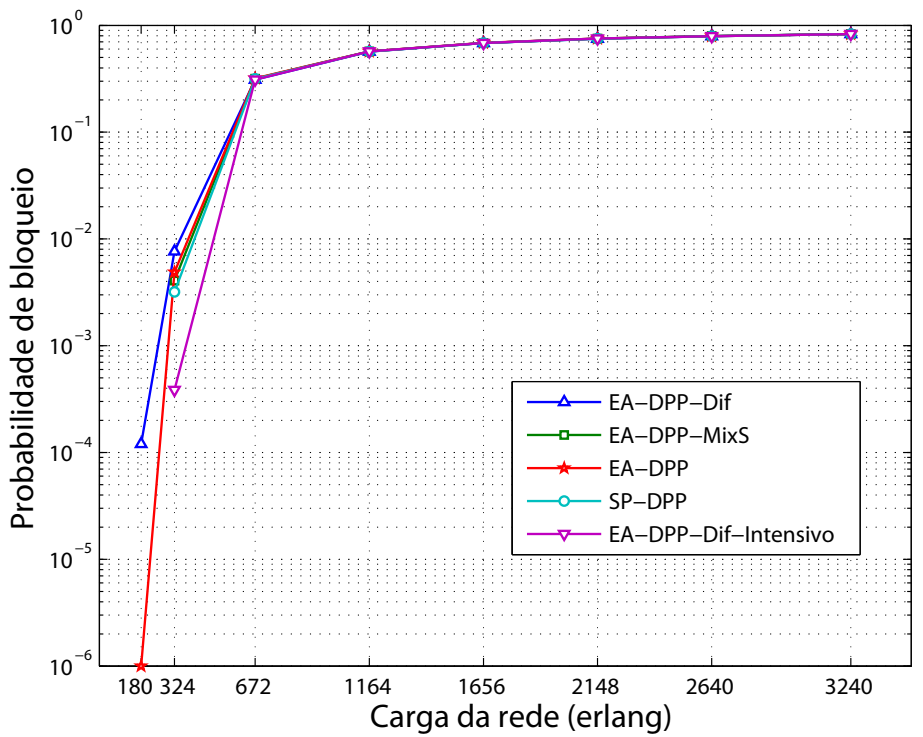

Figura 6.8.: Probabilidade de bloqueio (saturação) vs. carga da rede para Cost239. 


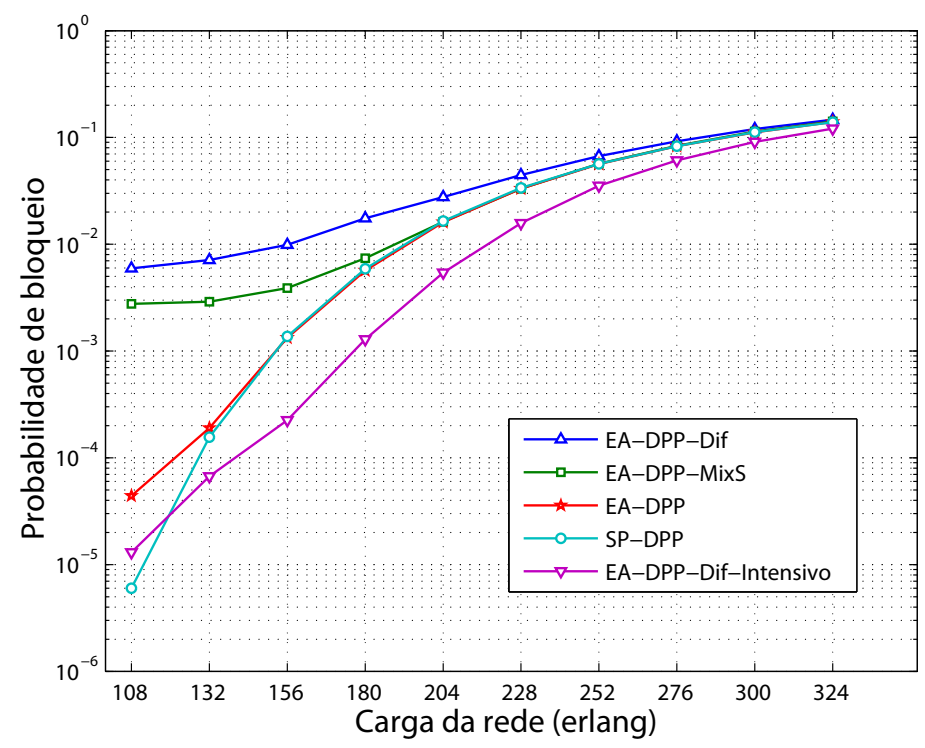

Figura 6.9.: Probabilidade de bloqueio vs. carga da rede para USNet.

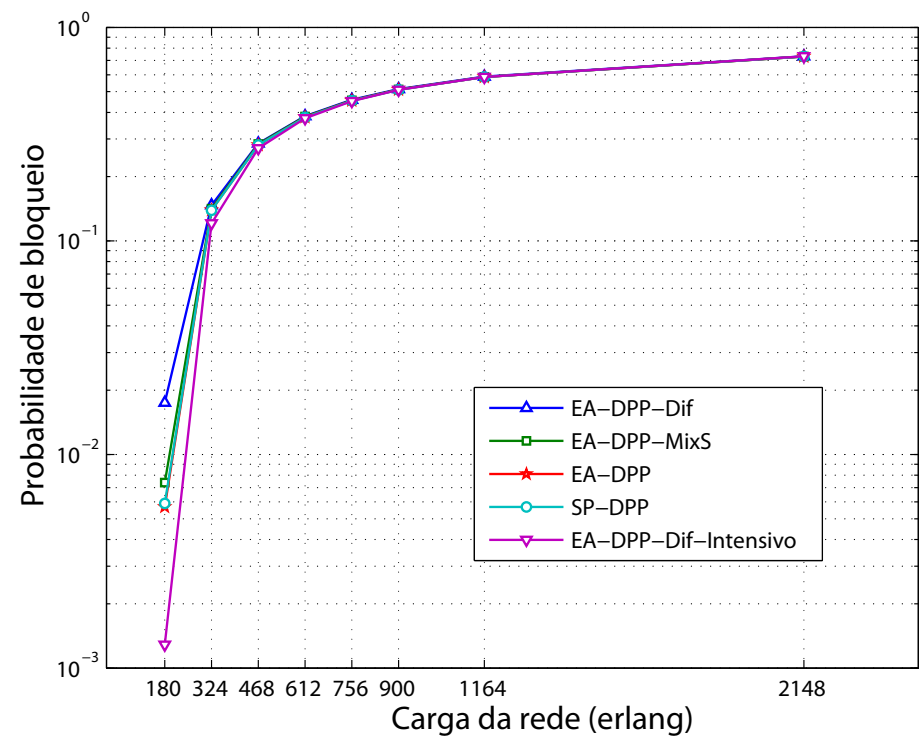

Figura 6.10.: Probabilidade de bloqueio (saturação) vs. carga da rede para USNet. 


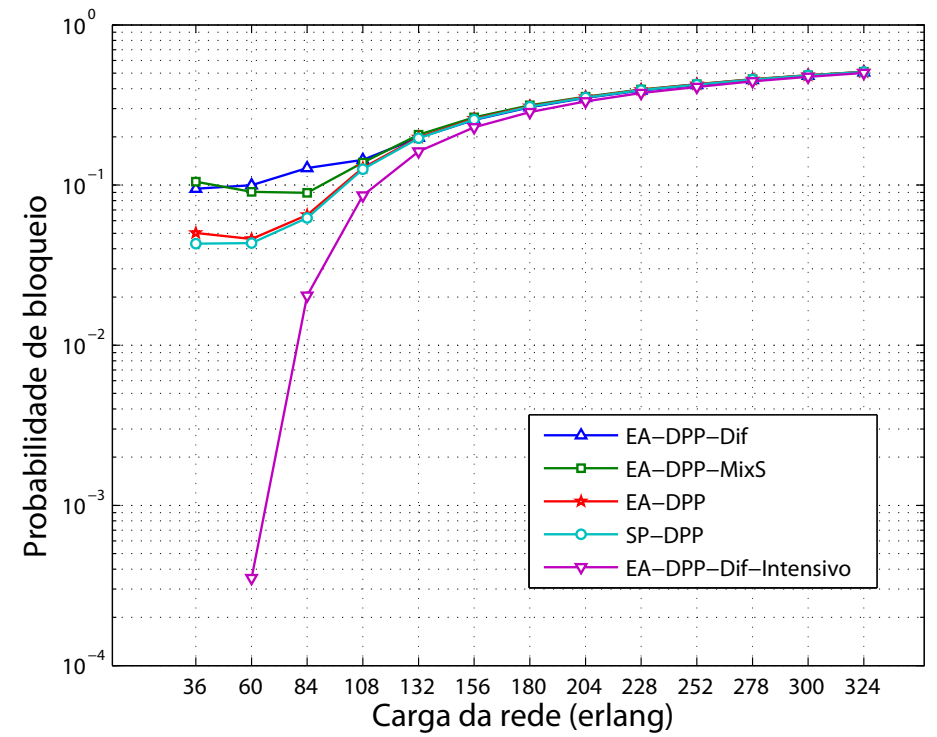

Figura 6.11.: Probabilidade de bloqueio vs. carga da rede para a rede brasileira Ipê.

para a menor das carga avaliadas, 108 erlangs). De forma geral, as estratégias podem ser ordenadas de menor a maior probabilidade de bloqueio como segue: EA-DPP-DifIntensivo, SP-DPP, EA-DPP, EA-DPP-MixS e EA-DPP-Dif. Porém, observamos que com cargas de rede médias, entre 180 é 252, três das estratégias apresentam quase a mesma probabilidade de bloqueio. A diferença com a rede Cost239, essas curvas convergem rapidamente para a rede UsNet devido a que a ela é mais esparsa que a rede Cost239. Além disso, note-se que com cargas altas a probabilidade de bloqueio para todas as estratégias, tende a convergir. Isso acontece porque os recursos da rede são insuficientes, para atender as demandas, seja qual for a estratégia.

Na Figura 6.10 mostra-se a probabilidade de bloqueio para cargas maiores, até 1164 erlangs. O intuito é encontrar o ponto de saturação da rede. Como pode-se observar, a partir de 612 erlangs as 5 curvas das estratégias avaliadas sobrepõem-se. Mas, a diferença entre probabilidade de bloqueio para as estratégias é mínima a partir de 324 erlangs.

A probabilidade de bloqueio para a rede brasileira Ipê é mostrada na Figura 6.11. As cargas de rede avaliadas nessa simulação variam de 36 a 324 erlangs. Na figura são comparadas as estratégias EA-DPP-Dif, EA-DPP-MixS, EA-DPP, SP-DPP e EA-DPP-Dif-Intensivo. Observamos que as estratégias apresentam comportamentos similares em termos de probabilidade de bloqueio para todas as cargas. A proposta EA-DPP-Dif-Intensivo é a única que consegue diminuir a probabilidade de bloqueio para cargas baixas (desde 36 até 204). Porém, como foi observado na Figura 6.6 a EA-DPP-Dif-Intensivo não é vantajosa para diminuir a potência consumida, além de ser computacionalmente mais custosa.

Na Figura 6.12 mostra-se a probabilidade de bloqueio para cargas maiores, até 1656 


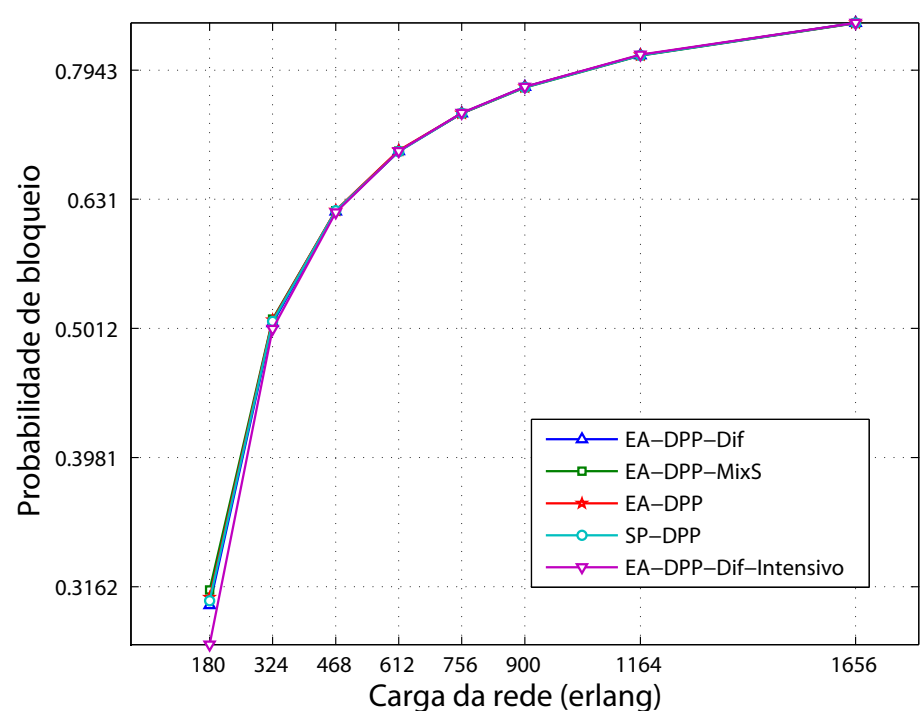

Figura 6.12.: Probabilidade de bloqueio (saturação) vs. carga da rede para a rede brasileira Ipê.

erlangs. Vemos que a probabilidade de bloqueio para todas as estratégias é igual a partir de 324 erlangs. Somente há uma pequena diferença para EA-DPP-Dif-Intensivo que apresenta menor probabilidade de bloqueio em cargas baixas. A topologia da rede é responsável pela saturação com altas cargas, devido à falta de recursos para atender as demandas.

\subsubsection{Tipo de utilização do enlace}

O tipo de utilização do enlace refere-se aos caminhos que formam parte de cada um dos enlaces em determinado período de tempo, sendo que os tipos de caminhos a serem considerados são caminhos principais ou caminhos de proteção. Serão mostrados gráficos com o número de enlaces que têm alocados caminhos principais $W$ (isto inclui enlaces que são parte somente de caminhos principais $W B^{\prime}$ e também enlaces mistos $W \& B$ ) versus enlaces que são parte somente de caminhos de proteção $B$. Esses enlaces $\left(B W^{\prime}\right)$ são os que podem ser postos em modo suspenso. O intuito da métrica é comparar como são utilizados os enlaces em função do tipo de caminho ao qual o enlace pertence. Essa métrica está diretamente relacionada com a potência consumida pela rede, pois quanto a maior quantidade de enlaces fazendo parte de caminhos somente de proteção, maior será a quantidade de energia economizada.

O número de caminhos (principais ou de proteção) por enlace é contabilizado em cada alocação ou desalocação de evento. Em seguida, esse número é dividido entre o número de enlaces e eventos para assim ter um número médio de tipo de utilização de enlace. Esse número médio é contabilizado por cada carga de tráfego avaliada. Além disso, é 


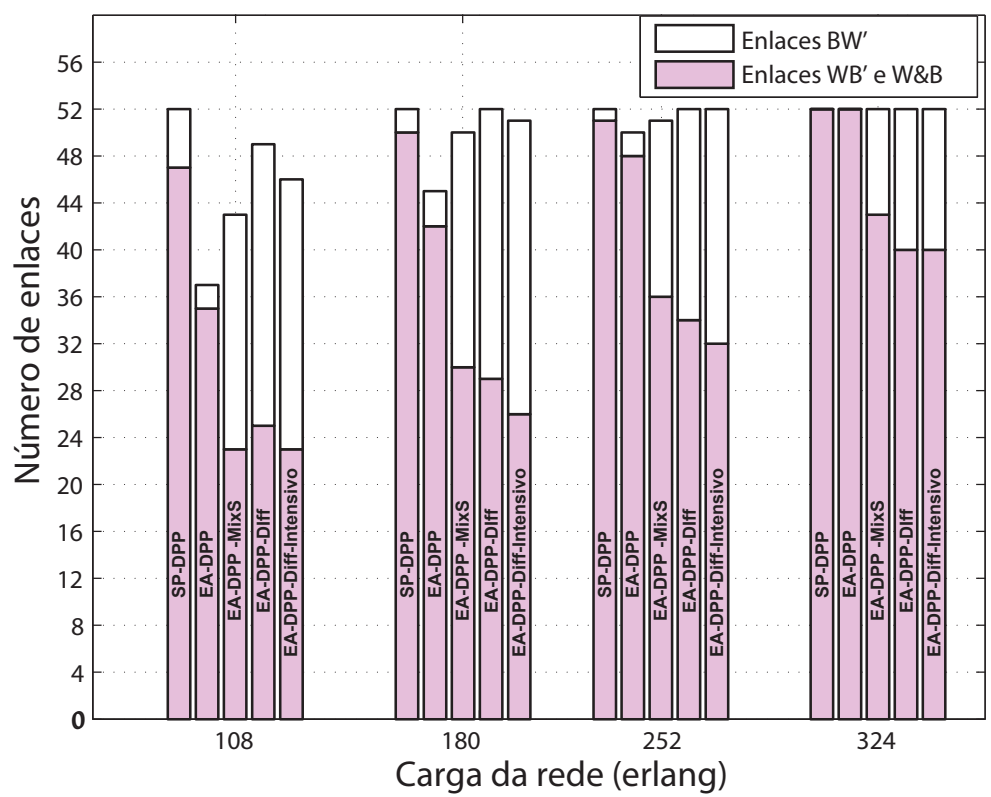

Figura 6.13.: Número de enlaces usados por $W_{\text {paths }}$ ou $W \& B$ e enlaces somente por $B_{\text {paths }}$ para a rede Cost239.

feita uma média entre os resultados de cada uma das repetições ou testes. A métrica é feita para cada uma das estratégias avaliadas. Cada barra no gráfico representa uma das estratégias seguindo a ordem: SP-DPP, EA-DPP, EA-DPP-MixS, EA-DPP-Dif, e a proposta de roteamento intensivo para a estratégia EA-DPP-Dif-Intensivo.

Na Figura 6.13 é mostrado o tipo de utilização de enlace para a rede Cost239 versus carga de rede. Os enlaces que são parte de caminhos principais são mostrados em roxo e os que são parte somente de caminhos de proteção, em branco. A quantidade total de enlaces para essa rede é de 52. A barra não chegar a 52 significa que, em média, há enlaces não utilizados. O número de enlaces a serem postos em modo suspenso é a soma dos enlaces somente usados como proteção e os que não estão sendo usados. O mesmo pode ser expressado como a diferença do total de enlaces e os enlaces que são parte de caminhos principais (parte roxa da barra). Pode-se observar que enquanto a carga de rede aumenta a quantidade de enlaces livres diminui. No caso da primeira carga avaliada, 108 erlangs, observamos que a estratégia com menor quantidade de enlaces usados é a EA-DPP representada pela segunda barra (ver Figura 6.13). Sem o modo suspenso a estratégia EA-DPP apresenta a menor quantidade de potência consumida. Isso é explicado porque a EA-DPP é uma estratégia que prioriza rotear as demandas por enlaces que já estejam sendo usados. Além disso, a estratégia não distingue enlaces principais e de proteção, permitido enlaces com caminhos misturados. Isso reflete na pouca quantidade de enlaces somente de proteção (3 enlaces), comparada com as outras estratégias. Ob- 
servamos o mesmo comportamento da estratégia EA-DPP para as cargas de rede de $180 \mathrm{e}$ 252 erlangs. Quer dizer, menor quantidade total de enlaces em uso, mas também menor quantidade de enlaces usados somente como parte de caminhos de proteção, que podem ser postos em modo suspenso. Já no caso de 324 erlangs observamos que para a EA-DPP a totalidade de enlaces são usados como parte de caminhos principais.

A estratégia SP-DPP, representada pela primeira barra na Figura 6.13 apresenta a totalidade dos enlaces em uso, para todas as cargas avaliadas. Note-se que enquanto aumenta a carga de rede o número de enlaces somente de proteção diminui (parte branca da barra). Lembremos que SP-DPP é uma estratégia baseada em encontrar o caminho mais curto. Ela não considera a economia de energia para fazer o roteamento das demandas. É por isso que para cargas de tráfego baixas, em média, todos os enlaces estão em uso. Há aproximadamente, 5, 2 e 1 enlaces (parte branca da barra) que podem ser postos em modo suspenso, para 108, 180 e 252 erlangs, respectivamente.

Observamos também na Figura 6.13 que as estratégias EA-DPP-MixS, EA-DPP-Dif e EA-DPP-Dif-Intensivo apresentam um comportamento similar com relação à quantidade de enlaces que são parte de caminhos principais e enlaces que são parte tanto de caminhos principais como de proteção (enlaces misturados). Significa que para cada carga de rede a quantidade de enlaces na parte roxa da barra é similar entre as três estratégias. Para 108 erlangs, considerando modo suspenso, as estratégias com menor consumo de potência são EA-DPP-MixS e EA-DPP-Dif-Intensivo. A quantidade de enlaces que são parte de caminhos principais ( $W B^{\prime}$ e $W \& B$ ) é a mesma para ambas as estratégias, 23 enlaces. São esses os enlaces que permanecem em estado ativo, consumindo energia.

Como se pode observar na Figura 6.7 para as duas estratégias todas as demandas foram atendidas. Como a carga de tráfego não é alta para a rede testada, a estratégia EA-DPP-MixS (que não tem como objetivo principal separar a atribuição de enlaces segundo o tipo de caminho) é suficientemente boa em termos de economia de energia, além de ser menos custosa em termos de operações computacionais.

Já no caso das cargas de rede maiores, a quantidade de enlaces atribuídos como parte de caminhos principais seguem a distribuição esperada. A estratégia com menor quantidade de enlaces que são parte de caminhos principais é a EA-DPP-Dif-Intensivo. O que quer dizer que essa estratégia é a que apresenta menor percentagem de potência consumida usando o modo suspenso. A estratégia EA-DPP-MixS, por não se importar pela mistura de tipos de caminhos, tem menor quantidade de enlaces usados. EA-DPP-Dif para esta rede é a segunda estratégia com menor quantidade de enlaces como parte de caminhos principais e, no caso da maior das cargas analisadas, empata com a EA-DPP-Dif-Intensivo, porque com altas cargas os recursos da rede não são suficientes e a busca exaustiva tornase desnecessária.

Os resultados para o tipo de utilização de enlaces para a rede USNet [77] são apre- 


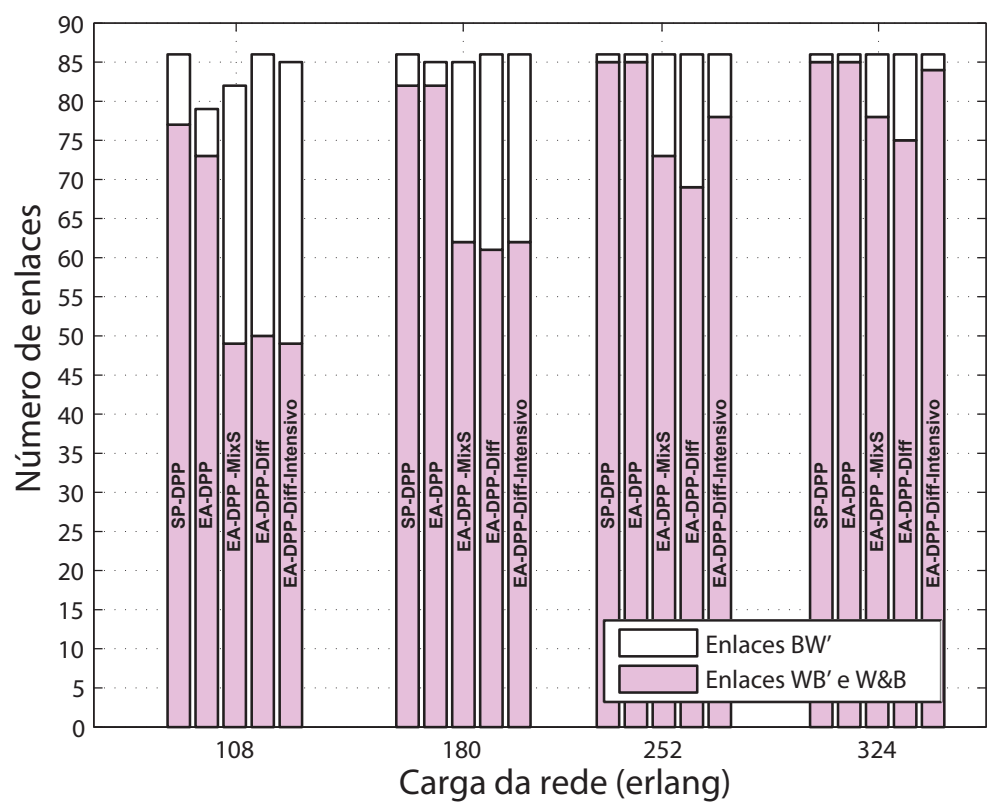

Figura 6.14.: Número de enlaces usados por $W_{\text {paths }}$ ou $W \& B$ e enlaces somente por $B_{\text {paths }}$ para a rede USNet.

sentados na Figura 6.14. A ordem das estratégias, representadas no gráfico por barras é: SP-DPP, EA-DPP, EA-DPP-MixS, EA-DPP-Dif e EA-DPP-Dif-Intensivo. Cada grupo de cinco barras representa uma carga de rede avaliada (108, 180, 252 e 324). A parte branca da barra representa os enlaces que fazem parte somente de caminhos de proteção, $B W^{\prime}$, e são eles que podem ser postos em modo suspenso. E a parte roxa da barra representa os enlaces que são parte de caminhos principais ( $W B^{\prime}$ e $W \& B$ ), isto, é enlaces em estado ativo. Podemos observar que a estratégia SP-DPP apresenta o maior número de enlaces em estado ativo para todos os valores de carga. A EA-DPP mostra um comportamento similar à estratégia anterior, exceto na carga de rede mais baixa onde há um menor número de enlaces, tanto em estado ativo como em modo suspenso. As outra três estratégias (EA-DPP-MixS, EA-DPP-Dif e EA-DPP-Dif-Intensivo) são bem similares quando submetidas a cargas baixas. No entanto, para cargas altas a EA-DPP-Dif-Intensivo apresenta maior quantidade de enlaces consumindo energia. A EA-DPP-Dif é a estratégia com melhor desempenho em relação a economia de energia.

Na Figura 6.15 pode-se observar a utilização dos enlaces para a rede brasileira Ipê. Da mesma maneira que nas redes anteriores a ordem das estratégias é SP-DPP, EA-DPP, EA-DPP-MixS, EA-DPP-Dif e EA-DPP-Dif-Intensivo. Assim, a EA-DPP-Dif apresenta o melhor desempenho para economizar energia, pois o número de enlaces que são parte de caminhos principais (parte roxa da barra) é menor. Também observamos que a 


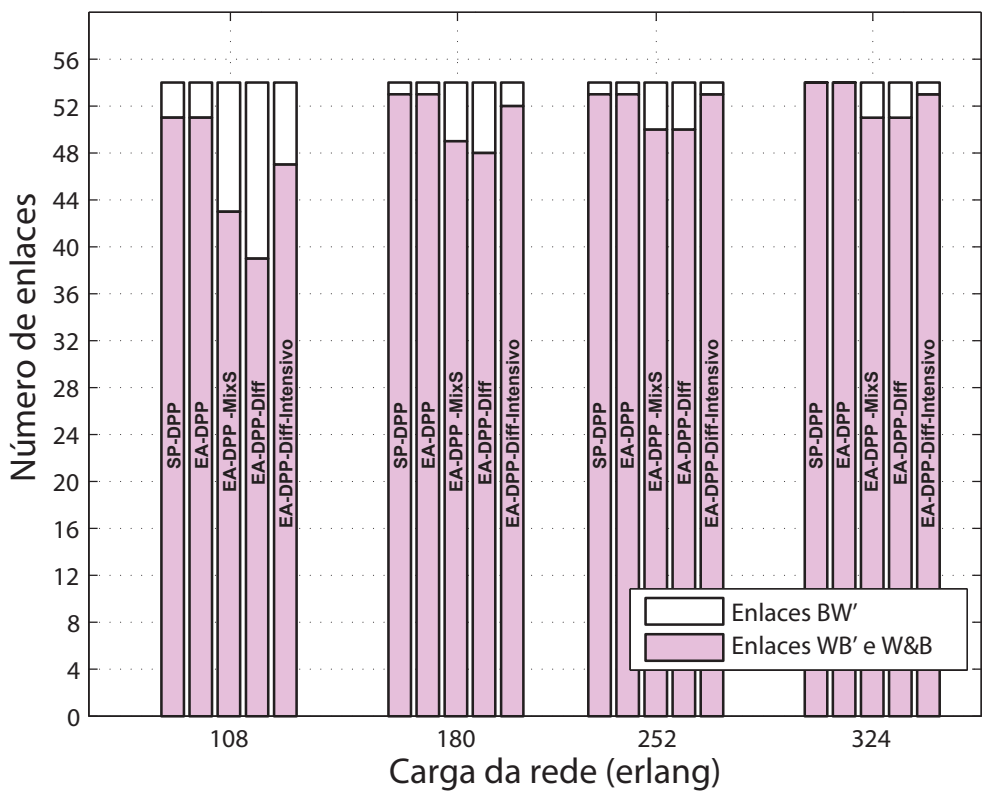

Figura 6.15.: Número de enlaces usados por $W_{\text {paths }}$ ou $W \& B$ e enlaces somente por $B_{\text {paths }}$ para a rede brasileira Ipê.

EA-DPP-MixS consegue agrupar efetivamente caminhos de proteção (barra branca). Para cargas altas de rede o comportante é similar à EA-DPP-Dif. A EA-DPP-Dif-Intensivo não é tão efetiva quanto essas duas estratégias, mas a proposta, EA-DPP-Dif-Intensivo, consegue economizar mais energia que SP-DPP e EA-DPP. É importante notar que para todas as estratégias e todos os valores de carga a quantidade total de enlaces usados sempre é 54, pois quando não é usado o modo suspenso a totalidade dos enlaces estariam em estado ativo.

6.1.4. Número médio de caminhos de proteção por enlace em modo suspenso

O número médio de caminhos de proteção por enlace em modo suspenso contabiliza quantos caminhos de proteção são parte de cada um dos enlaces que podem ser postos em modo suspenso na rede. Essa conta é feita cada vez que uma demanda é alocada ou desalocada e avaliados quais enlaces serão postos em modo suspenso. Em seguida, é feita a conta do número de caminhos de proteção por cada um desses enlaces suspensos e depois a média entre todos os enlaces suspensos. Finalmente, é feita uma média da quantidade de caminhos por enlaces suspensos ao longo da simulação. Essa métrica visa mostrar a eficiência das estratégias em relação à quantidade de caminhos de proteção que consegue agrupar nos enlaces a serem postos em modo suspenso. A seguir serão mostrados os gráficos comparando as estratégias SP-DPP, EA-DPP, EA-DPP-MixS, EA-DPP-Dif e EA-DPP-Dif-Intensivo para cada umas das redes. 


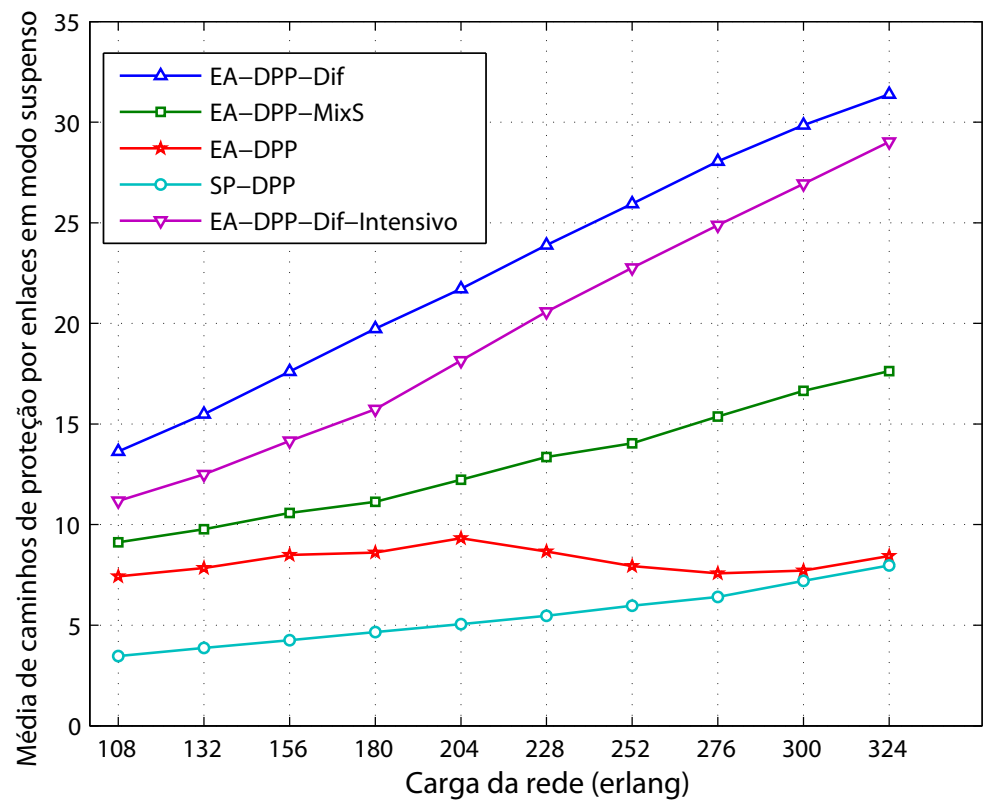

Figura 6.16.: Média de caminhos de proteção por enlace em modo suspenso na rede Cost239.

O número médio de caminhos de proteção por enlace em modo suspenso para a rede Cost239 é mostrado na Figura 6.16. Como foi explicado na Seção \$5.7, as estratégias SP-DPP e a EA-DPP não têm a finalidade de separar caminhos principais de caminhos de proteção. Observamos que essas estratégias apresentam o menor número de caminhos de proteção por enlace em modo suspenso. Segue em eficácia de agrupação de caminhos a EA-DPP-MixS que atribui os enlaces com base na diferenciação, mas sem ser essa sua prioridade. A estratégia EA-DPP-Dif seguida da EA-DPP-Dif-Intensivo são as que conseguem agrupar maior quantidade de caminhos de proteção. Isso é esperado, pois essas estratégias visam separar a alocação de caminhos principais e de proteção por enlaces diferentes.

O resultado para o número médio de caminhos de proteção por enlace em modo suspenso na rede UsNet é mostrado na Figura 6.17. Da mesma maneira que com a rede anterior (Cost239), os resultados seguem a ordem esperada. Além disso, podemos observar que SP-DPP e EA-DPP apresentam resultados muito similares para todas as cargas de rede.

Para a rede brasileira Ipê o número médio de caminhos de proteção por enlace em modo suspenso para a rede é mostrado na Figura 6.18. De maneira similar, observamos que a estratégia EA-DPP-Dif junto com EA-DPP-Dif-Intensivo são as que conseguem agrupar maior quantidade de caminhos de proteção por enlace. A EA-DPP-MixS consegue agrupar esses caminhos com menor eficácia que as estratégias anteriores, mas é melhor 


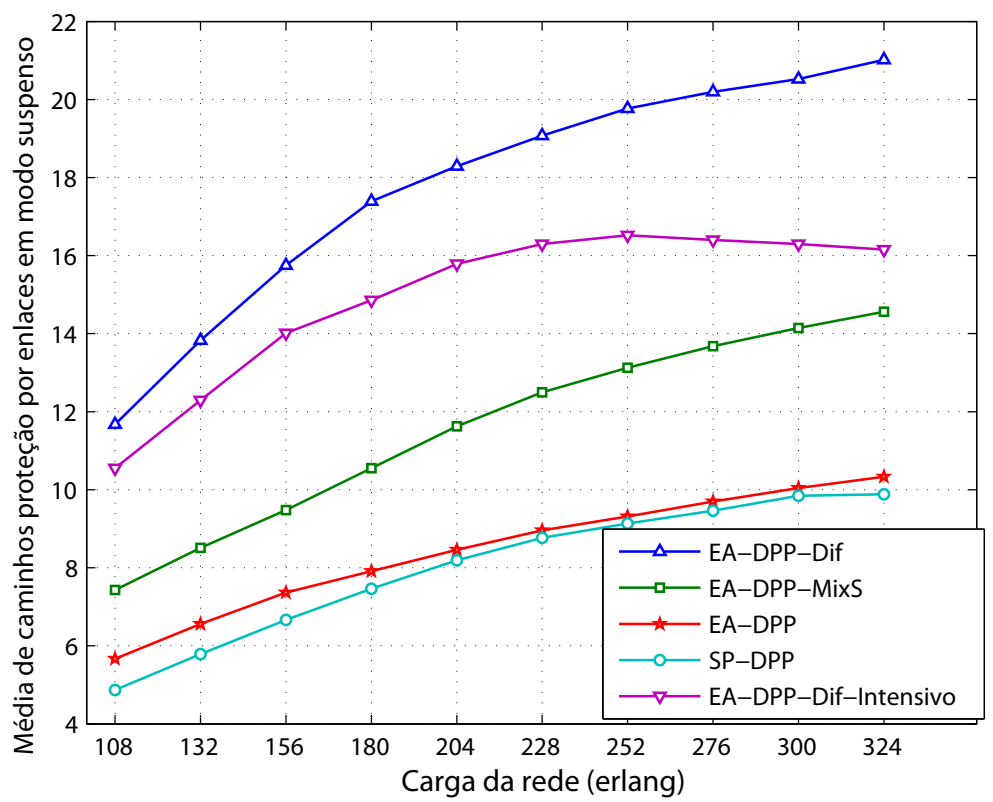

Figura 6.17.: Média de caminhos de proteção por enlace em modo suspenso na rede UsNet.

que a SP-DPP e a EA-DPP.

6.1.5. Número de comprimentos de onda por tipo de caminho

A métrica mostra o número de comprimentos de onda usadas pelos caminhos principais ou pelos de proteção. Em cada evento é contabilizada a quantidade de comprimentos de ondas usadas nos enlaces que são parte de caminhos principais ou parte de caminhos de proteção. A métrica é obtida pela divisão da soma total de comprimentos de ondas pelo número de eventos. O intuito da métrica é comparar a quantidade de comprimentos de onda usadas pelas distintas estratégias segundo o tipo de caminho. Nos gráficos são comparadas as estratégias SP-DPP, EA-DPP, EA-DPP-MixS, EA-DPP-Dif e EA-DPP-Dif-Intensivo.

O número de comprimentos de onda por caminhos principais para a rede Cost239 é mostrado na Figura 6.19. Vemos que a maior quantidade de comprimentos de onda corresponde à estratégia EA-DPP-Dif, o que poderia indicar que as rotas escolhidas por essa estratégia são as mais longas. A SP-DPP apresenta a menor quantidade de comprimentos de onda ou as rotas mais curtas, como esperado.

Na Figura 6.20 é mostrado o número de comprimentos de onda por caminhos de proteção para a rede Cost239. Novamente, EA-DPP-Dif é a estratégia que apresenta o maior número de comprimentos de onda. A EA-DPP-MixS é a que tem as rotas mais curtas. Foi 


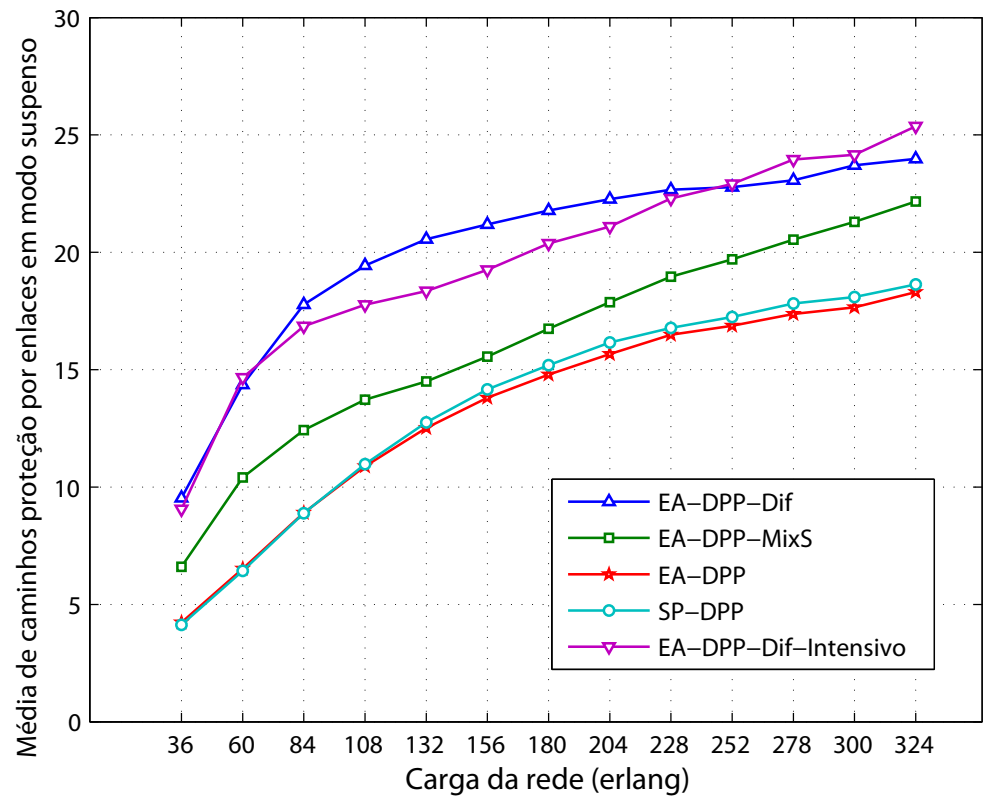

Figura 6.18.: Média de caminhos de proteção por enlace em modo suspenso na rede brasileira Ipê

observado que, para todas as estratégias, o número final atingido de comprimentos de onda é maior para os caminhos de proteção que para os principais. O que significaria que as rotas atribuídas para os caminhos de proteção são, em média, mais compridos.

O número de comprimentos de onda por caminhos principais para a rede UsNet é mostrado na Figura 6.21. De maneira similar ao gráfico anterior, a SP-DPP e a EA-DPP são as estratégias com menor número de comprimentos de onda usados pelos caminhos principais. Para cargas baixas e medias, a EA-DPP-Dif é a estratégia com as rotas mais longas. Para cargas altas, a EA-DPP-Dif-Intensivo é a que consegue o maior número de comprimentos de ondas.

Na Figura 6.22 é mostrado o número de comprimentos de onda por caminhos de proteção para a rede UsNet. O comportamento dos resultados segue o mesmo padrão que para a rede europeia, sendo que a EA-DPP-Dif é a estratégia com maior número de comprimentos de ondas por caminho de proteção e a EA-DPP-MixS a que utiliza o menor número. Assim mesmo, as rotas para os caminhos de proteção são mais longas que para os caminhos principais, para todas as estratégias e cargas.

Para a rede brasileira Ipê, os resultados de número de comprimentos de onda por caminhos principais são mostrados na Figura 6.23. Podemos observar que para cargas baixas de rede (36-108 erlangs), o comportamento das estratégias é similar ao apresentado pelas redes anteriores. Para cargas altas, diferentemente dos resultados anteriores, a EA-DPP-MixS é a que apresenta maior número de comprimentos de onda, e EA-DPP-Dif 


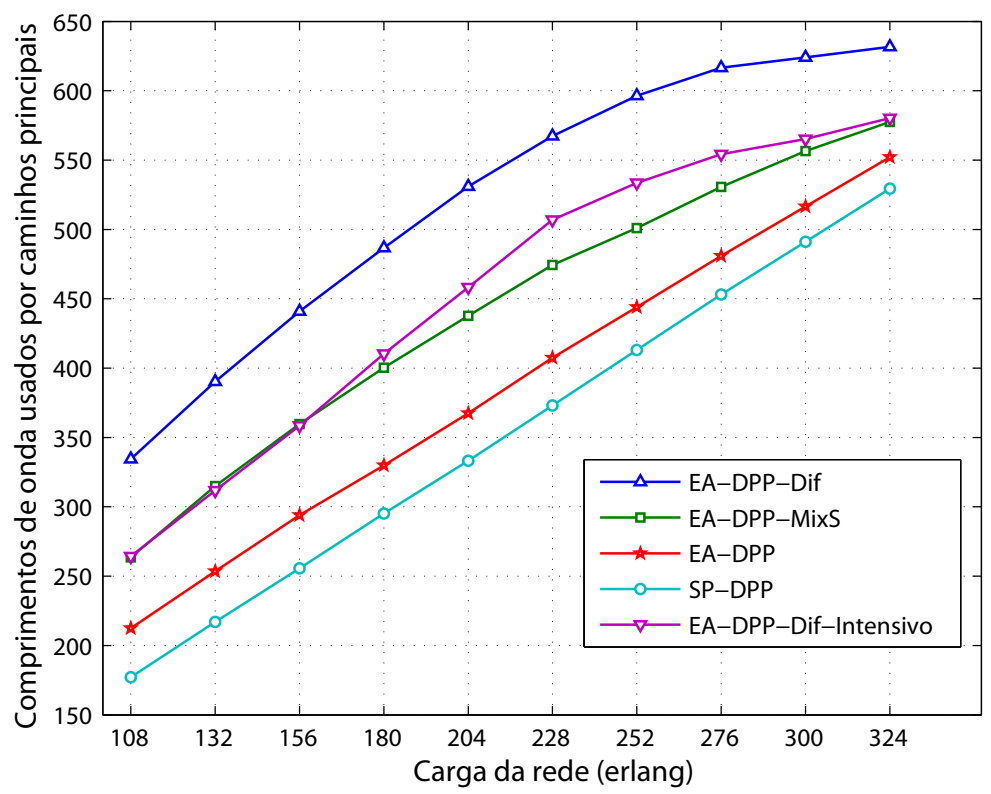

Figura 6.19.: Comprimentos de onda por caminhos principais para a rede Cost239

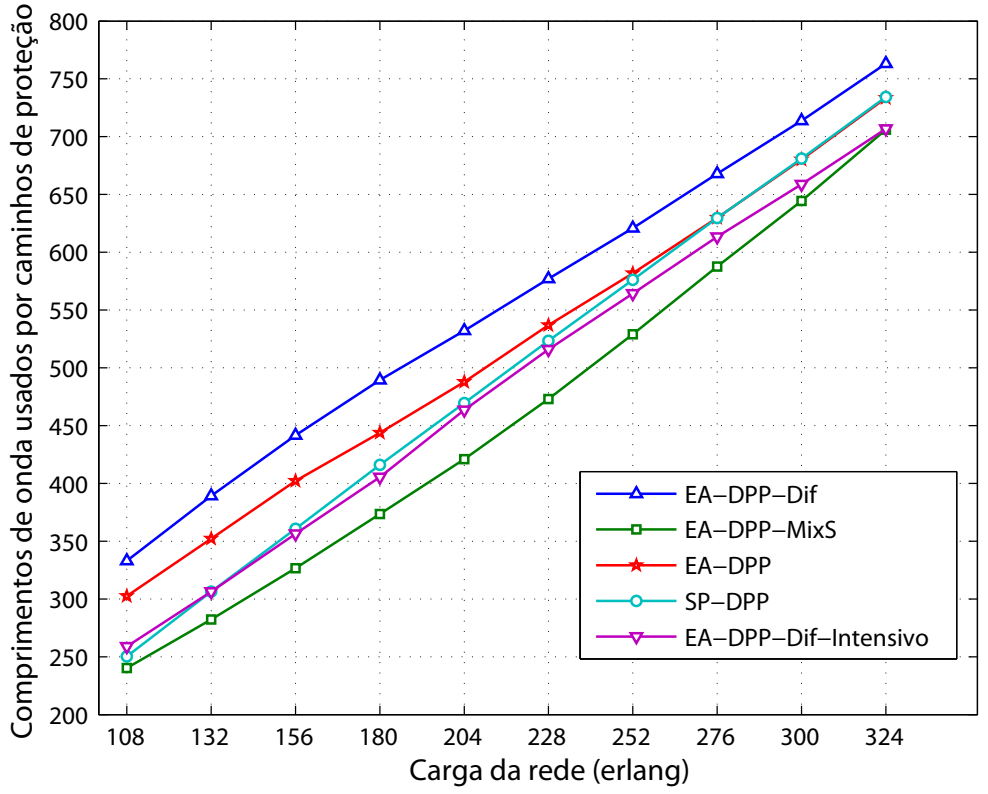

Figura 6.20.: Comprimentos de onda por caminhos de proteção para a rede Cost239 


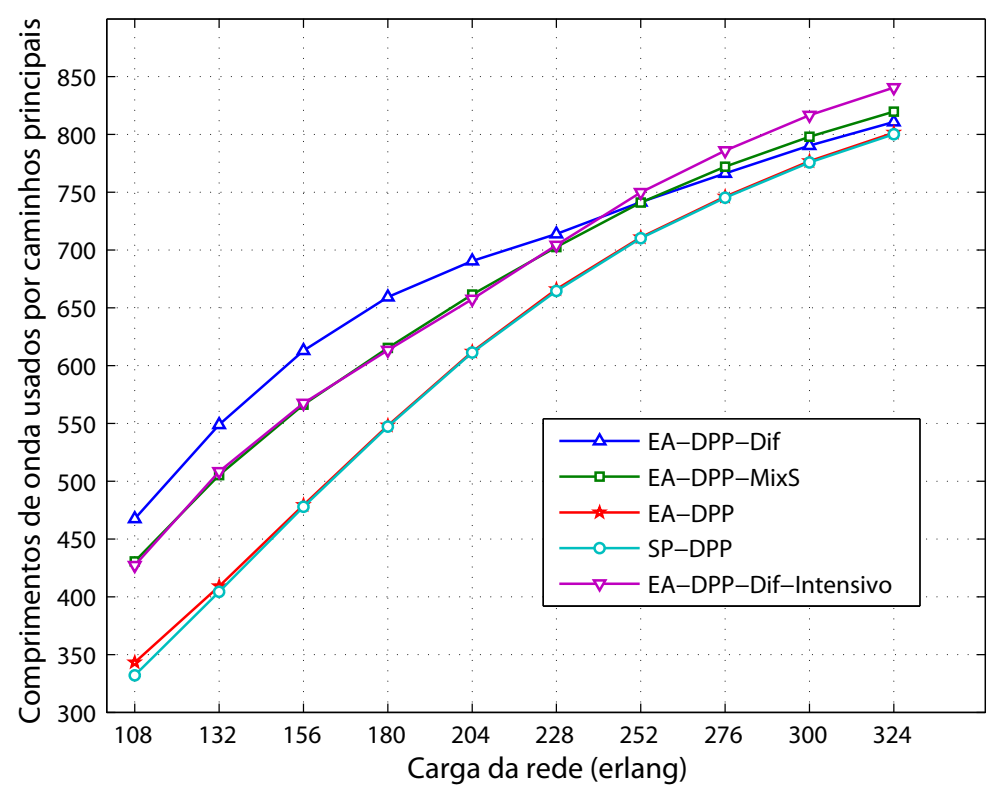

Figura 6.21.: Comprimentos de onda por caminhos principais para a rede UsNet

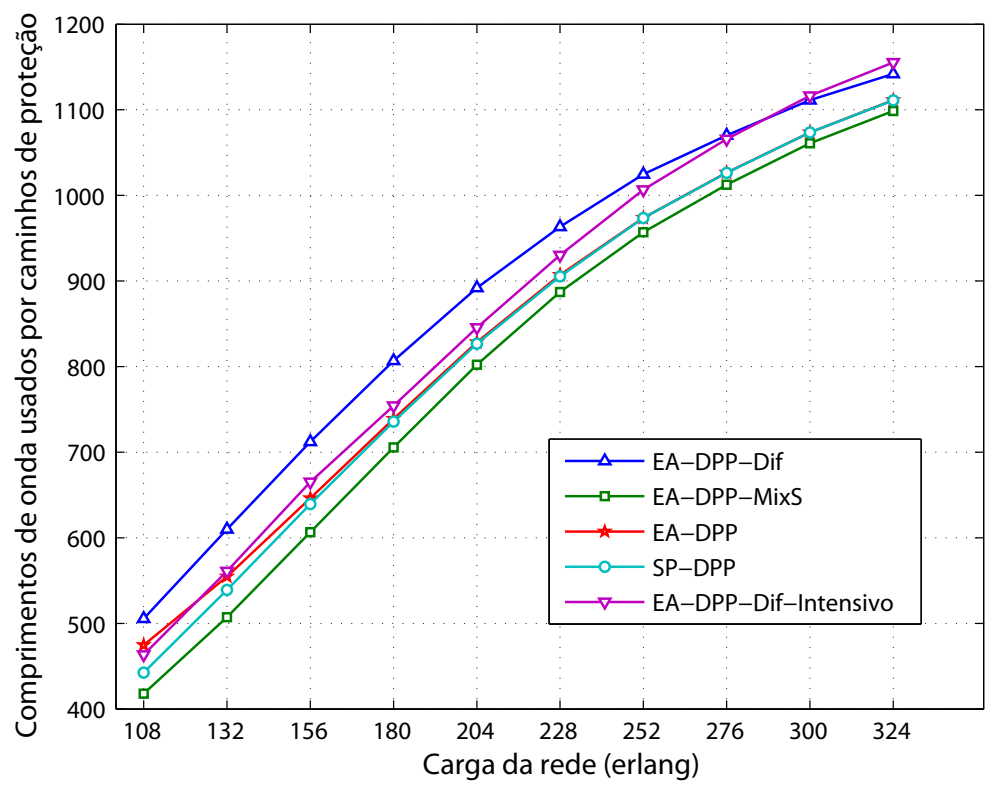

Figura 6.22.: Comprimentos de onda por caminhos de proteção para a rede UsNet 


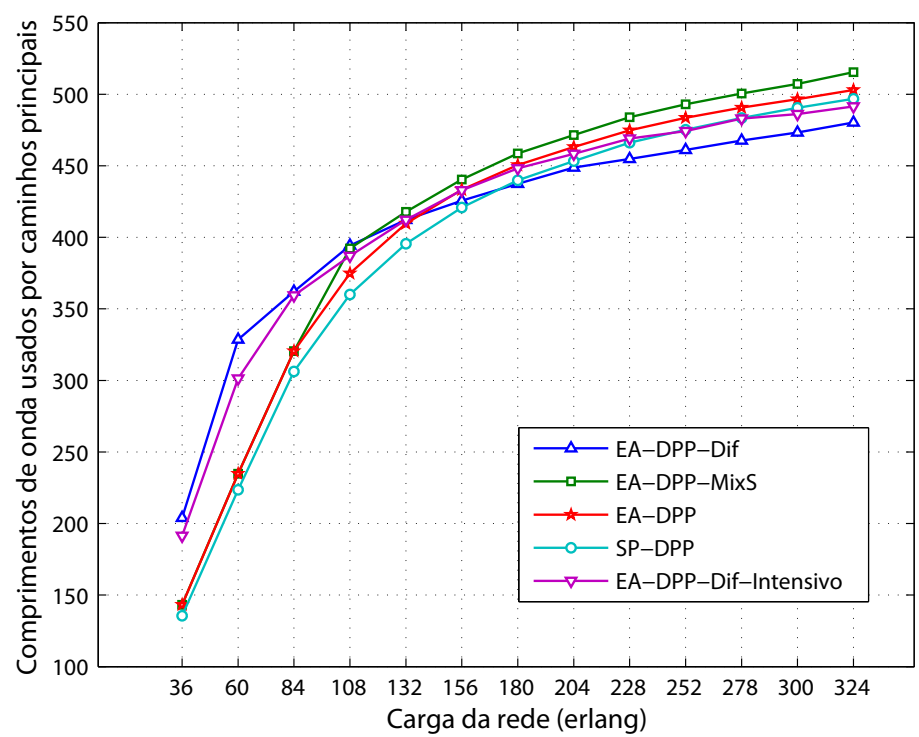

Figura 6.23.: Comprimentos de onda por caminhos principais para a rede brasileira Ipê

passa a ser a estratégia com menor valor. Isto é devido à alta probabilidade de bloqueio para essas cargas. A estratégia SP-DPP nas redes Cost239 e UsNet possui o menor número de comprimentos de onda, na rede brasileira Ipê isso somente foi observado nas cargas baixas.

Número de comprimentos de onda por caminhos de proteção para a rede brasileira Ipê é mostrado na Figura 6.24. A diferença das outras redes avaliadas, EA-DPP-Dif-Intensivo superou a EA-DPP-Dif em número de comprimentos de onda por caminhos de proteção. Como as redes anteriores, EA-DPP-MixS foi a que apresentou a menor número de comprimentos de onda.

\subsubsection{Carga do enlace mais carregado na rede}

A carga do enlace refere-se à quantidade de comprimentos de ondas utilizados no enlace dividido pela quantidade total de comprimento de ondas. Na simulação foram considerados quarenta comprimentos de onda por enlace, assim um enlace totalmente carregado seria aquele com os quarenta comprimentos utilizados ao mesmo tempo. Na métrica, em cada evento é avaliada a carga de cada um dos enlaces e determinado o enlace mais carregado. Ao final da simulação é encontrado o enlace mais carregado durante todos os eventos. Nos gráficos é apresentada unicamente a carga do enlace mais carregado por cada valor de carga. O objetivo da métrica é comparar a saturação dos enlaces devido ao processo de agrupamento de caminhos segundo a estratégia. Um enlace saturado pode representar um gargalo que aumenta a probabilidade de bloqueio.

Na Figura 6.25 são mostrados os resultados para a carga do enlace mais carregado na 


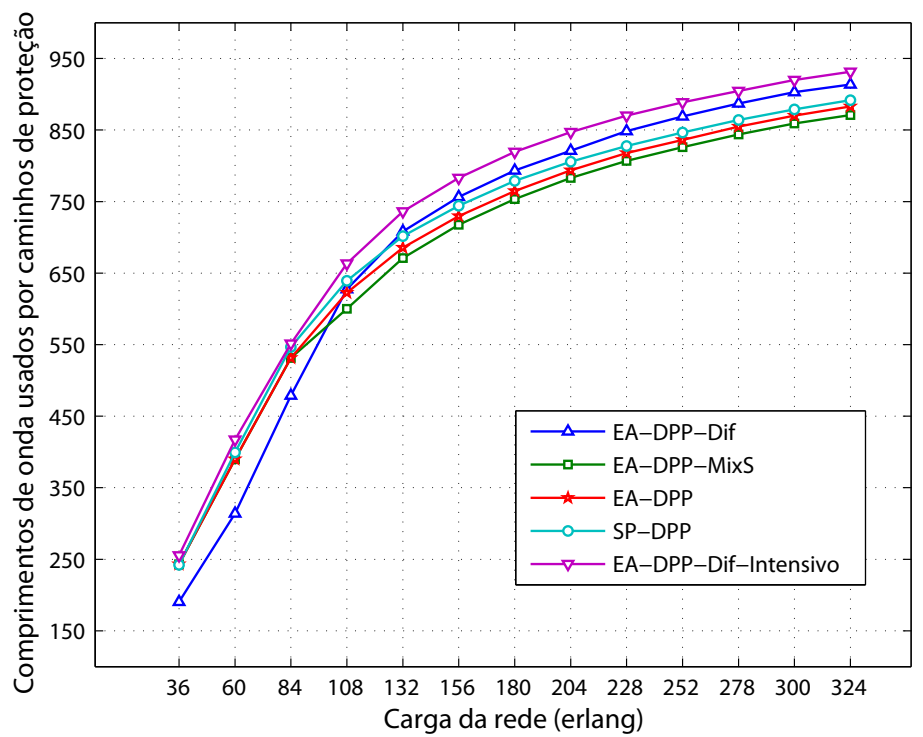

Figura 6.24.: Comprimentos de onda por caminhos de proteção para a rede brasileira Ipê

rede Cost239. Vemos que com exceção de SP-DPP e EA-DPP, as outras estratégias apresentam enlaces totalmente carregados para todos os valores de carga. Isso é esperado porque essas estratégias não tratam de agrupar os caminhos segundo a utilização do enlace. Assim, SP-DPP é a que apresenta enlaces menos carregados e menor probabilidade de gerar gargalos.

Para a rede UsNet a carga do enlace mais carregado é mostrada na Figura 6.26. As estratégias EA-DPP-Dif, EA-DPP-Dif-Intensivo e EA-DPP-MixS são as que apresentam enlaces mais carregados. A queda da carga do enlace mais carregado para a EA-DPP-MixS está relacionada ao incremento de probabilidade de bloqueio com cargas de rede maiores. Assim mesmo, a EA-DPP e a SP-DPP apresentam respostas similares. Essa carga menor é esperada pois elas atribuem os recursos sem fazer agrupamentos. 


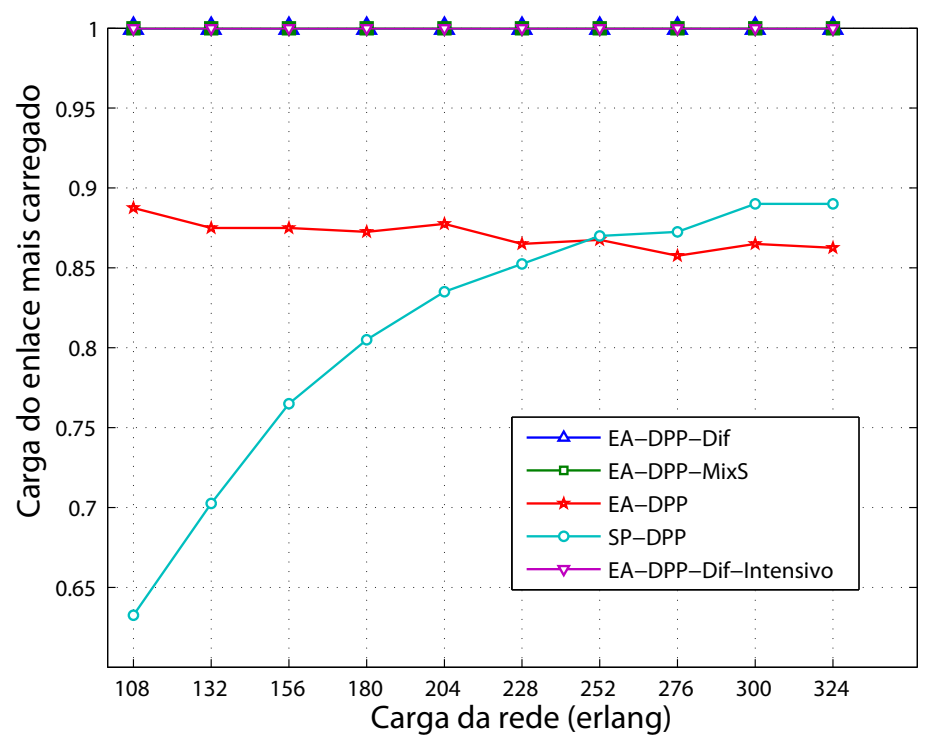

Figura 6.25.: Carga do enlace mais carregado para a rede Cost239

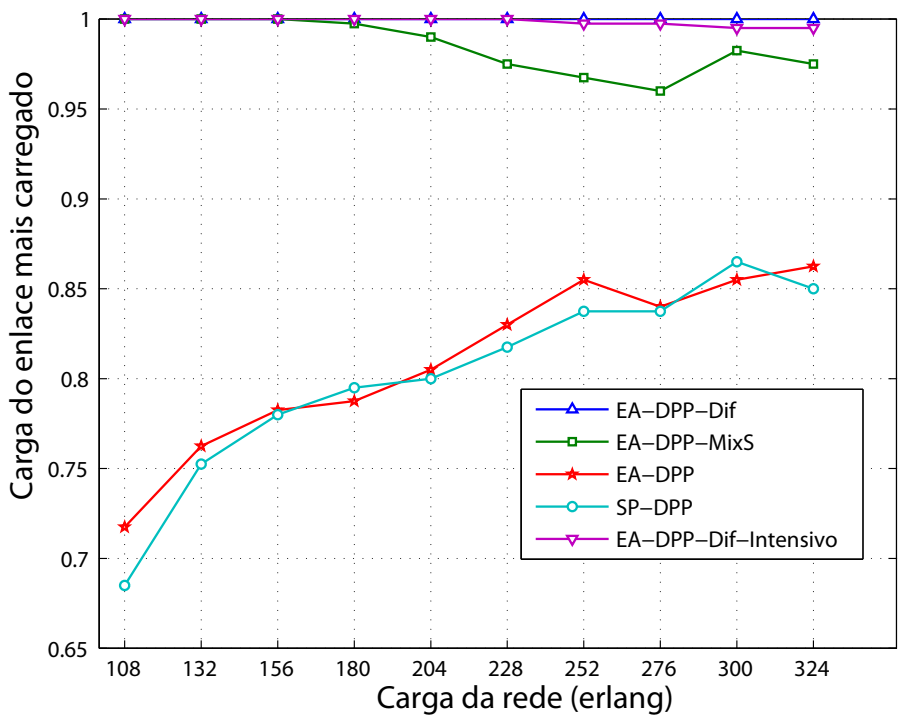

Figura 6.26.: Carga do enlace mais carregado para a rede UsNet 


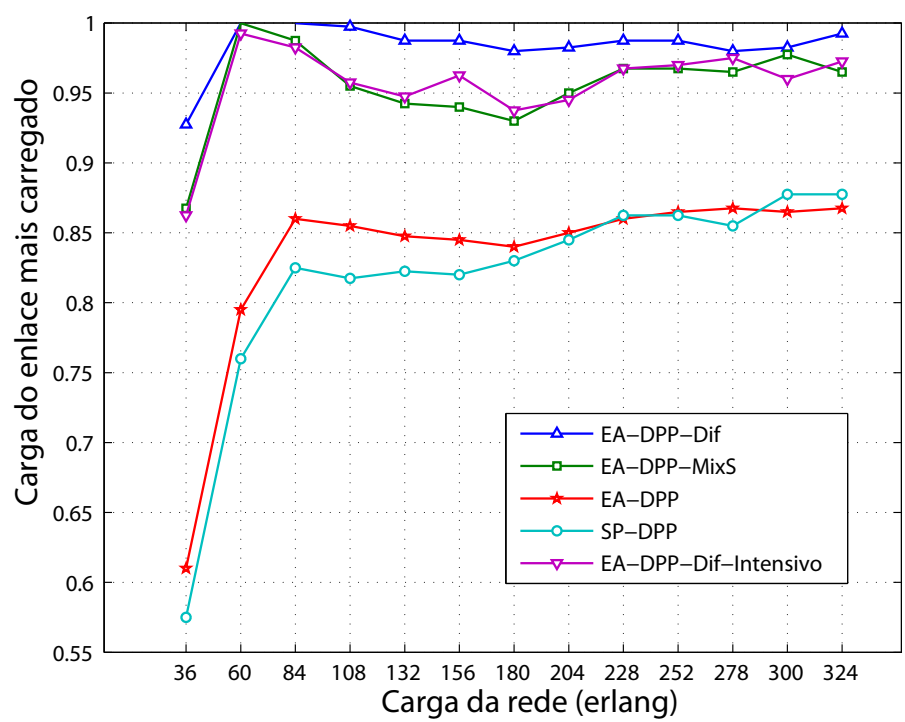

Figura 6.27.: Carga do enlace mais carregado para a rede brasileira Ipê

A carga do enlace mais carregado para a rede brasileira Ipê é mostrado na Figura 6.27. Nela podemos observar o mesmo padrão que nas redes anteriores, a EA-DPP e a SP-DPP são as estratégias com enlaces menos carregados. Mas, nesse caso, EA-DPP-Dif apresenta enlaces ligeiramente mais carregados que EA-DPP-MixS e EA-DPP-Dif-Intensivo.

\subsubsection{Compromisso entre probabilidade de bloqueio e potência consumida}

Os gráficos anteriores permitem avaliar a probabilidade de bloqueio e potência consumida independentemente. Porém, precisamos de uma métrica para calcular o compromisso entre potência consumida e probabilidade de bloqueio, e assim avaliar conjuntamente esse compromisso para as estratégias estudadas. A relação entre a potência consumida e a probabilidade de bloqueio foi calculada da seguinte maneira:

$$
C=1-(\text { Probabilidade de bloqueio } \cdot \text { Potência consumida })_{\text {normalizado }}
$$

Na equação, o valor $C$ representa o compromisso entre as duas variáveis, calculado para cada carga de rede. A normalização é realizada utilizando o máximo dos compromissos para todas as estratégias. O intuito é comparar as estratégias segundo a sua eficiência conjunta.

Podemos observar, para a rede Cost239 (Figura 6.28), que a estratégia que apresenta o melhor compromisso entre probabilidade de bloqueio e potência consumida é a estratégia EA-DPP-Dif usando a proposta de roteamento Intensivo. Embora o bom desempenho da estratégia EA-DPP-Dif na diminuição da potência consumida, a alta probabilidade de bloqueio que gera faz com que ela apresente a menor eficiência conjunta. Além disso, 


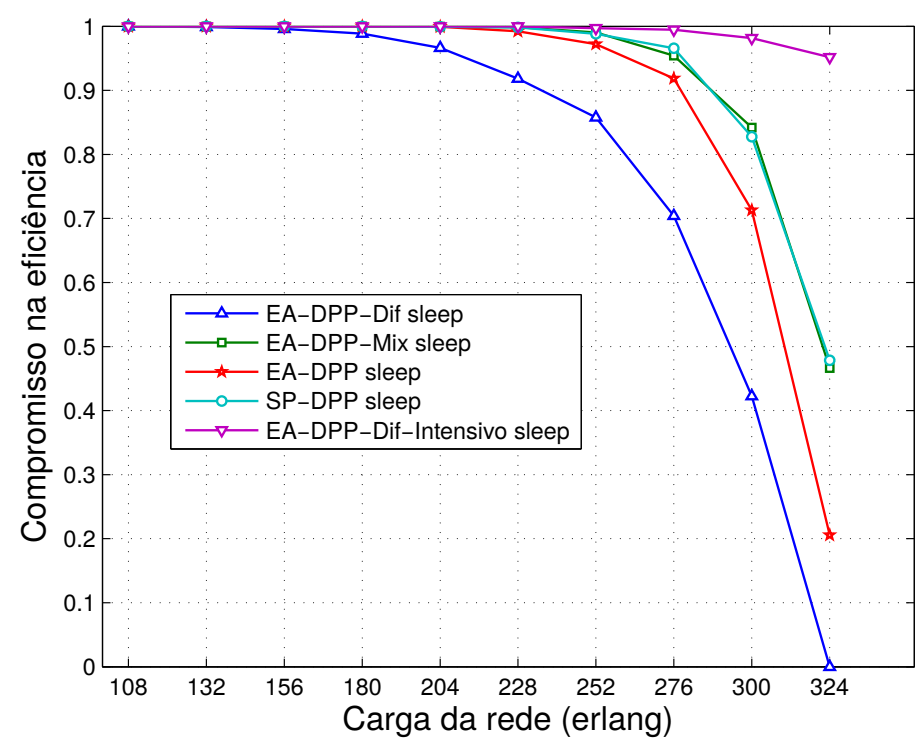

Figura 6.28.: Compromisso entre probabilidade de bloqueio e potência consumida para a rede Cost239.

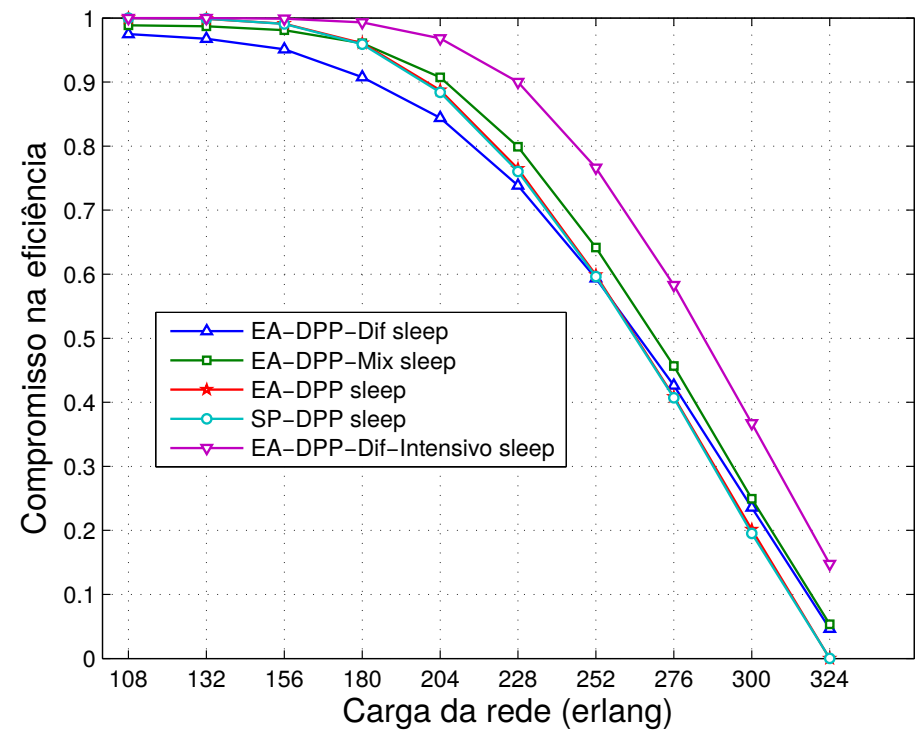

Figura 6.29.: Compromisso entre probabilidade de bloqueio e potência consumida para a rede UsNet. 


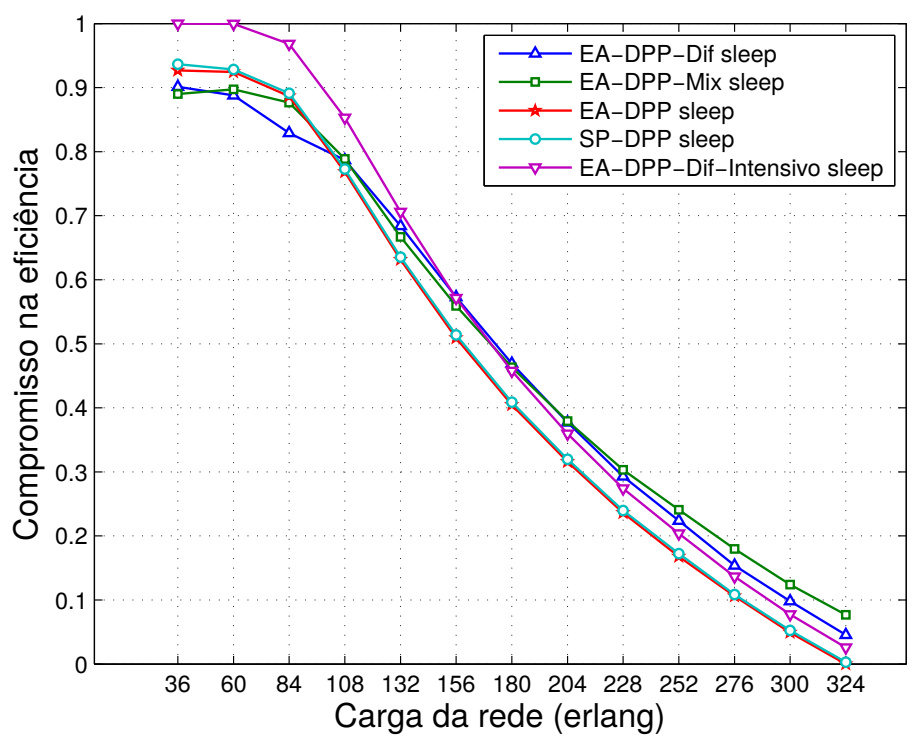

Figura 6.30.: Compromisso entre probabilidade de bloqueio e potência consumida para a rede brasileira Ipê.

podemos observar que embora as estratégias SP-DPP e a EA-DPP-MixS têm resultados diferentes, tanto na probabilidade de bloqueio, quanto na potência consumida (Figuras 6.7 e 6.2), elas apresentam a mesma eficiência conjunta. A escolha de uma das duas estratégias depende do que se deseje priorizar, menor probabilidade de bloqueio ou menor potência consumida.

Na Figura 6.29 é mostrado o compromisso na eficiência conjunta para a rede UsNet. Como no caso anterior, a EA-DPP-Dif-Intensivo teve a melhor relação entre probabilidade de bloqueio e potência consumida. Para cargas de redes baixas e médias, a estratégia EA-DPP-Dif é a que apresenta pior desempenho de eficiência conjunta, mas a diferença com as outras estratégias é menor que no caso da rede Cost239. Por outro lado, para a rede UsNet, a EA-DPP e a SP-DPP tiveram comportamento semelhante na avaliação do compromisso, sendo que para cargas altas (maiores que 252 erlangs) elas apresentam a menor eficiência conjunta.

Para a rede Ipê o compromisso entre probabilidade de bloqueio e potência consumida é mostrado na Figura 6.30. Como no caso das redes anteriores, a EA-DPP-Dif-Intensivo, devido à sua menor probabilidade de bloqueio, mostrou maior eficiência conjunta, isto para cargas entre 36 e 156 erlangs. Além disso, notamos que a estratégia com pior desempenho quanto ao compromisso entre probabilidade de bloqueio e potência consumida foram a EA-DPP e a SP-DPP. No entanto, os resultados deste compromisso são semelhantes para todas as estratégias. Para cargas altas, a estratégia EA-DPP-MixS apresenta um melhor compromisso. 


\subsection{Características da topologia das redes}

Nas métricas avaliadas na seção anterior, podemos observar que cada rede apresenta diferenças nos resultados obtidos. Por exemplo, a ordem das estratégias em cada métrica foi diferente dependendo da rede. Foi observado que em relação a potência consumida, a estratégia com melhor desempenho para a rede Cost239 foi a EA-DPP-Dif-Intensivo, mas para a rede UsNet foi a EA-DPP-Dif e para a rede Ipê a EA-DPP-MixS. Esse comportamento diferente das estratégias está relacionado com as características particulares de cada rede.

Para avaliar a topologia e características de cada uma das rede de teste usamos propriedades de grafos. Na Seção $\$ 2.2$ foram apresentados e explicados de maneira formal algumas propriedades de grafos relevantes para nosso estudo. Dentro delas temos o grau do nó, a densidade e o diâmetro do grafo e a conectividade algébrica, que serão usadas para comparar objetivamente a topologia das redes.

\subsubsection{Média do grau dos nós}

O grau de um nó refere-se ao número de enlaces que estão conectados ao nó. Usaremos a média do grau dos nós na rede para comparar as topologias avaliadas. Para a rede europeia, Cost239 [76], a média foi de 4.72. Onde 4 nós têm grau 4, 6 têm grau 5 e 1 nó tem grau 6. A rede estadunidense, UsNet [77], apresenta 3 nós com grau 2, 10 com grau 3, 5 com grau 4 e 6 nós com grau 5. Assim a média do grau para essa rede é 3.58. No caso da rede brasileira, Ipê [78], a média foi de 2.45. Onde 14 nós têm grau 2, 6 grau 3 e 2 nós grau 4. Comparando as redes, vemos que a rede Cost239 possui uma maior média do grau dos nós, seguida da rede UsNet, enquanto que, a rede Ipê apresenta a menor média do grau dos nós.

Como nenhuma das redes avaliadas presenta nós isolados (que restringiriam a possibilidade de caminhos de proteção disjuntos), o menor grau possível para qualquer dos nós é dois. Observamos que dos 22 nós que tem a rede brasileira, 14 nós apresentam o menor grau possível, 2. Isso reflete na rápida saturação da rede, pois a rede não tem recursos suficientes para atender altas demandas de tráfego. Pois, cada demanda precisa de um caminho principal e um de proteção e nós com grau dois diminuem a possibilidade de achar rotas disjuntas alternativas.

\subsubsection{Densidade do grafo}

A densidade da rede refere-se à interconectividade entre os nós. Numa rede totalmente interconectada, por cada par de nós existe um enlace que os coneta, a densidade para essa rede seria 1. Para uma rede totalmente desconexa ou sem enlaces a densidade seria 0. Para o cálculo dessa propriedade precisamos do número de enlaces e do número de 
nós da rede. A seguir é calculada a densidade para cada uma das redes avaliadas:

A rede Cost239 possui 52 enlaces e 11 nós, assim, a densidade para essa rede é

$$
D=52 /(11 \times 10)=0,47
$$

No caso da rede UsNet, a qual possui 86 enlaces e 24 nós, o valor da densidade é

$$
D=86 /(24 \times 23)=0,15
$$

A densidade para a rede brasileira Ipê que tem 54 enlaces e 22 nós é

$$
D=54 /(22 \times 21)=0,1
$$

Observamos que a rede de maior densidade ou a mais interconectada é a rede Cost239, enquanto que a rede brasileira é a de menor densidade.

\subsubsection{Diâmetro da rede}

O diâmetro da rede refere-se à longitude do caminho mais curto entre os nós mais distanciados da rede. A definição formal do diâmetro da rede foi apresentado na Seção §2.2. Assim, para calcular o diâmetro de uma rede primeiro é necessário achar os caminhos mais curtos entre todos os nós da rede. Esse cálculo foi realizado na fase de pré-cálculo de rotas (Seção \$5.1). Tendo as rotas mais curtas, e achado o par de nós mais distanciados, isto é, a maior das rotas mais curtas. Assim, o diâmetro da rede será o número de saltos da maior das rotas mais curtas entre todos os nós. O diâmetro para a rede Cost239 é 5 , para a rede UsNet é 8 e para a rede Ipê 11.

Um maior diâmetro significa uma maior probabilidade de ter rotas mais longas para atender as demandas, o que refletiria no aumento do consumo de energia.

\subsubsection{Conectividade algébrica da rede}

A conectividade algébrica refere-se a quão bem está conetada uma rede. Essa propriedade está relacionada com o número de vértices, com o grau de cada vértice e com a distância médio entre cada par de vértices. É por isso, que é uma propriedade adequada para medir a robustez das redes. Uma rede com maior conectividade algébrica é uma rede mais robusta.

A conectividade algébrica foi calculada para cada uma das redes avaliadas. Para a rede Cost239 a conectividade algébrica é 1106,41, para a rede UsNet é 304,25 e para a rede brasileira a conectividade algébrica é 84,20.

Dos resultados podemos concluir que a rede Cost239 é a mais robusta, o que é refletido 
na probabilidade de bloqueio. Baixo a mesmas condições de carga, a probabilidade de bloqueio para a rede Cost239 é menor, comparada com as outras redes avaliadas. Uma rede robusta também garante menor probabilidade de gargalos. Numa rede com baixa conectividade algébrica, como a rede brasileira, a possibilidade de nós da rede fiquem desconectados por uma possível queda de enlace é maior.

Com essas métricas podemos observar mais claramente como a topologia da rede afeta o desempenho das estratégias para economizar energia. Quanto menos interconectada a rede mais rapidamente é saturada e qualquer uma das estratégias deixa de fazer diferença na economia de energia.

Para facilitar a comparação entre as topologias de redes o resumo desses resultados é mostrado na Tabela 6.1.

Tabela 6.1.: Características da topologia das redes de teste.

\begin{tabular}{lccc}
\hline Características da rede & Cost239 & UsNet & Ipê \\
\hline Grau de nós & 4,72 & 3,58 & 2,45 \\
Densidade do grafo & 0,45 & 0,15 & 0,1 \\
Diâmetro da rede & 5 & 8 & 11 \\
Conectividade algébrica & 1106,41 & 304,25 & 84,20 \\
\hline
\end{tabular}

Neste capítulo foram apresentados os resultados obtidos das simulações realizadas no trabalho. Apresentamos os resultados paras as três redes de teste, Cost239, UsNet e a rede Ipê, segundo as métricas de avaliação de desempenho. Além disso, foram apresentados os resultados da análises de propriedades de grafos para cada uma das topologias de rede. 


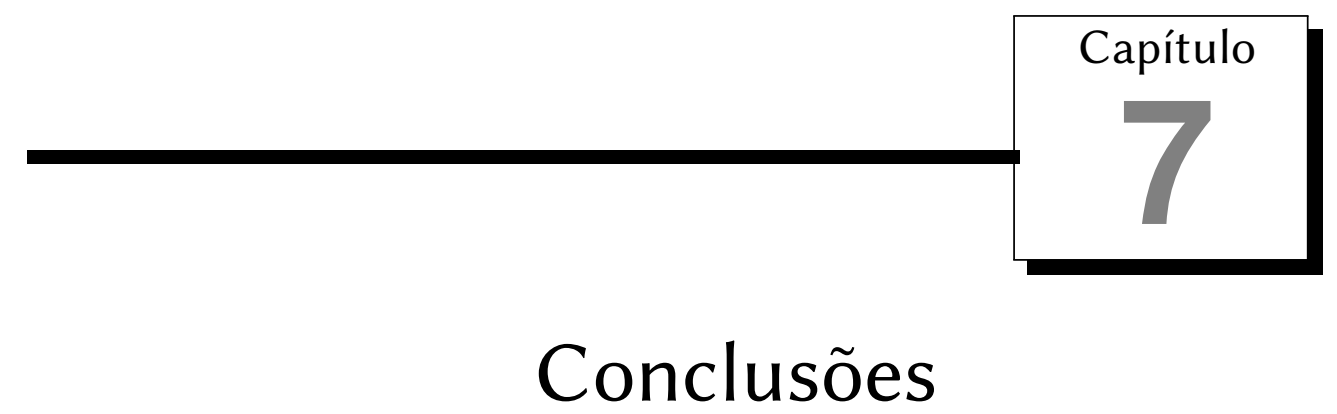

$\mathrm{O}$

planejamento de redes que diminuam o consumo de energia elétrica é imperativo, não somente por causa da questão ambiental, mas também para redução de custos. As principais contribuições e conclusões desta dissertação no contexto de economia de energia para redes WDM com proteção dedicada de caminhos (DPP) são apresentadas neste capitulo.

Para atingir o nosso objetivo principal, desenvolver um algoritmo de roteamento energeticamente eficiente, inicialmente foram propostas metas, listadas na Seção \$4.1.

1. Foi realizada uma integração das classificações de soluções em economia de energia para redes de telecomunicações, por tipo de abordagem e cenário de rede. Essa classificação foi apresentada na Seção §3.2;

2. Baseado no estudo de soluções com foco em modo suspenso (Seção §3.3), foi escolhida a solução orientada ao tráfego dinâmico, aplicando o modo suspenso em redes WDM com proteção dedicada de caminhos;

3. Foram implementados com sucesso o algoritmo de roteamento e as estratégias de economia de energia da solução escolhida;

4. Comparamos e avaliamos as estratégias implementadas de acordo com métricas de desempenho, como porcentagem de energia economizada e probabilidade de bloqueio;

5. Desenvolvemos a nossa proposta de roteamento intensivo de tráfego de acordo 
com os resultados da análise anterior. Isso com o intuito de melhor a qualidade de serviço;

6. Avaliamos a proposta de roteamento intensivo usando cada uma das estratégias implementadas.

Todas as metas planteadas no trabalho foram atingidas com sucesso. A seguir, apresentaremos mais detalhadamente as conclusões dos resultados obtidos na avaliação das estratégias de economia de energia e da nossa proposta de roteamento intensivo.

Os resultados obtidos e o desempenho de cada uma das estratégias é dependente do seu objetivo. A EA-DPP-Dif usando modo suspenso diminui a potência em até $40 \%$, mas apresenta a maior probabilidade de bloqueio. A EA-DPP-MixS com modo suspenso economiza até $35 \%$ de potência é a segunda com menor probabilidade de bloqueio. A EA-DPP-sleep mostrou diminuição de até $5 \%$ de potência, mas é a estratégia com menor consumo de energia sem usar o modo suspenso. Finalmente a SP-DPP-sleep diminuiu a potência até $10 \%$ e das quatro estratégias é a que apresenta menor probabilidade de bloqueio e em média caminhos mais curtos. O roteamento intensivo foi proposto neste trabalho para melhorar a probabilidade de bloqueio mantendo os níveis de economia de energia. Assim, nas simulações o roteamento intensivo foi testado para cada umas das estratégias. Usando o roteamento intensivo junto com o modo suspenso na estratégia EA-DPP-Dif a potência diminui, no melhor dos casos, em até $10 \%$ em comparação à EA-DPP-Dif-sleep, economizando no total até 50\%. Além disso, a EA-DPP-Dif-Intensivo sleep é a estratégia que possui a menor taxa de probabilidade de bloqueio. Quando é usado o roteamento intensivo para as outras estratégias não há melhora na quantidade de potência economizada. Como a economia de energia é o intuito principal deste trabalho, o uso de roteamento intensivo foi utilizado unicamente para a estratégia EA-DPP-Dif, pelo seu melhor desempenho.

\subsection{Principais contribuições}

Das análises dos resultados para potência consumida podemos concluir que:

1. O uso de modo suspenso diminui a potência consumida para todos as estratégias;

2. As estratégias EA-DPP-Dif e a EA-DPP-Dif-Intensivo são mais eficientes na economia de energia;

3. Aplicar o roteamento intensivo para todas as estratégias nem sempre reduz a quantidade de energia;

4. Os resultados para cada uma das estratégia é dependente da topologia da rede. 
Em relação à probabilidade de bloqueio podemos concluir que:

1. A estratégia EA-DPP-Dif mostrou-se eficiente para economizar energia, mas apresenta uma alta probabilidade de bloqueio;

2. O uso da proposta de roteamento intensivo melhora a probabilidade de bloqueio na maioria dos casos, o que significa maior número de demandas atendidas. No entanto, o roteamento intensivo é computacionalmente mais custoso;

3. Altas cargas saturam as redes fazendo que todas as estratégias atinjam os mesmos pontos máximos de probabilidade de bloqueio;

4. Na avaliação de compromisso entre probabilidade de bloqueio e potência consumida, a EA-DPP-Dif-Intensivo mostrou melhor desempenho. No entanto, para a EA-DPP-Dif esse compromisso foi inferior comparado com as outras estratégias.

Podemos concluir sobre as outras métricas avaliadas que:

1. Quando não é utilizado o modo suspenso, na maioria dos casos, todos os enlaces estão formando parte de algum tipo de caminho. Isso inclui vários enlaces que são parte somente de caminhos de proteção, que não transportam tráfego e estão consumindo energia;

2. A estratégia EA-DPP-Dif e EA-DPP-Dif-Intensivo apresenta caminhos mais longos, tanto para caminhos principais como de proteção;

3. De modo geral, os caminhos de proteção são mais longos que os principais;

4. A SP-DPP e EA-DPP apresentam melhor distribuição de demandas nos recursos disponíveis na rede, enlaces menos carregados e menor probabilidade de gargalos;

5. Os resultados são dependentes de características das topologias das redes como densidade ou grau dos nós. Redes menos conexas, como a brasileira, tendem a mostrar resultados menos satisfatórios, como maior probabilidade de bloqueio e menor eficiência das estratégias em relação a economia de energia.

De acordo com os resultados obtidos, independentemente das caraterísticas da topologia da rede, a EA-DPP-Dif-Intensivo tem a menor probabilidade de bloqueio e a EA-DPP-Dif é a estratégia com maior bloqueio. É importante notar que redes com menor densidade de conexões mostram maiores valores de probabilidade de bloqueio. No entanto, a potência consumida está relacionada com a topologia da rede. Para redes com maior densidade de conexões, como a Cost239[76], o roteamento intensivo para EA-DPP-Dif tem a menor porcentagem de potência consumida. Para a rede UsNet[77] 
a EA-DPP-Dif apresenta melhores resultados, sendo que essa rede é menos densa que a Cost239. Para redes com baixa densidade e com um grande número de nós com grau dois, como a rede brasileira[78], a EA-DPP-MixS é a estratégia com menor potência consumida. Por isso, é importante avaliar as características da topologia da rede para fazer a escolha da melhor estratégia segundo o objetivo a alcançar (como menor potência consumida, menor probabilidade de bloqueio, caminhos mais curtos, etc).

\subsection{Trabalhos futuros}

Após a pesquisa e desenvolvimento de roteamento de tráfego e estratégias em economia de energia, propomos algumas ideias para que sejam a base de possíveis trabalhos futuros. Como o trabalho desenvolvido foi para cenários de redes com proteção dedicada, propomos avaliar as estratégias para redes com proteção compartilhada [72].

Além disso, estudar a utilização de janelas de tempo onde seja mantida certa configuração da rede ([69]) com o intuito de diminuir as mudanças de estado (ativo, suspenso ou desligado) dos elementos da rede, visando diminuir o consumo de energia

Finalmente, propomos avaliar as estratégias estudadas em modelos de grafos aleatórios que tem características de redes de comunicação reais, como os modelos Erdös-Rényi (ER) [83] ou o Barabási-Albert (BA) [84]. Desta forma, conseguir inferir, a partir das características do grafo, qual estratégia minimizaria a potência consumida com uma probabilidade de bloqueio baixa. 
Apêndices 

Apêndice

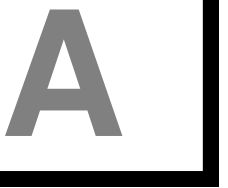

\section{Validação da implementação}

Nesta seção será feita uma explicação e exemplificação da implementação dos algoritmos usados nas simulações. O pseudocódigo dos algoritmos a serem exemplificados foram apresentados no Capítulo 5. A exemplificação será feita seguindo as etapas consideradas para o roteamento de tráfego e alocação de recursos para redes com proteção dedicada de caminhos, mostradas naquele capitulo.

\section{Fase de pré-cálculo de caminhos principais e de proteção}

Fazendo uso do algoritmo de Yen's [81] encontramos os $k$ caminhos mais curtos entre todos os nós. Esses $k$ caminhos serão os prováveis caminhos principais. Depois, para fazer o cálculo dos caminhos de proteção, um por um dos caminhos principais é invalidado no grafo, com a finalidade de obter rotas disjuntas. Assim, baseado nesse novo grafo achamos os $u$ caminhos disjuntos para a fonte destino do caminho invalidado, usando também o algoritmo de Yen's. Depois, todos esses caminhos principais e secundários são armazenados numa lista. As rotas serão extraídas dessa lista quando necessárias, dependendo da demanda a ser alocada.

Na Figura A.1 é ilustrada a rede de teste que será usada para exemplificar a implementação. Esta rede é composta de 6 nós e 11 enlaces bidirecionais. As distâncias estão em quilômetros.

Para ilustrar melhor esta fase, sorteamos um par de nós quaisquer, por exemplo, fonte nó 2 e destino nó 5 . Depois achamos os $n$ caminhos mais curtos, que serão os candidatos 


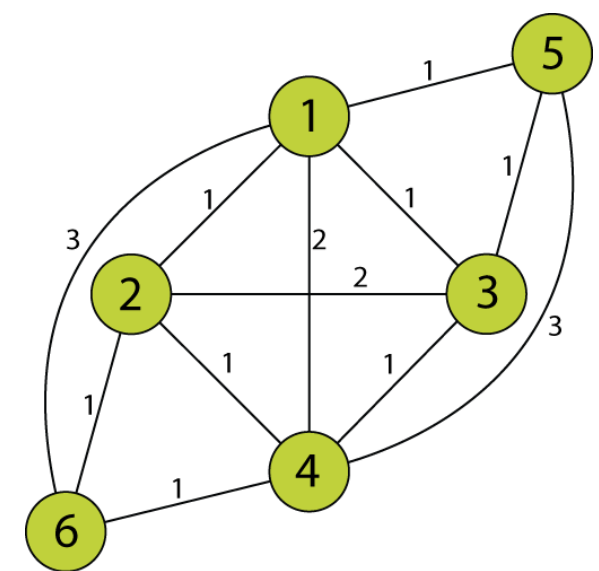

Figura A.1.: Rede de teste.

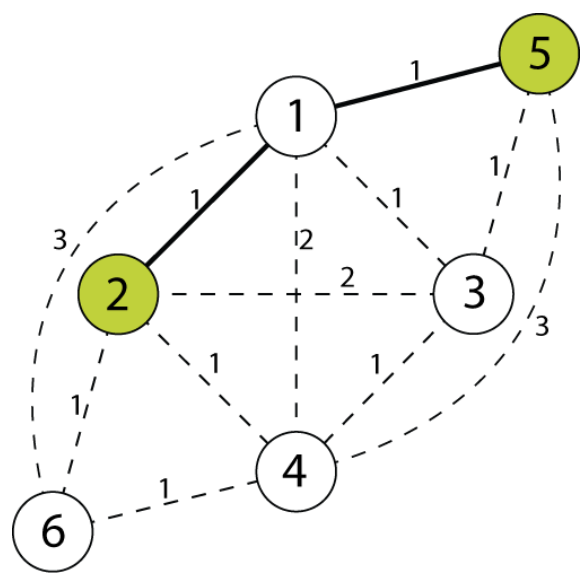

Figura A.2.: Primeiro caminho mais curto entre os nós 2 e 5.

a caminhos principais. Para exemplificar serão usados 5 caminhos.

Na Figura A.2 é indicado o primeiro caminho mais curto entre os nós. Esse caminho será o primeiro candidato a ser o caminho principal. O comprimento total desse caminho é $2 \mathrm{~km}$, sendo ele o menor caminho entre os nós 2 e 5 . Na lista $W^{(2),(5)}$ a seguir (Tabela A.1) são mostrados os 5 caminhos principais entre os nós 2 e 5 e suas distâncias, $\mathrm{km}$.

Tomando como referência o primeiro desses caminhos principais, $2-1-5$, invalidamos essa rota em um grafo auxiliar. Depois, são calculados 5 novos caminhos mais curtos entre os nós 2 e 5. O grafo auxiliar com o novo primeiro caminho mais curto é mostrado na Figura A.3. Esse caminho será o primeiro candidato de caminho de proteção para a rota $2-1-5$.

A seguir, são listados em $B^{(2),(5)}$ os 5 caminhos de proteção entre os nós 2 e 5, com suas distâncias em $k m$ (Tabela A.2). 


\begin{tabular}{lllc}
\hline & id & rotas & distância \\
\hline & 1 & $2-1-5$ & 2 \\
$W^{(2),(5)}$ & 2 & $2-3-5$ & 3 \\
& 3 & $2-1-3-5$ & 3 \\
& 4 & $2-4-3-5$ & 3 \\
5 & $2-3-1-5$ & 4 \\
\hline
\end{tabular}

Tabela A.1.: Lista de caminhos principais entre os nós 2 e 5.

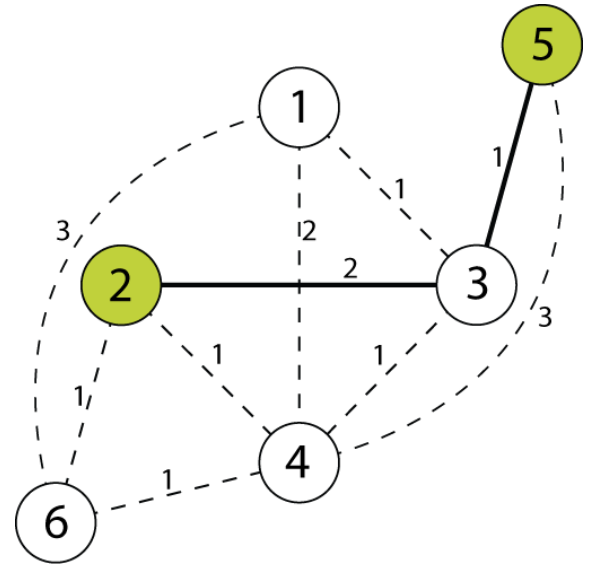

Figura A.3.: Primeiro caminho de proteção para a rota $2-1-5$.

\section{Matrizes auxiliares}

A rede está composta de enlaces bidirecionais e, assim, o grafo da rede é representado mediante uma matriz simétrica. Os enlaces de ida estão dispostos na região triangular superior da matriz e os de volta na triangular inferior. Sendo assim, a matriz de adjacência E para a rede de teste é mostrada na Tabela A.3.

Na qual as distâncias por enlace estão expressa em quilômetros e in $f$ significa que não

\begin{tabular}{lllc}
\hline & id & rotas & distância \\
\hline & 1 & $2-3-5$ & 3 \\
$B^{(2),(5)}$ & 2 & $2-4-3-5$ & 4 \\
& 3 & $2-4-5$ & 4 \\
4 & $2-6-4-3-5$ & 4 \\
5 & $2-6-4-5$ & 5 \\
\hline
\end{tabular}

Tabela A.2.: Lista de caminhos de proteção entre os nós 2 e 5. 


\begin{tabular}{|c|c|c|c|c|c|c|c|}
\hline \multirow{7}{*}{$=$} & nó & 1 & 2 & 3 & 4 & 5 & 6 \\
\hline & 1 & $i n f$ & 1 & 1 & 2 & 1 & 3 \\
\hline & 2 & 1 & $i n f$ & 2 & 1 & $i n f$ & 1 \\
\hline & 3 & 1 & 2 & inf & 1 & 1 & inf \\
\hline & 4 & 2 & 1 & 1 & inf & 3 & 1 \\
\hline & 5 & 1 & $i n f$ & 1 & 3 & $i n f$ & inf \\
\hline & 6 & 3 & 1 & inf & 1 & $\inf$ & inf \\
\hline
\end{tabular}

Tabela A.3.: Matriz de adjacência para a rede de teste.

existe enlace entre esses nós.

Além disso, seguindo a mesma ideia da matriz de adjacência, são geradas várias matrizes auxiliares. Como as matrizes de tráfego, tendo uma por cada comprimento de onda. Onde 0 representa que o enlace não está sendo utilizado e 1 que o enlace está em uso. No exemplo, há 3 comprimentos de onda por enlace. Também é gerada uma matriz de tipo de utilização do enlace $\left(U_{w b}\right)$, onde 0 significa que o enlace não está em uso, 1 que somente está sendo usado por caminhos principais, 2 só por caminhos de proteção e 3 que no enlace há tanto caminhos principais como de proteção. Assim também, têm-se uma matriz de quantidade de caminhos principias que há em cada enlace, e outra matriz que conta quantos caminhos secundários há por enlace. Todas essas matrizes são atualizadas em cada alocação e desalocação de demanda.

\section{Geracão de tráfego}

O seguinte da implementação é a geração de tráfego. Seguindo um processo de Poisson, são gerados tempos de chegada para cada demanda, dado um determinado número de conexões e uma carga de rede. A duração das conexões segue uma distribuição exponencial negativa. E os nós fonte e destino são escolhidos aleatoriamente com a mesma probabilidade.

Para ilustrar, a Tabela A.4 e a Figura A.4 mostram um exemplo em que são geradas 5 demandas de conexões com 324 erlangs, e uma média de duração de conexões de $60 \mathrm{~s}$. As conexões geradas são mostradas na Tabela A.4. Cada demanda é dividida em dois eventos, sendo um de alocação e o outro de desalocação, ambos com seu respectivo tempo e identificador de demanda.

Para explicar melhor a sucessão de eventos, eles foram ilustrados em uma linha de tempo (Figura A.4). No exemplo, observamos que os 5 primeiros eventos foram de alocação, mas as desalocações não seguem necessariamente a ordem em que aconteceram as 


\begin{tabular}{cccccc}
\hline Evento & Tempo & Fonte & Destino & Tipo de evento & Identificador \\
\hline 1 & 0,1532 & 1 & 4 & Alocação & 1 \\
2 & 0,3142 & 2 & 4 & Alocação & 2 \\
3 & 0,5589 & 4 & 1 & Alocação & 3 \\
4 & 0,8719 & 5 & 6 & Alocação & 4 \\
5 & 0,9028 & 1 & 4 & Alocação & 5 \\
6 & 40,5401 & 4 & 1 & Desalocação & 3 \\
7 & 43,1563 & 5 & 6 & Desalocação & 4 \\
8 & 50,0538 & 1 & 4 & Desalocação & 1 \\
9 & 72,6217 & 2 & 4 & Desalocação & 2 \\
10 & 164,641 & 1 & 4 & Desalocação & 5 \\
\hline
\end{tabular}

Tabela A.4.: Lista de eventos gerados.

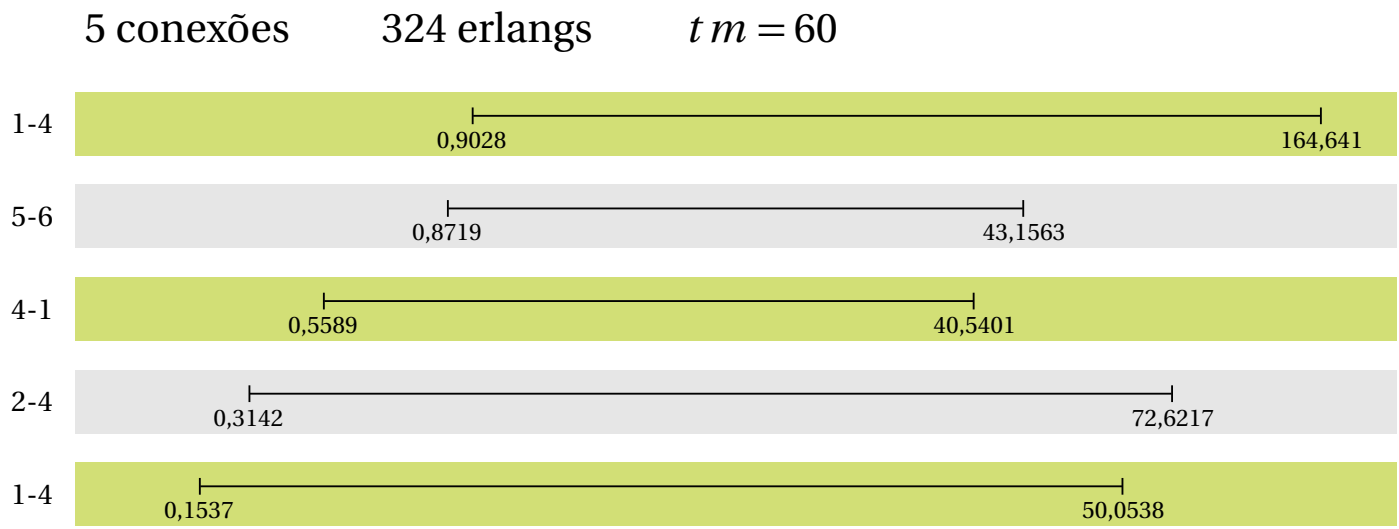

Figura A.4.: Linha de tempo de eventos gerados.

alocações. Isso é devido a que a duração dos eventos segue uma distribuição exponencial negativa, sendo alguns tempos maiores ou menores que outros.

\section{Busca de recursos e alocação de eventos}

Os eventos são analisados seguindo o Algoritmo 6 e será usada a estratégia EA-DPP-Dif. Se o primeiro evento, ao ser um evento é alocação, passamos ao Algoritmo 4 de busca de recursos para o caminho principal. Para um melhor entendimento, os passos dentro de cada algoritmo serão detalhados.

1. Algoritmo de busca de recursos para o caminho principal

a) São extraídas as rotas principais e os nós fonte e destino para esse evento são 1 e 4, respectivamente. Na Tabela A.5) é mostrada a lista das 5 rotas a serem analisada. 


\begin{tabular}{lll}
\hline & id & rotas \\
\hline & 1 & $1-4$ \\
& 2 & $1-2-4$ \\
$W^{(1),(4)}$ & 3 & $1-3-4$ \\
& 4 & $1-2-6-4$ \\
5 & $1-5-3-4$ \\
\hline
\end{tabular}

Tabela A.5.: Lista de candidatos a caminho principal entre os nós 1 e 4.

São procurados recursos para cada uma das rotas. Se toda a rota estiver disponível, em um único comprimento de onda, será armazenada em uma lista de rotas disponíveis $\left(W_{d i s p}^{(s),(d)}\right)$ para o caminho principal. Se está-se analisando, por exemplo, o primeiro comprimento de onda de cada enlace da rota e em algum deles já estiver ocupado esse primeiro comprimento de onda, a rota toda é considerada como não disponível. No caso de não haver rota disponível, isto é, a lista está vazia, a demanda de conexão será bloqueada. Nesse caso, o contador de bloqueios é incrementado. No exemplo, por ser o primeiro evento, todas as rotas candidatas estão disponíveis no primeiro comprimento de onda. Na Tabela A.6 pode ver-se a lista de rotas disponíveis, $W_{d i s p}^{(1),(4)}$.

\begin{tabular}{lllc}
\hline & id & rota & comprimento de onda \\
\hline & 1 & $1-4$ & $\lambda=1$ \\
& 2 & $1-2-4$ & $\lambda=1$ \\
$W_{\text {disp }}^{(1),(4)}$ & 3 & $1-3-4$ & $\lambda=1$ \\
& 4 & $1-2-6-4$ & $\lambda=1$ \\
& 5 & $1-5-3-4$ & $\lambda=1$ \\
\hline
\end{tabular}

Tabela A.6.: Lista de rotas disponíveis para o caminho principal entre os nós 1 e 4.

b) Depois, são calculados os custos por enlace. No exemplo, a estratégia usada é a EA-DPP-Dif, onde os custos são calculados de acordo com a matriz de utilização do enlace $U_{w b}$

$$
P_{\text {cost }}(l)= \begin{cases}0 & \text { se } U_{w b}(l)=1 \\ n_{\text {links }} P_{t o t} & \text { se } U_{w b}(l)=2 \\ P_{t o t} & \text { se } U_{w b}(l)=3 \\ P_{a m p} k(l) & \text { se } U_{w b}(l)=0\end{cases}
$$

na qual $n_{l i n k s}$ é a quantidade de enlaces na rede, $P_{\text {tot }}$ a potência total e $k(l)$ 


$k l=$\begin{tabular}{ccccccc}
\hline nó $\backslash$ nó & $\mathbf{1}$ & $\mathbf{2}$ & $\mathbf{3}$ & $\mathbf{4}$ & $\mathbf{5}$ & $\mathbf{6}$ \\
\hline $\mathbf{1}$ & 0 & 4 & 4 & 6 & 4 & 8 \\
$\mathbf{2}$ & 4 & 0 & 6 & 4 & 0 & 4 \\
$\mathbf{3}$ & 4 & 6 & 0 & 4 & 4 & 0 \\
$\mathbf{4}$ & 6 & 4 & 4 & 0 & 8 & 4 \\
$\mathbf{5}$ & 4 & 0 & 4 & 8 & 0 & 0 \\
$\mathbf{6}$ & 8 & 4 & 0 & 4 & 0 & 0 \\
\hline
\end{tabular}

Tabela A.7.: Matriz de quantidade de amplificadores por enlace para a rede de teste.

é a quantidade de amplificadores por enlace. A potência total é determinada por

$$
P_{t o t}=n\left(P_{o x c}+P_{T x R x}\right)+k(l)_{t o t} P_{a m p}
$$

na qual $n$ é o número de nós, $P_{o x c}$ é a potência do cross-conect óptico, $P_{T x R x}$ é a potência do transmissor-receptor e $P_{a m p}$ a potência por amplificador. No exemplo, para facilitar os cálculos, $P_{o x c}=5 \mathrm{~W}, P_{T x R x}=10 \mathrm{~W}$ e $P_{a m p}=12 \mathrm{~W}$. $k(l)_{\text {tot }}$ é o total de amplificadores na rede e $k(l)$ é a quantidade de amplificadores por enlace, que depende do comprimento do enlace e é dada por

$$
k(l)=(2 d l / d \operatorname{span})+2
$$

na qual $d l$ é o comprimento do enlace, em $k m$, e $d s p a n$ é a distância, $k m$, na qual devem ser alocados os amplificadores de línea. Novamente para facilitar os cálculos, no exemplo, $d s p a n$ é $1 \mathrm{~km}$. Assim, é calculada a quantidade de amplificadores por enlace $k(l)$ e armazenadas na matriz $k l$. A matriz pode ver-se na Tabela A.7.

Como foi mencionado, a matriz $U_{w b}$ representa o tipo de utilização do enlace. No primeiro evento, nenhum enlace está sendo usado. Mostra-se a matriz $U_{w b}$ na Tabela A.8.

Os custos por enlace são colocados de acordo com $U_{w b}$ e, então, a matriz de custos é atualizada de acordo com a Equação (A.1). Na Tabela A.9 pode-se observar a matriz de custos inicial, $P_{\text {cost }}$.

c) O passo seguinte no algoritmo é o cálculo de custos por rotas disponíveis segundo a nova matriz de custos, na qual é feita uma lista com a soma dos custos por salto de cada uma das rotas disponíveis, que é mostrada na Tabela A.10. 


$U_{w b}=$\begin{tabular}{ccccccc}
\hline nó $\backslash$ nó & $\mathbf{1}$ & $\mathbf{2}$ & $\mathbf{3}$ & $\mathbf{4}$ & $\mathbf{5}$ & $\mathbf{6}$ \\
\hline $\mathbf{1}$ & inf & 0 & 0 & 0 & 0 & 0 \\
$\mathbf{2}$ & 0 & inf & 0 & 0 & inf & 0 \\
$\mathbf{3}$ & 0 & 0 & $\inf$ & 0 & 0 & inf \\
$\mathbf{4}$ & 0 & 0 & 0 & inf & 0 & 0 \\
$\mathbf{5}$ & 0 & inf & 0 & 0 & inf & inf \\
$\mathbf{6}$ & 0 & 0 & inf & 0 & inf & inf \\
\hline
\end{tabular}

Tabela A.8.: Matriz inicial de tipo de utilização do enlace.

\begin{tabular}{cccccccc}
\hline nó $\backslash$ nó & $\mathbf{1}$ & $\mathbf{2}$ & $\mathbf{3}$ & $\mathbf{4}$ & $\mathbf{5}$ & $\mathbf{6}$ \\
\cline { 2 - 8 }$P_{\text {cost }}=\mathbf{1}$ & inf & 48 & 48 & 72 & 48 & 96 \\
$\mathbf{2}$ & 48 & inf & 72 & 48 & inf & 48 \\
$\mathbf{3}$ & 48 & 72 & inf & 48 & 48 & inf \\
$\mathbf{4}$ & 72 & 48 & 48 & inf & 96 & 48 \\
$\mathbf{5}$ & 48 & inf & 48 & 96 & inf & inf \\
$\mathbf{6}$ & 96 & 48 & inf & 48 & inf & inf \\
\hline
\end{tabular}

Tabela A.9.: Matriz inicial de custos por enlace.

d) A rota escolhida é a rota com o menor custo da lista anterior $P_{\text {cost }}^{w_{\text {disp }}}$. Assim a rota escolhida no exemplo será a primeira $W_{\text {path }}: 1-4$. Mas, se houver empates de custos, dependendo da estratégia escolhida, há métodos de desempate. No caso de EA-DPP-Dif, é escolhida a rota com o maior número médio (entre número de saltos) de rotas primárias que tiver os enlaces que compõem a rota. Esse cálculo é feito com ajuda das matrizes auxiliares Num_ $W$ e Num_ $P$, que contam o número de caminhos principais e de proteção por enlace.

e) A escolha do comprimento de onda é feita pelo método first-fit, para qual é escolhido o primeiro comprimento de onda que estiver disponível para a rota toda. Na implementação, quando é feita a lista das rotas disponíveis ( $W_{d i s p}^{p a t h}$ ), os recursos para as rotas são procurados por comprimento de onda, usando o método first-fit para cada uma dessas rotas disponíveis. Assim, o primeiro comprimento de onda disponível para a rota $W_{\text {path }}^{(1),(4)}$ é $\lambda_{W_{\text {path }}^{(1),(4)}}=1$.

2. Algoritmo de busca de recursos para o caminho de proteção

Para fazer a escolha da rota de proteção, utilizamos o Algoritmo 5 de busca de recursos para o caminho de proteção, que é similar ao processo anterior de escolha do caminho principal assim,

a) Primeiro são extraídas as rotas disjuntas para a rota escolhida como caminho 


\begin{tabular}{rrrc}
\hline & id & custo por salto & custo total \\
\hline & 1 & 72 & 72 \\
$P_{\text {cost }}^{w_{\text {disp }}}$ & 2 & $48+48$ & 96 \\
& 3 & $48+48$ & 96 \\
& 4 & $48+48+48$ & 144 \\
& 5 & $48+48+48$ & 144 \\
\hline
\end{tabular}

Tabela A.10.: Lista de custos para os caminhos principais disponíveis entre os nós 1 e 4 .

\begin{tabular}{lll}
\hline & id & rotas \\
\hline & 1 & $1-2-4$ \\
$B^{(1),(4)}$ & 2 & $1-3-4$ \\
& 3 & $1-2-6-4$ \\
& 4 & $1-5-3-4$ \\
& 5 & $1-3-2-4$ \\
\hline
\end{tabular}

Tabela A.11.: Lista de candidatos a caminho de proteção entre os nós 1 e 4.

principal. Todas elas estão armazenadas na fase de pré-cálculo de rotas. As rotas candidatas de proteção, $B_{p a t h}$, para o caminho principal $W_{p a t h}: 1-4$ são mostras na Tabela A.11.

Em seguida, são procurados recursos, comprimentos de onda disponíveis, para as rotas candidatas de proteção, $B_{(1),(4)}$. Isso, lembrando que a continuidade de comprimento de onda por rota deve ser respeitada. Assim, é analisada cada rota segundo a matriz de tráfego. No exemplo, como é a primeira conexão ao ser alocada, a matriz de tráfego está vazia pelo que o primeiro comprimento de onda para todas as rotas está disponível. Na Tabela A.12 é mostrada a lista de rotas de proteção disponíveis entre os nós 1 e $4, B_{\text {disp }}^{(1),(4)}$.

Se a lista de rotas disponíveis estiver vazia, a demanda é bloqueada.

b) Recalculamos a matriz de custos $P_{\text {cost }}$ de acordo com a matriz de utilização,

\begin{tabular}{lllc}
\hline & id & rota & comprimento de onda \\
\hline & 1 & $1-2-4$ & $\lambda=1$ \\
$B_{\text {disp }}^{(1),(4)}$ & 2 & $1-3-4$ & $\lambda=1$ \\
& 3 & $1-2-6-4$ & $\lambda=1$ \\
& 4 & $1-5-3-4$ & $\lambda=1$ \\
5 & $1-3-2-4$ & $\lambda=1$ \\
\hline
\end{tabular}

Tabela A.12.: Lista de caminhos de proteção disponíveis entre os nós 1 e 4. 


\begin{tabular}{rccccccc}
\hline nó $\backslash$ nó & $\mathbf{1}$ & $\mathbf{2}$ & $\mathbf{3}$ & $\mathbf{4}$ & $\mathbf{5}$ & $\mathbf{6}$ \\
\cline { 2 - 7 }$P_{\text {cost }}=\mathbf{1}$ & inf & 48 & 48 & 72 & 48 & 96 \\
$\mathbf{2}$ & 48 & inf & 72 & 48 & inf & 48 \\
$\mathbf{3}$ & 48 & 72 & inf & 48 & 48 & inf \\
$\mathbf{4}$ & 72 & 48 & 48 & inf & 96 & 48 \\
$\mathbf{5}$ & 48 & inf & 48 & 96 & inf & inf \\
$\mathbf{6}$ & 96 & 48 & inf & 48 & inf & inf \\
\hline
\end{tabular}

Tabela A.13.: Matriz de custos por enlace atualizada.

\begin{tabular}{ccrc}
\hline & id & custo por salto & custo total \\
\hline & 1 & $48+48$ & 96 \\
$P_{\text {cost }}^{B_{\text {disp }}}$ & 2 & $48+48$ & 96 \\
& 3 & $48+48+48$ & 144 \\
& 4 & $48+72+48$ & 144 \\
& 5 & $48+72+48$ & 168 \\
\hline
\end{tabular}

Tabela A.14.: Lista de custos para os caminhos de proteção disponíveis entre os nós 1 e 4.

$U_{w b}$, de acordo com A.2.

$$
P_{\text {cost }}(l)= \begin{cases}n_{\text {links }} P_{\text {tot }} & \text { se } U_{w b}(l)=1 \\ 0 & \text { se } U_{w b}(l)=2 \\ P_{\text {tot }} & \text { se } U_{w b}(l)=3 \\ P_{a m p} k(l) & \text { se } U_{w b}(l)=0\end{cases}
$$

Assim, a matriz de custos é recalculada, $P_{\text {cost }}$ é mostrada na Tabela A.13.

c) São calculados os custos por rotas disponíveis, $B_{\text {disp }}^{(1),(4)}$, de acordo com a nova matriz $P_{\text {cost }}$ (Tabela A.13). Na Tabela A.14 é mostrada a lista de custos para os caminhos de proteção disponíveis entre os nós 1 e 4.

d) Escolhemos a rota com o menor custo. Nesse caso, há empate entre as dos primeiras rotas. No caso de empate para a estratégia EA-DPP-Dif, é escolhida a rota com o maior número médio (entre número de saltos) de rotas de proteção que tiver os enlaces que compõem a rota.

Como é o primeiro evento, ainda não há rota alocada, o promédio de rotas que têm os enlaces para ambas as rotas é zero. Novamente, há um empate, e é escolhida a rota com a menor distância física. Os caminhos principais e secundários pré-calculados estão ordenados por distância, da menor para maior. 


$T_{\lambda 1}=$\begin{tabular}{ccccccc}
\hline nó $\backslash$ nó & $\mathbf{1}$ & $\mathbf{2}$ & $\mathbf{3}$ & $\mathbf{4}$ & $\mathbf{5}$ & $\mathbf{6}$ \\
\hline $\mathbf{1}$ & 0 & 0 & 0 & $\mathbf{1}$ & 0 & 0 \\
$\mathbf{2}$ & 0 & 0 & 0 & 0 & 0 & 0 \\
$\mathbf{3}$ & 0 & 0 & 0 & 0 & 0 & 0 \\
$\mathbf{4}$ & 0 & 0 & 0 & 0 & 0 & 0 \\
$\mathbf{5}$ & 0 & 0 & 0 & 0 & 0 & 0 \\
$\mathbf{6}$ & 0 & 0 & 0 & 0 & 0 & 0 \\
\hline
\end{tabular}

Tabela A.15.: Matriz de tráfego para $\lambda 1$ com o caminho principal do primeiro evento alocado.

Assim, neste caso de empate é escolhida a primeira rota, resultado da ordenação por comprimento físico. A rota de proteção escolhida é a $B_{\text {path }}^{(1),(4)}: 1-2-4$.

e) Da mesma forma que no caminho principal, o comprimento de onda é escolhido pelo método first-fit. Assim, para a rota de proteção do exemplo será usado o comprimento disponível calculado no primeiro passo do algoritmo, $\lambda_{B_{\text {path }}^{(1),(4)}}=1$.

3. Algoritmo de alocação de caminho principal e de proteção

Depois de serem escolhidas as rotas primária e secundária, elas devem ser alocada na matriz de tráfego, segundo o algoritmo de alocação 6. Além disso, devem ser feitos alguns cálculos e atualizações das matrizes auxiliares, descritas a seguir.

a) Primeiro, é alocado o caminho principal e para isso, cada salto da rota é marcado na matriz de tráfego segundo o comprimento de onda. A matriz de tráfego quando é alocado o caminho principal do primeiro evento $(1-4 \mathrm{com} \lambda=$ 1) é mostrada na Tabela A.15.

Da mesma forma, é alocado o caminho de proteção, sendo marcado na matriz de tráfego, $T_{\lambda 1}$.Alocamos o caminho secundário $1-2-4 \operatorname{com} \lambda=1$, como é mostrado na tabela Tabela A.16.

b) São atualizadas a matriz $U_{w b}$ (utilização de enlaces), a matriz Num_w, que contêm a quantidade de caminhos principais por enlace, e a matriz Num_b , que contêm a quantidade de caminhos de proteção por enlace.

Assim, na matriz $U_{w b}$ os enlaces usados podem ser marcados com $0,1,2,3$, ou inf se não houver enlace. Na Tabela A.17 pode ver-se a atualização da matriz $U_{w b}$ para o primeiro evento.

A atualização da matriz de quantidade de caminhos principais por enlace, Num_w, para o primeiro evento é mostrada na Tabela A.18. E a matriz atuali- 


$T_{\lambda 1}=$\begin{tabular}{ccccccc}
\hline nó $\backslash$ nó & $\mathbf{1}$ & $\mathbf{2}$ & $\mathbf{3}$ & $\mathbf{4}$ & $\mathbf{5}$ & $\mathbf{6}$ \\
\hline $\mathbf{1}$ & 0 & $\mathbf{1}$ & 0 & $\mathbf{1}$ & 0 & 0 \\
$\mathbf{2}$ & 0 & 0 & 0 & $\mathbf{1}$ & 0 & 0 \\
$\mathbf{3}$ & 0 & 0 & 0 & 0 & 0 & 0 \\
$\mathbf{4}$ & 0 & 0 & 0 & 0 & 0 & 0 \\
$\mathbf{5}$ & 0 & 0 & 0 & 0 & 0 & 0 \\
$\mathbf{6}$ & 0 & 0 & 0 & 0 & 0 & 0 \\
\hline
\end{tabular}

Tabela A.16.: Atualização da matriz de tráfego para $\lambda 1$ com o caminho de proteção do primeiro evento alocado.

$U_{w b}=$\begin{tabular}{ccccccc}
\hline nó $\backslash$ nó & $\mathbf{1}$ & $\mathbf{2}$ & $\mathbf{3}$ & $\mathbf{4}$ & $\mathbf{5}$ & $\mathbf{6}$ \\
\hline $\mathbf{1}$ & inf & $\mathbf{2}$ & 0 & $\mathbf{1}$ & 0 & 0 \\
$\mathbf{2}$ & 0 & inf & 0 & $\mathbf{2}$ & inf & 0 \\
$\mathbf{3}$ & 0 & 0 & $\inf$ & 0 & 0 & $\inf$ \\
$\mathbf{4}$ & 0 & 0 & 0 & inf & 0 & 0 \\
$\mathbf{5}$ & 0 & inf & 0 & 0 & inf & inf \\
$\mathbf{6}$ & 0 & 0 & inf & 0 & inf & inf \\
\hline
\end{tabular}

Tabela A.17.: Atualização da matriz de utilização de enlaces para o primeiro evento.

zada de quantidade de caminhos de proteção por enlace, Num_ $b$, pode ver-se na Tabela A.32.

Em seguida, ilustraremos o desenvolvimento dos algoritmos para o segundo evento segundo os passos descritos. Evento 2 -> Nó fonte: 2, Nó destino: 4, Alocação.

1. Algoritmo de busca de recursos para o caminho principal.

a) Primeiro é feita a extração dos candidatos a caminhos principais. A lista é mos-

Num_w $=$\begin{tabular}{ccccccc}
\hline nó $\backslash$ nó & $\mathbf{1}$ & $\mathbf{2}$ & $\mathbf{3}$ & $\mathbf{4}$ & $\mathbf{5}$ & $\mathbf{6}$ \\
\hline $\mathbf{1}$ & 0 & 0 & 0 & $\mathbf{1}$ & 0 & 0 \\
$\mathbf{2}$ & 0 & 0 & 0 & 0 & 0 & 0 \\
$\mathbf{3}$ & 0 & 0 & 0 & 0 & 0 & 0 \\
$\mathbf{4}$ & 0 & 0 & 0 & 0 & 0 & 0 \\
$\mathbf{5}$ & 0 & 0 & 0 & 0 & 0 & 0 \\
$\mathbf{6}$ & 0 & 0 & 0 & 0 & 0 & 0 \\
\hline
\end{tabular}

Tabela A.18.: Atualização da matriz quantidade de caminhos principais por enlace para o primeiro evento. 


Num_b $_{-}=$\begin{tabular}{ccccccc}
\hline nó $\backslash$ nó & $\mathbf{1}$ & $\mathbf{2}$ & $\mathbf{3}$ & $\mathbf{4}$ & $\mathbf{5}$ & $\mathbf{6}$ \\
\hline $\mathbf{1}$ & 0 & $\mathbf{1}$ & 0 & 0 & 0 & 0 \\
$\mathbf{2}$ & 0 & 0 & 0 & $\mathbf{1}$ & 0 & 0 \\
$\mathbf{3}$ & 0 & 0 & 0 & 0 & 0 & 0 \\
$\mathbf{4}$ & 0 & 0 & 0 & 0 & 0 & 0 \\
$\mathbf{5}$ & 0 & 0 & 0 & 0 & 0 & 0 \\
$\mathbf{6}$ & 0 & 0 & 0 & 0 & 0 & 0 \\
\hline
\end{tabular}

Tabela A.19.: Atualização da matriz quantidade de caminhos de proteção por enlace para o primeiro evento.

trada na Tabela A.20. A seguir é analisada a disponibilidade de cada um deles. As rotas disponíveis são mostradas na Tabela A.21.

\begin{tabular}{lll}
\hline & id & rotas \\
\hline & 1 & $2-4$ \\
$W^{(2),(4)}$ & 2 & $2-6-4$ \\
& 3 & $2-1-4$ \\
4 & $2-3-4$ \\
5 & $2-1-3-4$
\end{tabular}

Tabela A.20.: Lista de candidatos a caminho principal entre os nós 2 e 4.

\begin{tabular}{lllc}
\hline & id & rota & comprimento de onda \\
\hline & 1 & $2-4$ & $\lambda=1$ \\
& 2 & $2-6-4$ & $\lambda=2$ \\
$W_{\text {disp }}^{(2),(4)}$ & 3 & $2-1-4$ & $\lambda=1$ \\
& 4 & $2-3-4$ & $\lambda=2$ \\
& 5 & $2-1-3-4$ & $\lambda=1$ \\
\hline
\end{tabular}

Tabela A.21.: Lista de rotas disponíveis para o caminho principal entre os nós 2 e 4.

b) O seguinte passo é a atualização da matriz de custos de acordo com os custos de A.1. A matriz de custos atualizada, $P_{\text {cost }}$, pode observar-se na Tabela A.22.

c) Cálculo de custos para as rotas disponíveis. Na Tabela A.23 é mostrada a lista com custos por rota disponível.

d) Escolhemos a rota com menor custo (rota 3)

$$
W_{\text {path }}^{(2),(4)}: 2-1-4
$$




\begin{tabular}{rccccccc}
\hline nó $\backslash$ nó & $\mathbf{1}$ & $\mathbf{2}$ & $\mathbf{3}$ & $\mathbf{4}$ & $\mathbf{5}$ & $\mathbf{6}$ \\
\cline { 2 - 7 }$P_{\text {cost }}=\mathbf{1}$ & inf & 36720 & 48 & 0 & 48 & 96 \\
$\mathbf{2}$ & 48 & inf & 72 & 36720 & inf & 48 \\
$\mathbf{3}$ & 48 & 72 & inf & 48 & 48 & inf \\
$\mathbf{4}$ & 72 & 48 & 48 & inf & 96 & 48 \\
$\mathbf{5}$ & 48 & inf & 48 & 96 & inf & inf \\
$\mathbf{6}$ & 96 & 48 & inf & 48 & inf & inf \\
\hline
\end{tabular}

Tabela A.22.: Matriz de custos por enlace atualizada.

\begin{tabular}{rcrc}
\hline & id & custo por salto & custo total \\
\hline & 1 & 36720 & 36720 \\
$P_{\text {cost }}^{W_{\text {diss }}}$ & 2 & $48+48$ & 96 \\
& 3 & $48+0$ & 48 \\
& 4 & $72+48$ & 120 \\
& 5 & $48+48+48$ & 144 \\
\hline
\end{tabular}

Tabela A.23.: Lista de custos para os caminhos principais disponíveis entre os nós 2 e 4 .

e) A rota será alocada no comprimento de onda seguindo o método first-fit. Assim, o comprimento de onda para o caminho principal do segundo evento será $\lambda_{W_{\text {path }}^{(2),(4)}}=2$

2. Algoritmo de busca de recursos para o caminho de proteção

a) Extração dos candidatos a caminhos de proteção tendo como rota principal 2-1-4. A lista de candidatos é mostrada na Tabela A.24. Depois, é analisada a disponibilidade de cada um dos candidatos. As rotas disponíveis estão listadas na Tabela A.25.

\begin{tabular}{lll}
\hline & id & rotas \\
\hline & 1 & $2-4$ \\
& 2 & $2-6-4$ \\
$B^{(2),(4)}$ & 3 & $2-3-4$ \\
& 4 & $2-6-1-3-4$ \\
& 5 & $2-3-5-4$ \\
\hline
\end{tabular}

Tabela A.24.: Lista de candidatos a caminho de proteção entre os nós 2 e 4.

b) A matriz de custos é atualizada de acordo com A.2. A Tabela A.26 contém a matriz $P_{\text {cost }}$ atualizada. 


\begin{tabular}{lllc}
\hline & id & rota & comprimento de onda \\
\hline & 1 & $2-4$ & $\lambda=2$ \\
& 2 & $2-6-4$ & $\lambda=2$ \\
$B_{\text {disp }}^{(2),(4)}$ & 3 & $2-3-4$ & $\lambda=2$ \\
& 4 & $2-6-1-3-4$ & $\lambda=1$ \\
& 5 & $2-3-5-4$ & $\lambda=1$ \\
\hline
\end{tabular}

Tabela A.25.: Lista de rotas disponíveis para o caminho de proteção entre os nós 2 e 4.

\begin{tabular}{cccccccc}
\hline nó $\backslash$ nó & $\mathbf{1}$ & $\mathbf{2}$ & $\mathbf{3}$ & $\mathbf{4}$ & $\mathbf{5}$ & $\mathbf{6}$ \\
\hline $\mathbf{1}$ & inf & 0 & 48 & 36720 & 48 & 96 \\
$\mathbf{2}$ & 48 & inf & 72 & 0 & inf & 48 \\
$\mathbf{3}$ & 48 & 72 & inf & 48 & 48 & inf \\
$\mathbf{4}$ & 72 & 48 & 48 & inf & 96 & 48 \\
$\mathbf{5}$ & 48 & inf & 48 & 96 & inf & inf \\
$\mathbf{6}$ & 96 & 48 & inf & 48 & inf & inf \\
\hline
\end{tabular}

Tabela A.26.: Matriz de custos por enlace atualizada.

c) São calculados os custos para as rotas disponíveis. Os custos são mostrados na Tabela A.27.

d) É escolhida a rota com menor custo para o caminho de proteção (rota 1)

$$
B_{\text {path }}^{(2),(4)}: 2-4
$$

e) Comprimento de onda de acordo ao método first-fit, $\lambda_{B_{\text {path }}^{(2),(4)}}=2$.

3. Algoritmo de alocação de caminho principal e de proteção.

a) Atualização da matriz de tráfego por comprimento de onda, com os caminhos principal e de proteção escolhidos para segundo evento alocados. Nas tabelas

\begin{tabular}{rcrc}
\hline & id & custo por salto & custo total \\
\hline & 1 & 0 & 0 \\
$P_{\text {cost }}^{B_{\text {disp }}}$ & 2 & $48+48$ & 96 \\
& 3 & $72+48$ & 120 \\
& 4 & $48+96+48+48$ & 240 \\
& 5 & $72+48+96$ & 216 \\
\hline
\end{tabular}

Tabela A.27.: Lista de custos para os caminhos de proteção disponíveis entre os nós 2 e 4. 


$T_{\lambda 1}=$\begin{tabular}{ccccccc}
\hline nó $\backslash$ nó & $\mathbf{1}$ & $\mathbf{2}$ & $\mathbf{3}$ & $\mathbf{4}$ & $\mathbf{5}$ & $\mathbf{6}$ \\
\hline $\mathbf{1}$ & 0 & 1 & 0 & 1 & 0 & 0 \\
$\mathbf{2}$ & 0 & 0 & 0 & 1 & 0 & 0 \\
$\mathbf{3}$ & 0 & 0 & 0 & 0 & 0 & 0 \\
$\mathbf{4}$ & 0 & 0 & 0 & 0 & 0 & 0 \\
$\mathbf{5}$ & 0 & 0 & 0 & 0 & 0 & 0 \\
$\mathbf{6}$ & 0 & 0 & 0 & 0 & 0 & 0 \\
\hline
\end{tabular}

Tabela A.28:: Atualização da matriz de tráfego para $\lambda 1$ no evento 2 .

$T_{\lambda 2}=$\begin{tabular}{ccccccc}
\hline nó $\backslash$ nó & $\mathbf{1}$ & $\mathbf{2}$ & $\mathbf{3}$ & $\mathbf{4}$ & $\mathbf{5}$ & $\mathbf{6}$ \\
\hline $\mathbf{1}$ & 0 & 0 & 0 & $\mathbf{1}$ & 0 & 0 \\
$\mathbf{2}$ & $\mathbf{1}$ & 0 & 0 & $\mathbf{1}$ & 0 & 0 \\
$\mathbf{3}$ & 0 & 0 & 0 & 0 & 0 & 0 \\
$\mathbf{4}$ & 0 & 0 & 0 & 0 & 0 & 0 \\
$\mathbf{5}$ & 0 & 0 & 0 & 0 & 0 & 0 \\
$\mathbf{6}$ & 0 & 0 & 0 & 0 & 0 & 0 \\
\hline
\end{tabular}

Tabela A.29.: Atualização da matriz de tráfego para $\lambda 2$ no evento 2.

A.28 e A.29 são mostradas as matrizes de tráfego para os comprimentos 1 e 2 respectivamente.

b) Atualização das matrizes auxiliares $U_{w b}$, Num_ $w$ e Num_b. A matriz de tipo de utilização do enlace atualizada é mostrada na Tabela A.30.

Na Tabela A.31 mostra-se a atualização da matriz de número de caminhos principais por enlace. E a matriz de número de caminhos de proteção por enlace atualizada pode ver-se na Tabela A.32.

$U_{w b}=$\begin{tabular}{ccccccc}
\hline nó $\backslash$ nó & $\mathbf{1}$ & $\mathbf{2}$ & $\mathbf{3}$ & $\mathbf{4}$ & $\mathbf{5}$ & $\mathbf{6}$ \\
\hline $\mathbf{1}$ & inf & 2 & 0 & $\mathbf{1}$ & 0 & 0 \\
$\mathbf{2}$ & $\mathbf{1}$ & inf & 0 & $\mathbf{2}$ & inf & 0 \\
$\mathbf{3}$ & 0 & 0 & $\inf$ & 0 & 0 & $\inf$ \\
$\mathbf{4}$ & 0 & 0 & 0 & $\inf$ & 0 & 0 \\
$\mathbf{5}$ & 0 & inf & 0 & 0 & inf & inf \\
$\mathbf{6}$ & 0 & 0 & inf & 0 & inf & inf \\
\hline
\end{tabular}

Tabela A.30.: Matriz de tipo de utilização do enlace para o evento 2. 


Num_w $=$\begin{tabular}{ccccccc}
\hline nó $\backslash$ nó & $\mathbf{1}$ & $\mathbf{2}$ & $\mathbf{3}$ & $\mathbf{4}$ & $\mathbf{5}$ & $\mathbf{6}$ \\
\hline $\mathbf{1}$ & 0 & 0 & 0 & $\mathbf{2}$ & 0 & 0 \\
$\mathbf{2}$ & $\mathbf{1}$ & 0 & 0 & 0 & 0 & 0 \\
$\mathbf{3}$ & 0 & 0 & 0 & 0 & 0 & 0 \\
$\mathbf{4}$ & 0 & 0 & 0 & 0 & 0 & 0 \\
$\mathbf{5}$ & 0 & 0 & 0 & 0 & 0 & 0 \\
$\mathbf{6}$ & 0 & 0 & 0 & 0 & 0 & 0 \\
\hline
\end{tabular}

Tabela A.31.: Atualização da matriz de quantidade de caminhos principais por enlace para o evento 2 .

\begin{tabular}{|c|c|c|c|c|c|c|c|c|}
\hline \multirow{7}{*}{ Num_b } & \multirow{7}{*}{$=$} & nó \nó & 1 & 2 & 3 & 4 & 5 & 6 \\
\hline & & 1 & 0 & 1 & 0 & 0 & 0 & 0 \\
\hline & & 2 & 0 & 0 & 0 & 2 & 0 & 0 \\
\hline & & 3 & 0 & 0 & 0 & 0 & 0 & 0 \\
\hline & & 4 & 0 & 0 & 0 & 0 & 0 & 0 \\
\hline & & 5 & 0 & 0 & 0 & 0 & 0 & 0 \\
\hline & & 6 & 0 & 0 & 0 & 0 & 0 & 0 \\
\hline
\end{tabular}

Tabela A.32.: Atualização da matriz de quantidade de caminhos de proteção por enlace para o evento 2.

Dessa maneira, são roteados os eventos de alocação que, no exemplo, foram os 5 primeiros. Assim, depois de achar e alocar os caminhos principal e de proteção as matrizes auxiliares são atualizadas como segue. As matrizes de tráfego para os comprimentos de onda 1, 2 e 3, para o evento 5, são mostradas nas tabelas A.33, A.34 e A.35 respectivamente.

A matriz de tipo de utilização do enlace atualizada, para o evento 5, é mostrada na Tabela A.36. Nas tabelas A.37 e A.38 mostra-se, respectivamente, a atualização da matriz de número de caminhos principais e da matriz de número de caminhos de proteção por

$T_{\lambda 1}=$\begin{tabular}{ccccccc}
\hline nó $\backslash$ nó & $\mathbf{1}$ & $\mathbf{2}$ & $\mathbf{3}$ & $\mathbf{4}$ & $\mathbf{5}$ & $\mathbf{6}$ \\
\hline $\mathbf{1}$ & 0 & 1 & 0 & 1 & 0 & 0 \\
$\mathbf{2}$ & 1 & 0 & 0 & 1 & 0 & 0 \\
$\mathbf{3}$ & 0 & 0 & 0 & 1 & 0 & 0 \\
$\mathbf{4}$ & 1 & 1 & 0 & 0 & 0 & 1 \\
$\mathbf{5}$ & 0 & 0 & 1 & 0 & 0 & 0 \\
$\mathbf{6}$ & 0 & 0 & 0 & 0 & 0 & 0 \\
\hline
\end{tabular}

Tabela A.33.: Atualização da matriz de tráfego para $\lambda 1$ no evento 5. 


$$
T_{\lambda 2}=\begin{array}{ccccccc}
\hline \text { nó } \backslash \text { nó } & \mathbf{1} & \mathbf{2} & \mathbf{3} & \mathbf{4} & \mathbf{5} & \mathbf{6} \\
\hline \mathbf{1} & 0 & 1 & 0 & 1 & 0 & 0 \\
\mathbf{2} & 1 & 0 & 0 & 1 & 0 & 1 \\
\mathbf{3} & 0 & 0 & 0 & 0 & 0 & 0 \\
\mathbf{4} & 0 & 0 & 0 & 0 & 0 & 0 \\
\mathbf{5} & 1 & 0 & 0 & 0 & 0 & 0 \\
\mathbf{6} & 0 & 0 & 0 & 0 & 0 & 0
\end{array}
$$

Tabela A.34.: Atualização da matriz de tráfego para $\lambda 2$ no evento 5.

$T_{\lambda 3}=$\begin{tabular}{ccccccc}
\hline nó $\backslash$ nó & $\mathbf{1}$ & $\mathbf{2}$ & $\mathbf{3}$ & $\mathbf{4}$ & $\mathbf{5}$ & $\mathbf{6}$ \\
\hline $\mathbf{1}$ & 0 & 1 & 0 & 1 & 0 & 0 \\
$\mathbf{2}$ & 0 & 0 & 0 & 1 & 0 & 0 \\
$\mathbf{3}$ & 0 & 0 & 0 & 0 & 0 & 0 \\
$\mathbf{4}$ & 0 & 0 & 0 & 0 & 0 & 0 \\
$\mathbf{5}$ & 0 & 0 & 0 & 0 & 0 & 0 \\
$\mathbf{6}$ & 0 & 0 & 0 & 0 & 0 & 0 \\
\hline
\end{tabular}

Tabela A.35.: Atualização da matriz de tráfego para $\lambda 3$ no evento 5.

enlace.

$U_{w b}=$\begin{tabular}{ccccccc}
\hline nó $\backslash$ nó & $\mathbf{1}$ & $\mathbf{2}$ & $\mathbf{3}$ & $\mathbf{4}$ & $\mathbf{5}$ & $\mathbf{6}$ \\
\hline $\mathbf{1}$ & inf & 2 & 0 & 1 & 0 & 0 \\
$\mathbf{2}$ & 1 & inf & 0 & 2 & inf & 2 \\
$\mathbf{3}$ & 0 & 0 & inf & 1 & 0 & inf \\
$\mathbf{4}$ & 2 & 1 & 0 & inf & 0 & 1 \\
$\mathbf{5}$ & 2 & inf & 1 & 0 & inf & inf \\
$\mathbf{6}$ & 0 & 0 & inf & 0 & inf & inf \\
\hline
\end{tabular}

Tabela A.36.: Atualização da matriz de utilização de enlaces para o evento 5.

\section{Desalocação de eventos}

Em seguida, ilustraremos o desenvolvimento do algoritmo de desalocação 7. O primeiro evento de desalocação no exemplo é

Evento 6 -> Nó fonte: 4, Nó destino: 1, Deslocação, Identificador: 3.

1. Algoritmo de desalocação de caminho principal e de proteção. 


Num_ $_{-} w=$\begin{tabular}{ccccccc}
\hline nó $\backslash$ nó & $\mathbf{1}$ & $\mathbf{2}$ & $\mathbf{3}$ & $\mathbf{4}$ & $\mathbf{5}$ & $\mathbf{6}$ \\
\hline $\mathbf{1}$ & 0 & 0 & 0 & 3 & 0 & 0 \\
$\mathbf{2}$ & 2 & 0 & 0 & 0 & 0 & 0 \\
$\mathbf{3}$ & 0 & 0 & 0 & 1 & 0 & 0 \\
$\mathbf{4}$ & 0 & 1 & 0 & 0 & 0 & 1 \\
$\mathbf{5}$ & 0 & 0 & 1 & 0 & 0 & 0 \\
$\mathbf{6}$ & 0 & 0 & 0 & 0 & 0 & 0 \\
\hline
\end{tabular}

Tabela A.37.: Atualização da matriz de quantidade de caminhos principais por enlace para o evento 5 .

Num_b $=$\begin{tabular}{ccccccc}
\hline nó $\backslash$ nó & $\mathbf{1}$ & $\mathbf{2}$ & $\mathbf{3}$ & $\mathbf{4}$ & $\mathbf{5}$ & $\mathbf{6}$ \\
\hline $\mathbf{1}$ & 0 & 3 & 0 & 0 & 0 & 0 \\
$\mathbf{2}$ & 0 & 0 & 0 & 3 & 0 & 1 \\
$\mathbf{3}$ & 0 & 0 & 0 & 0 & 0 & 0 \\
$\mathbf{4}$ & 1 & 0 & 0 & 0 & 0 & 0 \\
$\mathbf{5}$ & 1 & 0 & 0 & 0 & 0 & 0 \\
$\mathbf{6}$ & 0 & 0 & 0 & 0 & 0 & 0 \\
\hline
\end{tabular}

Tabela A.38.: Atualização da matriz de quantidade de caminhos de proteção por enlace para o evento 5 .

a) O primeiro passo segundo o identificador do evento, é confirmar se o evento foi alocado ou se foi bloqueado por não haver recursos disponíveis.

No caso em que o evento tenha sido alocado, é extraído o caminho principal e de proteção que foi achado no seu respectivo evento de alocação (evento 3), além do comprimento de onda.

$$
\begin{gathered}
W_{\text {path }}^{e v 3}=4-2-1, \lambda_{W_{\text {path }}^{e v 3}}=1 \\
B_{\text {path }}^{\text {ev3 }}=4-1, \lambda_{B_{\text {path }}^{e v 3}=1}=1
\end{gathered}
$$

b) Depois, é desalocado o caminho principal e o de proteção. Cada salto das rotas é desmarcado nas matrizes de tráfego (marcado com 0). A atualização das matrizes de tráfego por comprimento de onda $(1,2$ e 3), pode observar-se nas tabelas A.39, A.40 e A.41.

c) Atualização das matrizes auxiliares $U_{w b}$, Num_ $w$ e Num_b

Para atualizar a matriz de utilização $U_{w b}$ são usada a matrizes Num_w e Num_ $b$, já que elas contêm informação sobre a quantidade de caminhos que 


$T_{\lambda 1}=$\begin{tabular}{ccccccc}
\hline nó $\backslash$ nó & $\mathbf{1}$ & $\mathbf{2}$ & $\mathbf{3}$ & $\mathbf{4}$ & $\mathbf{5}$ & $\mathbf{6}$ \\
\hline $\mathbf{1}$ & 0 & 1 & 0 & 1 & 0 & 0 \\
$\mathbf{2}$ & $\mathbf{0}$ & 0 & 0 & 1 & 0 & 0 \\
$\mathbf{3}$ & 0 & 0 & 0 & 1 & 0 & 0 \\
$\mathbf{4}$ & $\mathbf{0}$ & $\mathbf{0}$ & 0 & 0 & 0 & 1 \\
$\mathbf{5}$ & 0 & 0 & 1 & 0 & 0 & 0 \\
$\mathbf{6}$ & 0 & 0 & 0 & 0 & 0 & 0 \\
\hline
\end{tabular}

Tabela A.39.: Atualização da matriz de tráfego para $\lambda 1$ no evento 6 .

$T_{\lambda 2}=$\begin{tabular}{ccccccc}
\hline nó $\backslash$ nó & $\mathbf{1}$ & $\mathbf{2}$ & $\mathbf{3}$ & $\mathbf{4}$ & $\mathbf{5}$ & $\mathbf{6}$ \\
\hline $\mathbf{1}$ & 0 & 1 & 0 & 1 & 0 & 0 \\
$\mathbf{2}$ & 1 & 0 & 0 & 1 & 0 & 1 \\
$\mathbf{3}$ & 0 & 0 & 0 & 0 & 0 & 0 \\
$\mathbf{4}$ & 0 & 0 & 0 & 0 & 0 & 0 \\
$\mathbf{5}$ & 1 & 0 & 0 & 0 & 0 & 0 \\
$\mathbf{6}$ & 0 & 0 & 0 & 0 & 0 & 0 \\
\hline
\end{tabular}

Tabela A.40.: Atualização da matriz de tráfego para $\lambda 2$ no evento 6 .

$T_{\lambda 3}=$\begin{tabular}{ccccccc}
\hline nó $\backslash$ nó & $\mathbf{1}$ & $\mathbf{2}$ & $\mathbf{3}$ & $\mathbf{4}$ & $\mathbf{5}$ & $\mathbf{6}$ \\
\hline $\mathbf{1}$ & 0 & 1 & 0 & 1 & 0 & 0 \\
$\mathbf{2}$ & 0 & 0 & 0 & 1 & 0 & 0 \\
$\mathbf{3}$ & 0 & 0 & 0 & 0 & 0 & 0 \\
$\mathbf{4}$ & 0 & 0 & 0 & 0 & 0 & 0 \\
$\mathbf{5}$ & 0 & 0 & 0 & 0 & 0 & 0 \\
$\mathbf{6}$ & 0 & 0 & 0 & 0 & 0 & 0 \\
\hline
\end{tabular}

Tabela A.41.: Atualização da matriz de tráfego para $\lambda 3$ no evento 6 . 
estão passando pelo enlace. Cada salto da rota ao ser desalocado é atualizado na matriz. Assim, se um enlace $l$ na matriz $U_{w b}$ é 1 (significando que há somente caminhos principais) e Num_ $w(l)=1$ (há somente um caminho principal), então ao desalocar, o enlace $l$ ficaria vazio, pelo que $U_{w b}(l)=0$. Procede-se da mesma maneira com os caminhos de proteção.

Um outro caso é se há um enlace misto, $U_{w b}(l)=3$, e $l$ é parte de um caminho de proteção. Por exemplo, se ao analisar Num_b(l) se encontramos somete um caminho de proteção (Num_b $=1$ ), quando seja feita a desalocação, o enlace estará sendo usado somente por caminhos principais. Significando que deixaria de ser um enlace misto, $U_{w b}(l)=1$. No exemplo a rota principal é 4-2-1 e 4-1 é a de proteção. Os enlace 4-2 e 4-1 somente há um caminho principal e um de proteção, respectivamente, pelo que ficarão vazios ao momento da desalocação. No caso do enlace $2-1$, ele tem dois caminhos principais alocados. Ao desalocar um deles o enlace na matriz $U_{w b}$ seguirá sendo 1 porque é usado somente por caminhos principais.

Assim, a matriz de tipo de utilização do enlace depois da desalocação é apresentada na Tabela A.42.

$U_{w b}=$\begin{tabular}{ccccccc}
\hline nó $\backslash$ nó & $\mathbf{1}$ & $\mathbf{2}$ & $\mathbf{3}$ & $\mathbf{4}$ & $\mathbf{5}$ & $\mathbf{6}$ \\
\hline $\mathbf{1}$ & inf & 2 & 0 & 1 & 0 & 0 \\
$\mathbf{2}$ & $\mathbf{1}$ & inf & 0 & 2 & inf & 2 \\
$\mathbf{3}$ & 0 & 0 & $\inf$ & 1 & 0 & inf \\
$\mathbf{4}$ & $\mathbf{0}$ & $\mathbf{0}$ & 0 & inf & 0 & 1 \\
$\mathbf{5}$ & 2 & inf & 1 & 0 & inf & inf \\
$\mathbf{6}$ & 0 & 0 & inf & 0 & inf & inf \\
\hline
\end{tabular}

Tabela A.42.: Atualização da matriz de utilização de enlaces para o evento 6.

Segundo os saltos do caminho principal a soma dos enlaces que fazem parte dele é diminuída em 1 . Assim, a matriz de número de caminhos principais por enlace mostra-se na Tabela A.43. Da mesma forma, a soma dos enlaces que fazem parte do caminho de proteção é diminuída em 1. A matriz de número de caminhos de proteção por enlace é apresentada na Tabela A.44.

Dessa maneira são analisados todos os eventos segundo seu tipo, já seja de alocação ou desalocação. No caso de ser eventos de alocação, são extraídas as rotas candidatas para o caminho principal e de proteção. Analisada a disponibilidade das rotas candidatas, calculados os custos delas, escolhida a rota com o menor custo para ambos os caminhos e atualizada a alocação nas matrizes auxiliares. Se o eventos é de desalocação e o seu 


Num_w $=$\begin{tabular}{ccccccc}
\hline nó $\backslash$ nó & $\mathbf{1}$ & $\mathbf{2}$ & $\mathbf{3}$ & $\mathbf{4}$ & $\mathbf{5}$ & $\mathbf{6}$ \\
\hline $\mathbf{1}$ & 0 & 0 & 0 & 3 & 0 & 0 \\
$\mathbf{2}$ & $\mathbf{1}$ & 0 & 0 & 0 & 0 & 0 \\
$\mathbf{3}$ & 0 & 0 & 0 & 1 & 0 & 0 \\
$\mathbf{4}$ & 0 & $\mathbf{0}$ & 0 & 0 & 0 & 1 \\
$\mathbf{5}$ & 0 & 0 & 1 & 0 & 0 & 0 \\
$\mathbf{6}$ & 0 & 0 & 0 & 0 & 0 & 0 \\
\hline
\end{tabular}

Tabela A.43.: Atualização da matriz de quantidade de caminhos principais por enlace para o evento 6.

Num_$\_b_{-}=$\begin{tabular}{ccccccc}
\hline nó $\backslash$ nó & $\mathbf{1}$ & $\mathbf{2}$ & $\mathbf{3}$ & $\mathbf{4}$ & $\mathbf{5}$ & $\mathbf{6}$ \\
\hline $\mathbf{1}$ & 0 & 3 & 0 & 0 & 0 & 0 \\
$\mathbf{2}$ & 0 & 0 & 0 & 3 & 0 & 1 \\
$\mathbf{3}$ & 0 & 0 & 0 & 0 & 0 & 0 \\
$\mathbf{4}$ & $\mathbf{0}$ & 0 & 0 & 0 & 0 & 0 \\
$\mathbf{5}$ & 1 & 0 & 0 & 0 & 0 & 0 \\
$\mathbf{6}$ & 0 & 0 & 0 & 0 & 0 & 0 \\
\hline
\end{tabular}

Tabela A.44.: Atualização da matriz de quantidade de caminhos de proteção por enlace para o evento 6.

respectivo evento de alocação foi previamente atendido, são extraídas as rotas que foram alocadas e atualizada a desalocação nas matrizes auxiliares.

Nesta seção foi apresentado um exemplo passo a passo dos algoritmos implementados para uma rede de teste pequena. O objetivo foi mostrar o desenvolvimento dos algoritmos de uma maneira mas clara e detalhada, e assim validar o correto funcionamento da implementação dos algoritmos de roteamento com base em economia de energia. 


\section{Referências Bibliográficas}

[1] Y. Zhang, P. Chowdhury, M. Tornatore, and B. Mukherjee, "Energy efficiency in telecom optical networks," Communications Surveys Tutorials, IEEE, vol. 12, no. 4, pp. 441-458, 2010.

[2] R. Bolla, R. Bruschi, F. Davoli, and F. Cucchietti, "Energy efficiency in the future internet: A survey of existing approaches and trends in energy-aware fixed network infrastructures," Communications Surveys Tutorials, IEEE, vol. 13, no. 2, pp. 223-244, 2011.

[3] A. Bianzino, C. Chaudet, D. Rossi, and J. Rougier, "A survey of green networking research," Communications Surveys Tutorials, IEEE, vol. 14, no. 1, pp. 3-20, 2012.

[4] J. E. P. de Farias, "Eficiência energética em redes ópticas de transporte," REVISTA DE TECNOLOGIA DA INFORMACAO E COMUNICAC AO, vol. 2, no. 1, p. 9, 2012.

[5] P. Leisching and M. Pickavet, "Energy footprint of ict: Forecasts and network solutions," in Ofc/nfoec, vol. 9, 2009.

[6] C. Lange, D. Kosiankowski, R. Weidmann, and A. Gladisch, "Energy consumption of telecommunication networks and related improvement options," Selected Topics in Quantum Electronics, IEEE Journal of, vol. 17, no. 2, pp. 285-295, 2011.

[7] W. Vereecken, W. Van Heddeghem, D. Colle, M. Pickavet, and P. Demeester, "Overall ict footprint and green communication technologies," in Communications, Control and Signal Processing (ISCCSP), 2010 4th International Symposium on, 2010, pp. 1-6.

[8] D. Pamlin and K. Szomolányi, "Saving the climate at the speed of light. first roadmap for reduced co2 emissions in the eu and beyond," European Telecommunications Network Operators Association and WWF, 2006. 
[9] D. Kilper, "Tutorial: Energy efficient networks," in Optical Fiber Communication Conference and Exposition (OFC/NFOEC), 2011 and the National Fiber Optic Engineers Conference, 2011, pp. 1-67.

[10] M. Webb et al., "Smart 2020: Enabling the low carbon economy in the information age," The Climate Group. London, vol. 1, no. 1, pp. 1-1, 2008.

[11] K. Roth, F. Goldstein, and J. Kleinman, "Energy consumption by office and telecommunications equipment in commercial buildings volume i: energy consumption baseline," National Technical Information Service (NTIS), US Department of Commerce, Springfield, VA, vol. 22161, 2002.

[12] B. Nordman and K. Christensen, "Reducing the energy consumption of network devices," Tutorial presented at the July, 2005.

[13] B. Mukherjee, "Energy savings in telecom network," in Tutorial SBRC, Campo Grande, MS, 2011.

[14] C. Miller. (2011) Energy efficiency guide: Data center temperature. [Online]. Available: http://www.datacenterknowledge.com/archives/2011/03/10/ energy-efficiency-guide-data-center-temperature/

[15] D. Zuckerman, "Green communications-management included," in IEEE International Conference on Communications Workshops (Green-Comm09), 2009.

[16] Y. Yano, "Take the expressway to go greener," in Solid-State Circuits Conference Digest of Technical Papers (ISSCC), 2012 IEEE International, 2012, pp. 24-30.

[17] H. G. Perros, Connection-oriented networks: SONET/SDH, ATM, MPLS and optical networks. Wiley, 2005.

[18] N.-H. Bao, L.-M. Li, H.-F. Yu, Z.-Z. Zhang, and H.-B. Luo, "Power-aware provisioning strategy with shared path protection in optical wdm networks," Optical Fiber Technology, vol. 18, pp. 81-87, 2012.

[19] M. Liotine, Mission-Critical Network Planning, ser. Artech House telecommunications library. Artech House, Incorporated, 2003.

[20] W. R. de Santana, "Estudo sobre modelagem e avaliação de confiabilidade em redes óticas,” Dissertação de Mestrado em Engenharia da Informação, UFABC, 2007.

[21] R. Diestel, Graph Theory (Graduate Texts in Mathematics), 4th ed. Springer, 2010, vol. 173. 
[22] D. B. West et al., Introduction to graph theory. Prentice hall Upper Saddle River, 2001, vol. 2.

[23] F. R. Chung, Spectral graph theory. American Mathematical Soc., 1997, vol. 92.

[24] L.-C. Wang and S. Rangapillai, "A survey on green 5g cellular networks," in Signal Processing and Communications (SPCOM), 2012 International Conference on, 2012, pp. 1-5.

[25] L. Irish and K. J. Christensen, "A green tcp/ip to reduce electricity consumed by computers," in Southeastcon'98. Proceedings. IEEE. IEEE, 1998, pp. 302-305.

[26] M. Gupta and S. Singh, "Greening of the internet," in Proceedings of the 2003 conference on Applications, technologies, architectures, and protocols for computer communications, ser. SIGCOMM'03. New York, NY, USA: ACM, 2003, pp. 19-26.

[27] K. Christensen, B. Nordman, and R. Brown, "Power management in networked devices," Computer, vol. 37, no. 8, pp. 91-93, 2004.

[28] H. Ikebe, N. Yamashita, and R. Nishii, "Green energy for telecommunications," in Telecommunications Energy Conference, 2007. INTELEC 2007. 29th International, 2007, pp. 750-755.

[29] G. Goth, "The net is going green: Multipronged approach might save costs, energy and the climate," Internet Computing, IEEE, vol. 12, no. 1, pp. 7-9, 2008.

[30] L. Ceuppens, A. Sardella, and D. Kharitonov, "Power saving strategies and technologies in network equipment opportunities and challenges, risk and rewards," in $A p$ plications and the Internet, 2008. SAINT 2008. International Symposium on, 2008, pp. 381-384.

[31] M. Jimeno, K. Christensen, and B. Nordman, "A network connection proxy to enable hosts to sleep and save energy," in Performance, Computing and Communications Conference, 2008. IPCCC 2008. IEEE International, 2008, pp. 101-110.

[32] L. Hu, H. Jin, X. Liao, X. Xiong, and H. Liu, "Magnet: A novel scheduling policy for power reduction in cluster with virtual machines," in Cluster Computing, 2008 IEEE International Conference on, 2008, pp. 13-22.

[33] R. Tucker, "Green optical communications-part i: Energy limitations in transport," Selected Topics in Quantum Electronics, IEEE Journal of, vol. 17, no. 2, pp. 245-260, 2011. 
[34] J. Chabarek, J. Sommers, P. Barford, C. Estan, D. Tsiang, and S. Wright, "Power awareness in network design and routing," in INFOCOM 2008. The 27th Conference on Computer Communications. IEEE, 2008, pp. 457-465.

[35] S.-W. Wong, L. Valcarenghi, S.-H. Yen, D. Campelo, S. Yamashita, and L. Kazovsky, "Sleep mode for energy saving pons: Advantages and drawbacks," in GLOBECOM Workshops, 2009 IEEE, 2009, pp. 1-6.

[36] W.-K. Park, C.-S. Choi, H. Lee, and K.-R. Park, "Energy efficient home gateway based on user service traffic in always-on home network environment," in Advances in Electronics and Micro-electronics, 2008. ENICS '08. International Conference on, 2008, pp. 121-125.

[37] Y. Zeng, J. Wu, N. Xiong, and D. Li, "Energy-efficient routing and rate allocation for delay tolerant networks," in Distributed Computing Systems Workshops (ICDCSW), 2012 32nd International Conference on, 2012, pp. 260-266.

[38] R. Khan, R. Bolla, M. Repetto, R. Bruschi, and M. Giribaldi, "Smart proxying for reducing network energy consumption," in Performance Evaluation of Computer and Telecommunication Systems (SPECTS), 2012 International Symposium on, 2012, pp. $1-8$.

[39] I. Kamitsos, P. Tsiaflakis, S. Ha, and M. Chiang, "Stable sleeping in dsl broadband access: Feasibility and tradeoffs," in Global Telecommunications Conference (GLOBECOM 2011), 2011 IEEE, 2011, pp. 1-6.

[40] M. Guenach, C. Nuzman, J. Maes, and M. Peeters, "On power optimization in dsl systems," in Communications Workshops, 2009. ICC Workshops 2009. IEEE International Conference on, 2009, pp. 1-5.

[41] R. Nielsen, M. Riaz, J. Pedersen, and O. Madsen, "On the potential of using the cable trench problem in planning of ict access networks," in ELMAR, 2008. 50th International Symposium, vol. 2, 2008, pp. 585-588.

[42] R. Tucker, "Green optical communications-part ii: Energy limitations in networks," Selected Topics in Quantum Electronics, IEEE Journal of, vol. 17, no. 2, pp. 261-274, 2011.

[43] W. Meng, Y. Wang, C. Hu, K. He, J. Li, and B. Liu, "Greening the internet using multifrequency scaling scheme," in Advanced Information Networking and Applications (AINA), 2012 IEEE 26th International Conference on, 2012, pp. 928-935. 
[44] W. Yang, J.-H. Jung, and Y.-C. Kim, "Performance evaluation of energy saving in core router architecture with low power idle for obs networks," in Information Networking (ICOIN), 2012 International Conference on, 2012, pp. 318-323.

[45] Z. Hasan, H. Boostanimehr, and V. Bhargava, "Green cellular networks: A survey, some research issues and challenges," Communications Surveys Tutorials, IEEE, vol. 13, no. 4, pp. 524-540, 2011.

[46] A. Fehske, G. Fettweis, J. Malmodin, and G. Biczok, "The global footprint of mobile communications: The ecological and economic perspective," Communications Magazine, IEEE, vol. 49, no. 8, pp. 55-62, 2011.

[47] P. Ghosh, S. Das, S. Naravaram, and P. Chandhar, "Energy saving in ofdma cellular systems using base-station sleep mode: 3gpp-lte a case study," in Communications (NCC), 2012 National Conference on, 2012, pp. 1-5.

[48] M. Ismail and W. Zhuang, "Network cooperation for energy saving in green radio communications," Wireless Communications, IEEE, vol. 18, no. 5, pp. 76-81, 2011.

[49] C.-T. Tung, Y.-L. Chung, and Z. Tsai, "An efficient power-saving downlink transmission scheme in ofdm-based multiple component carrier systems," in Advanced Communication Technology (ICACT), 2012 14th International Conference on, 2012, pp. 116-120.

[50] X. Guo, G. Shou, Q. Xiao, Y. Hu, and Z. Guo, "Toward green pon with adaptive sleep mode," in Network Infrastructure and Digital Content (IC-NIDC), 2012 3rd IEEE International Conference on, 2012, pp. 184-188.

[51] A. S. Hussaini, I. T. E. Elfergani, J. Rodriguez, and R. A. Abd-Alhameed, "Efficient multi-stage load modulation radio frequency power amplifier for green radio frequency front end," Science, Measurement Technology, IET, vol. 6, no. 3, pp. 117-124, January 2012.

[52] J. Kwak, K. Son, Y. Yi, and S. Chong, "Greening effect of spatio-temporal power sharing policies in cellular networks with energy constraints," Wireless Communications, IEEE Transactions on, vol. 11, no. 12, pp. 4405-4415, 2012.

[53] M. Parker, R. Martin, K. Guild, and S. Walker, "Hierarchical wireless and optical access networking: Convergence and energy efficiency," in Transparent Optical Networks (ICTON), 2011 13th International Conference on, 2011, pp. 1-4. 
[54] A. Ali, I. Ullah, T. Tauqeer, and S. H. Zaidi, "Greening fiwi access networks," in Emerging Technologies (ICET), 2011 7th International Conference on, vol., no, 2011, pp. $1-6$.

[55] X. Liu, N. Ghazisaidi, L. Ivanescu, R. Kang, and M. Maier, "On the tradeoff between energy saving and qos support for video delivery in eee-based fiwi networks using real-world traffic traces," Lightwave Technology, Journal of, vol. 29, no. 18, pp. 26702676, 2011.

[56] A. Reaz, V. Ramamurthi, M. Tornatore, and B. Mukherjee, "Green provisioning of cloud services over wireless-optical broadband access networks," in Global Telecommunications Conference (GLOBECOM 2011), 2011 IEEE, 2011, pp. 1-5.

[57] F. Chuan and L. Anqing, "Key techniques in green communication," in Consumer Electronics, Communications and Networks (CECNet), 2011 International Conference on, 2011, pp. 1360-1363.

[58] R. Rojas-Cessa, S. Pessima, and T. Tian, "Experimental evaluation of energy savings of virtual machines in the implementation of cloud computing," in Wireless and Optical Communications Conference (WOCC), 2012 21st Annual, 2012, pp. 65-70.

[59] Y.-M. Kim, E.-J. Lee, H.-S. Park, J.-K. Choi, and H.-S. Park, "Ant colony based selfadaptive energy saving routing for energy efficient internet," Computer Networks, vol. 56, no. 10, pp. $2343-2354,2012$.

[60] P. Zhang and B. Helvik, "Towards green p2p: Analysis of energy consumption in p2p and approaches to control," in High Performance Computing and Simulation (HPCS), 2012 International Conference on, 2012, pp. 336-342.

[61] Z. Xiao, W. Song, and Q. Chen, "Dynamic resource allocation using virtual machines for cloud computing environment," IEEE Transactions on Parallel and Distributed Systems, vol. 24, no. 6, pp. 1107-1117, 2013.

[62] Y. Jin, Y. Wen, and Q. Chen, "Energy efficiency and server virtualization in data centers: An empirical investigation," in Computer Communications Workshops (INFOCOM WKSHPS), 2012 IEEE Conference on, 2012, pp. 133-138.

[63] A. Tzanakaki, K. Katrinis, T. Politi, A. Stavdas, M. Pickavet, P. Van Daele, D. Simeonidou, M. O"Mahony, S. Aleksic, L. Wosinska, and P. Monti, "Dimensioning the future pan-european optical network with energy efficiency considerations," Optical Communications and Networking, IEEE/OSA Journal of, vol. 3, no. 4, pp. 272-280, 2011. 
[64] J. Fan, C. Hu, K. He, J. Jiang, and B. Liu, "Reducing power of traffic manager in routers via dynamic on/off-chip scheduling," in INFOCOM, 2012 Proceedings IEEE, 2012, pp. 1925-1933.

[65] F. Francois, N. Wang, K. Moessner, and S. Georgoulas, "Optimization for time-driven link sleeping reconfigurations in isp backbone networks," in Network Operations and Management Symposium (NOMS), 2012 IEEE, 2012, pp. 221-228.

[66] P. Monti, A. Muhammad, I. Cerutti, C. Cavdar, L. Wosinska, P. Castoldi, and A. Tzanakaki, "Energy-efficient lightpath provisioning in a static wdm network with dedicated path protection," in Transparent Optical Networks (ICTON), 2011 13th International Conference on, 2011, pp. 1-5.

[67] A. Muhammad, P. Monti, I. Cerutti, L. Wosinska, P. Castoldi, and A. Tzanakaki, "Energy-efficient wdm network planning with dedicated protection resources in sleep mode," in Global Telecommunications Conference (GLOBECOM 2010), 2010 IEEE. IEEE, 2010, pp. 1-5.

[68] B. Addis, A. Capone, G. Carello, L. G. Gianoli, and B. Sanso, "Energy management through optimized routing and device powering for greener communication networks," IEEE/ACM Transactions on Networking (TON), vol. 22, no. 1, pp. 313-325, 2014.

[69] L. Chiaraviglio, A. Cianfrani, E. L. Rouzic, and M. Polverini, "Sleep modes effectiveness in backbone networks with limited configurations," Computer Networks, vol. 57, no. 15, pp. 2931-2948, 2013.

[70] S. Tan, X. Zhang, L. Li, and S. Wang, "Green optical networks with availability guarantee," in Communications and Information Technologies (ISCIT), 2011 11th International Symposium on, 2011, pp. 97-102.

[71] A. Jirattigalachote, C. Cavdar, P. Monti, L. Wosinska, and A. Tzanakaki, "Dynamic provisioning strategies for energy efficient wdm networks with dedicated path protection," Optical Switching and Networking, vol. 8, no. 3, pp. 201 -213, 2011.

[72] A. Muhammad, P. Monti, I. Cerutti, L. Wosinska, and P. Castoldi, "Reliability differentiation in energy efficient optical networks with shared path protection," in IEEE Online GreenCom 2013 Proceedings, 2013.

[73] F. Cuomo, A. Cianfrani, M. Polverini, and D. Mangione, "Network pruning for energy saving in the internet," Computer Networks, vol. 56, no. 10, pp. 2355 - 2367, 2012. 
[74] R. He and B. Lin, "Dynamic power-aware shared path protection algorithms in wdm mesh networks," Journal of Communications, vol. 8, no. 1, pp. 55-65, 2013.

[75] A. Cianfrani, V. Eramo, M. Listanti, M. Marazza, and E. Vittorini, "An energy saving routing algorithm for a green ospf protocol," in INFOCOM IEEE Conference on Computer Communications Workshops , 2010, 2010, pp. 1-5.

[76] P. Batchelor, B. Daino, P. Heinzmann, D. Hjelme, R. Inkret, H. Jager, M. Joindot, A. Kuchar, E. Coquil, P. Leuthold, G. Marchis, F. Matera, B. Mikac, H.-P. Nolting, J. Spath, F. Tillerot, B. Caenegem, N. Wauters, and C. Weinert, "Study on the implementation of optical transparent transport networks in the european environment results of the research project cost 239," Photonic Network Communications, vol. 2, no. 1, pp. 15$32,2000$.

[77] M. Xia, M. Tornatore, Y. Zhang, P. Chowdhury, C. Martel, and B. Mukherjee, "Green provisioning for optical wdm networks," Selected Topics in Quantum Electronics, IEEE Journal of, vol. 17, no. 2, pp. 437-445, 2011.

[78] RNP. (2013) Rede ipê. [Online]. Available: http://www.rnp.br/ipe/

[79] S. Avallone and G. Ventre, "Energy efficient online routing of flows with additive constraints," Computer Networks, vol. 56, no. 10, pp. 2368-2382, 2012.

[80] A. Mokhtar and M. Azizoglu, "Adaptive wavelength routing in all-optical networks," Networking, IEEE/ACM Transactions on, vol. 6, no. 2, pp. 197-206, 1998.

[81] E. Q. Martins and M. M. Pascoal, "A new implementation of yen?s ranking loopless paths algorithm," Quarterly Journal of the Belgian, French and Italian Operations Research Societies, vol. 1, no. 2, pp. 121-133, 2003.

[82] S. Meral. (2011) K-shortest path- yen's algorithm - file exchange - matlab central. [Online]. Available: http://www.mathworks.com/matlabcentral/fileexchange/ 32513-k-shortest-path-yen-s-algorithm

[83] P. Erdős and A. Rényi, "On the evolution of random graphs," Selected Papers of Alfréd Rényi, vol, vol. 2, pp. 482-525, 1976.

[84] A.-L. Barabási and R. Albert, "Emergence of scaling in random networks," science, vol. 286, no. 5439, pp. 509-512, 1999. 